\title{
Nordadriatische Gastrotrichen
}

\author{
H. SCHROM \\ Mediterranean Marine Sorting Center; Khereddine, Tunisia
}

\begin{abstract}
North Adriatic gastrotrichs. Twentytwo new and 8 known species of gastrotrichs are described from eulittoral and sublittoral sandy bottoms of the northern Adriatic Sea. The $\mathrm{MgCl}_{2}$ method was used for extraction from the substrate. Only living material was studied employing phase contrast microscopy. Seven of the new species belong to the order Macrodasyoidea, 15 are members of the order Chaetonotoidea. In Macrodasys caudatus, 4 different types of bursae copulatrices were found to be ustally correlated with a specific number of mature and immature eggs. In 2 new species of Tetranchyroderma, the four-pronged hooks are restricted to narrow bands; another species of that genus has four-pronged hooks only in the pharyngeal region being reduced to small lateral patches. Four new species of Chaetonotus belong to the schultzei group; the diagnostic feature of this group is the tri-cornered spine whose distal edge is more oblique and extends always in only one fine tip. Halichaetonotus is given the rank of a genus distinct from Chaetonotus; the diagnostic feature of Halicbaetonotus species is the dorsal occurrence of both keeled scales and of spines, as well as the ventrolateral spined scales or foliaceous scales. Four new species of Heterolepidoderma lead to the discussion of the characters of the genus. Species belong to Heterolepidoderma if they are covered by keeled scales only or by keels lacking a distinct base scale. The number of longitudinal rows composed by these cuticular elements is, at the present, of no value to the diagnosis of the genus.
\end{abstract}

\section{EINLEITUNG}

Durch die Arbeiten von Remane (1924, 1925, 1926, 1927 etc.) wurde das Interesse an der Erforschung mariner Gastrotrichen gewedkt. Den zahlreichen Einzelfunden in den darauffolgenden Jahren schlossen sich aber erst in jüngerer Zeit wieder planmäßige Bestandsaufnahmen in eng umgrenzbaren Biotopen oder einheitlichen Untersuchungsgebieten an: umfangreiche Aufsammlungen wurden von WILKE (1954), SWEDMARK (1956), VALKANOV (1957), ForNERIs (1961) und BOADEN (1963) an europäischen, von Ganapati \& Chandrasekhara Rao $(1967,1968)$ an asiatischen und von ThaneFENCHEL (1970) an amerikanischen Küsten vorgenommen, ließen jedoch, auf Grund nicht wirklich quantitativer Extraktionsmethoden, noch Fragen über das jeweils vorhandene Artenvolumen offen.

Uberdies sank der Bekanntheitsgrad mariner Gastrotrichen proportional zu ihrer Körpergröße: von den durchschnittlich 400-700 $\mu \mathrm{m}$ langen Macrodasyoiden wurde etwa dreimal häufiger berichtet als von Chatonotoiden, deren mittlere Körperlänge, etwa 100-200 $\mu \mathrm{m}$, von vielen Protozoen des gleichen Lebensraumes übertroffen wird. Zusätzlich behindert das extrem haptische Vethalten der Tiere vor allem die Ent- 
deckung der kleinen Formen, so daß die Macrodasyoiden artenmäßig als dominierend erscheinen mußten.

In den Jahren 1962-1965 ermöglichten mir zahlreiche Aufenthalte in der Umgebung von Venedig und Rovinj (Istrien) den Versuch, die Gastrotrichenfauna in eulitoralen und benthischen Sanden einiger ökologisch signifikanter Untersuchungsstellen qualitativ lückenlos zu erfassen; systematisch-morphologische Studien erbrachten über 20 neue und 11 bereits bekannte Arten und fanden in einem kurzen Bericht (ScHrom 1966b) ihren ersten Niederschlag. Die quantitative Verteilung einiger Arten konnte im oberen Eulitoral mit der Substratbeschaffenheit korreliert werden (SCHROM 1966a).

\section{FUNDORTE UND MATERIAL}

Vom Charakter der Substrate bestimmt, konzentrierten sich die Aufsammlungen auf die Feinsande des Eulitorals vor Venedig und Caorle sowie auf die mittelgroben Sande des Benthos bei Rovinj - die feinen und detritusreichen Sedimente sublitoral im venezianischen und eulitoral im Gebiet um Rovinj enthielten entweder nur wenige Gastrotrichen oder schlossen mangels eines Lückenraumsystems eine interstitielle Besiedlung überhaupt aus. Ganz allgemein nimmt mit steigendem Sinkstoffgehalt die Individuendichte $a b$, wiewohl einige Arten, etwa Paraturbanella dobrni oder Arten aus der Gattung Tetranchyroderma, gerade die etwas detritushaltigeren Substrate bevorzugen, ohne sich freilich dort derart reich zu entfalten, wie vor allem Macrodasys caudatus im detritusfreien Feinsand des Eulitorals.

Das venezianische Material entstammt dem Küstenstrich vor Alberoni (am Südende des Litorale di Lido) und dem lagunenseitigen Strand dieser Ortschaft, ferner der Küste vor S. Nicolo (am Nordende des Litorale di Lido) und dem südlichen Ufer des Porto di Lido bei S. Nicolo, ebenso wie der Punta Sabbioni (am Südende des Litorale di Cavallino). In Caorle wurde hauptsächlich etwa $1 \mathrm{~km}$ östlich der Livenca-Mündung gesammelt. Das Material aus Rovinj fand sich größtenteils in Proben aus 3-8 $\mathrm{m}$ Tiefe, die aus der Strada di Conversada, bei der Punta Croce, dem Val di Bora und bei den Inseln Due Sorelle gewonnen wurden.

Im Ablauf meiner Studien konnte ich an der Nordadria insgesamt 46 Gastrotrichen-Arten finden; davon waren: 11 Arten von anderen Autoren bereits beschrieben (bei 7 Arten konnte ich ergänzende Beobachtungen vornehmen); 19 neue Arten zu beschreiben; 5 neue Arten in zu geringer Zahl oder nur juvenil gefunden worden, sie wurden deshalb nur vorläufig beschrieben und noch nicht endgültig benannt; 11 vermutlich neue Arten wegen stärkerer Deformationen nicht genauer untersuchbar.

In vorliegende Arbeit werden die Notizen und Beschreibungen von 8 bekannten und die Beschreibungen von 22 neuen Arten aufgenommen: aus der Ordnung Macrodasyoidea 12 Arten ( 5 bekannte, 7 neue, von diesen 4 vorläufig beschriebene) und aus der Ordnung Chaetonotoidea 18 Arten ( 3 bekannte, 15 neue, von diesen 1 vorläufig beschriebene).

In der Umgebung von Venedig verteilten sich die Probenaufsammlungen mehrere Jahre hindurch gleichmäßig auf Frühjahr, Sommer und Herbst, in Rovinj auf Frühjahr und Herbst; in Caorle wurde nur einmal, im Herbst, gesammelt. 


\section{ME'THODE}

\section{Gewinnung und Behandlang der Probeth}

Die eulicoralen Proben wurden yon Hand mit einom einfachen PVC-Becher gesammelt, zur Entrahme des sublitoralen Substrates diente eine kleine Dredsche. Die Gewinuung der Tiere aus den Proben geschah anfangs nach der von Rlimane (1936) angegebenen Mcthode; die Ausbeute war jedod gering, stieg auch durch Ausschütteln des abpipettierten, obarfiächlichen Sandmaterials nur wenig an und bildete vor alten für quantitative Untersuchungen kcine Ausgangsbasis. Hervorragend geeignet erwies sich hingegen die bereits von BosDEN und SwlEMrkK angewandte, von STERRLi (1968) für die Gewinnung von Gnathostomuliden modifierte $\mathrm{MgCl}$-Betäubungs-Methode, dic aus einem $1 / 2$ I Probevolumen mühelos bis zu 5000 Tndiyiduen erbringen konnte, während erstere Mctlode aus derselben Substratmenge knapp 100 Individuen (von etwa der İ̈älte der durch Betäubung gewonnenen Arten) ljeferte.

\section{Auswertung des Materials}

Dic in dieser Arbeit niedergelegten Befunde entstanmen ausschließlich Lebendbeobachtungen in Quetschpräparat. Von den Tieren wurden Habitus-Skizzen angefertigt sowie Detailbezeichnutigen aller jener Organe und Strukturen, die bis zur Auflösungsgremze von Phasenkontrast- und konwentioneller Hellfeldoptik erkennbar waren; Hand in Hand damit ging die Vermossung aller morphologischer Einzclheiten, um cine maßstabsgetreue zeichnerische Erfassung zu erzielent. Was die Gastrotrichen anlangt, ycrlhilf die Ausnützung aller Möglichkeiten der Lebendbcobachtung zu den eindeutigsten Aussagen iber Struktur und Anordnung der systematisch wichtigen Merlsmalsträger und gestattet zudem in den. meisten Fällen eine befriedigende Analyse der inneren Anatomie.

Die Anfertigung von Totalpräparaten erwies sid weitgehend als nutzlos, da jede Art der lixierung die Gowebsstrukturen vetschleiert und der mikroskopischen Untersuchung in situ schlecht deutbare Bilder liefert. Hier sei erwähnt, daß der Einschluß in Formol-Glyzerin (1:3) binnen weniger Wochen zur vollständigen Auflösung aller kutikularen Ilemente führt, weshalb solche Präparate, vor allem von Chaetonotoiden, wertlos sind.

\section{Beschreibung und Gliedertug}

Bei der Besdireibung der neuen Arten wurde ciuheitlich vorgegangen. Immer findet sich nach dem Artnamen die Angabe des Fundortes und die Anzahl der untersuchten Lxemplare, gefolgt von der Artbeschreibung; diese enthält bei Macrodasyoiden die widhtigsten Körpermaße; Körperform; Anordjung der äuBeren kutikularen Llemente (sofern vorhanden) und deren Maße; Anordnung der Hattöhrchen (vordere, laterale, hintere) und deren Maße; Beschreibung der ventralen Bewimperung und der des Vorderendes; Beschreibung von Darmtrakt, Ptotoncphridien und Gonaden. Die 
Artbeschreibungen der Chaetonotoiden sind ähnlich aufgebaut, sie enthalten die wichtigsten Körpermaße; Körperform; Anordnung der äußeren kutikularen Elemente, deren Form, Strukturierung und Maße; Beschreibung der ventralen Bewimperung und der des Vorderendes; Position der Tastborsten (sofern vorhanden); Beschreibung des Darmtraktes und der kutikularen Bildungen im Pharynx (falls vorhanden); Position der Protonephridien; Beobachtungen an Geschlechtsorganen (nur bei Xenotrichula lineata); Anzahl und Lage der Eier.

Die Beschreibungen der neuen Arten repräsentieren ausschließlich die Deskription aller der mikroskopischen Analyse zugänglichen Merkmale, einer Diskussion derselben sowie einer Beurteilung der systematischen Stellung der Art dient ein eigener, der Beschreibung angeschlossener Absatz. In der darauffolgenden Diagnose werden die differentialdiagnostischen Merkmale hervorgehoben und die wichtigsten Körpermaße rekapituliert.

Die Beschreibung bekannter Arten wurde grundsätzlich gleich gehandhabt; wo ich jedoch die Angaben anderer Autoren bestätigen konnte, konzentrieren sich die Analysen naturgemäß auf jene Organe, deren Eigenheiten bislang weniger erforscht oder bei den nordadriatischen Exemplaren anders ausgeprägt waren. Auch hier wird fallweise eine Diskussion der behandelten Merkmale angeschlossen.

Sofern mir von einer Gattung oder einer Arten-Gruppe genügend Arten vorgelegen haben, eine allgemeine Betrachtung der interspezifischen Beziehungen daher möglich und notwendig war, wird im Anschluß an die betreffende systematische Einheit ebenfalls eine Diskussion zur Sichtung und Beurteilung der Befunde herangezogen. Die zur Gattung erhobene ehemalige Untergattung Halichaetonotus erfährt überdies eine Diagnose. Die Terminologie hält sich an Begriffe und Bezeichnungen, wie sie seit Remane (1936) in der Gastrotrichen-Kunde allgemein uiblich sind.

\section{BESCHREIBUNGEN, DISKUSSIONEN UND DIAGNOSEN}

$$
\text { Macrodasyoidea }
$$

Lepidodasyidae

\section{Acanthodasys aculeatus Remane $1927 \mathrm{c}$}

Fundorte: Alberoni, Pta. Sabbioni.

Untersuchtes Material: 42 Individuen.

Die größten Individuen werden knapp $800 \mu \mathrm{m}$ lang; die meisten. Tiere erreichen allerdings bloß eine Länge von 570-650 $\mu \mathrm{m}$; die Länge des Pharynx beträgt $180 \mu \mathrm{m}$ bis maximal $210 \mu \mathrm{m}$, verhält sich jedoch bei erwachsenen Tieren nicht immer proportional zu deren Gesamtlänge: kurze adulte Tiere besitzen zahlenmäßig zu etwa gleichen Anteilen sowohl verhältnismäßig kürzere als auch längere Pharynges, lange Tiere ebenso. Mit ca. $50 \mu \mathrm{m}$ sind großgewachsene Exemplare kaum breiter als kleinere.

Dorsal und lateral ist der Körper von vorne bis hinten gleichmäßig mit $2 \mu \mathrm{m}$ langen Schuppen und $5 \mu \mathrm{m}$ langen Stacheln bededkt. Im Umkreis eines Stachels befin- 
den sich 10-14 Schuppen. Die ventralen Schuppen und Stacheln sind sehr klein, die Schüppchen und die Basalteile der Stacheln daher kaum erkennbar. Auf den beiden Schwanzlappen stehen nur kurze, basislose Stacheln.

Die meisten Exemplare tragen knapp hinter der Mundöffnung 4-5 Paare ventral und ventrolateral stehender Haftröhrchen, die 8-11 $\mu \mathrm{m}$ lang sind; an einigen Individuen wurde nur ein vorderes Haftröhrchenpaar beobachtet. Während die vordere Hälfte der Pharynxregion sonst keine Haftröhrchen trägt, stehen ab der zweiten Pharynxhälfte bis zu den Schwanzlappen ventrolaterale und laterale Haftröhrchen jederseits ziemlich regelmäßig verteilt, jedoch in beträchtlich schwankender Anzahl: in der lateralen Reihe 5 bis 15 , in der ventrolateralen 8 bis 12. Die Haftröhrchen sind nicht symmetrisch angeordnet; bisweilen finden sich auf der einen Körperseite 12, auf der anderen bloß 5 oder 6 . Dies gilt sowohl für die lateralen als auch für die ventrolateralen Haftröhrchen. Ungleich ist auch ihre Länge an ein und demselben Tier: die Länge der lateralen Haftröhrchen schwankt zwischen 15 und $20 \mu \mathrm{m}$, die der ventrolateralen zwischen 10 und $12 \mu \mathrm{m}$. Die beiden Schwanzlappen tragen jeweils zwei 12-14 $\mu \mathrm{m}$ lange Haftröhrchen, an den Innenseiten der Lappen entspringt jederseits noch ein etwas kürzeres.

Die Ventralseite des Körpers trägt von den vorderen Haftröhrchen bis in die Nähe der Schwanzlappen zwei undeutlich getrennte Wimperbänder; auch dort, wo im ventromedianen Feld feine Stacheln stehen, sind Wimpern in lockerer Verteilung anzutreffen. Stempelgruben konnten an $A$, aculeatus bislang nicht gefunden werden.

Der Durchmesser des Pharynx beträgt 18-20 $\mathrm{m}$. Das ungestörte Tier öffnet den Pharynxeingang trichterförmig so weit, daß er die Körperseiten überragt. In diesem Zustand äußerster Dehnung zeigt sich der Pharynxeingang als aus längsliegenden Zellwülsten bestehend, die mit regelmäßigen, kurze Tastborsten tragenden Erhebungen den Mundrand bilden, weiter hinten im Pharynxlumen aber abflachen. Etwa $10 \mu \mathrm{m}$ hinter dem Mundrand entspringt auf jedem Wulst der Pharyngeal-Wandzellen eine ca. $30 \mu \mathrm{m}$ lange Tastwimper. Gleich dahinter befindet sich ein starker Sphinkter, der bei seiner Kontraktion nicht nur den Pharynx verschließt, sondern auch eine Einschnürung der vordersten Körperregion bewirkt. Die Pharyngeal-Pori liegen ca. $10, \mu \mathrm{m}$ vor dem Pharynxende.

Protonephridien wurden bisher nicht gefunden. Die paarigen Hoden liegen in der vorderen Hälfte der Darmregion, der eng zusammengedrängte weibliche Genitalapparat in der hinteren. Nur an wenigen reifen Individuen sind hier die gleichen Strukturen in gleicher Lage anzutreffen. Wohl liegen Ovar und Eilager immer dorsal vom Darm, die reifen Eier ( = Eilager = Uterus im Sinne Remane 1936) vor dem Ovar; die akzessorischen Organe, Bursa, Receptaculum seminis und die membranartige Umhüllung des gesamten Komplexes sind jedoch of sehr verschieden ausgeprägt. Nicht nur die Ausbildung des Receptaculums differiert, auch seine Lage ist nicht konstant: als kleine, kugelige, scharf umrissene Kapsel, oder als eine große, lockenartig gelegte, nicht deutlich umhüllte Anhäufung lebhaft sich bewegender Spermien liegt es zwar immer hinter den reifen Eiern, doch manchmal lateral neben dem Darm, manchmal dorsal neben dem etwas zur Seite gedrängten Ovar. Die Bursa befindet sich immer hinter dem Ovar, oft nur $30 \mu \mathrm{m}$ vor dem Rumpfende und stellt zumeist ein ovales, schwach granuliertes Organ dar, ohne deutliche Zellgrenzen; in manchen Fällen ist sie hingegen 
kugelförmig und aus großen, stark granulierten und deutlich differenzierten Zellen aufgebaut. Bei letzterer Art der Ausbildung ist knapp hinter der Bursa immer ein konisch zusammenlaufendes Kutikularrohr von $6 \mu \mathrm{m}$ Länge vorhanden. Manche der längsten Individuen tragen bloß 1-3 große reife Eier, aber keine Ovocyten; der Darm dieser Tiere endet blind unter dem Eilager, etwa $200 \mu \mathrm{m}$ vor dem Körperende; die Bursa findet sich hier in schwach granulierter, ovaler Ausprägung. Uber die Gonodukte liegen keine Beobachtungen vor.

Diskussion. Das hier beschriebene Material weicht von den ersten adriatischen Funden (vgl. Scrrom 1966b) nur in den Körpermaßen ab. Gegenüber den, nach der Erstbeschreibung durch REMANE (1927c), ergänzenden Angaben von LEvi (1950), Wilke (1954), Gerlach (1961), Forneris (1961) und BoAden (1963) zeigt die äußere Morphologie der von mir untersuchten Tiere keine gravierenden Unterschiede. Meine Befunde über die Geschlechtsorgane decken sich am ehesten mit den Beobachtungen von ForNeris, wiewohl die Autorin die gegenseitige Lage von Ovar, Receptaculum und Bursa nicht erwähnt. BoAden skizziert (1963, Fig. 3) eine offenbar spermienerfullte Blase vor den reifen Eiern und läßt die Entscheidung offen, ob es sich hier um eine Bursa oder ein Receptaculum handelt. Die adriatischen Exemplare trugen Receptaculum und Bursa immer hinter den reifen Eiern.

\section{Acanthodasys spec.}

Fundort: Alberoni.

Untersuchtes Material: 10 Individuen.

Ein schuppenloser Vertreter der Gattung Acanthodasys wurde bereits von FORNERIS (1961) erwähnt. SCHrom (1966b) notierte einen ebenfalls nur stacheltragenden Acanthodasys in der Adria. Mittlerweile konnte festgestellt werden, daß diese Tiere in Körperform und innerer Organisation völlig mit $A$. aculeatus übereinstimmen. Die Länge der reifen Individuen beträgt $780 \mu \mathrm{m}$ bis $830 \mu \mathrm{m}$.

Die Stacheln sind sehr dicht angeordnet und ca. $7 \mu \mathrm{m}$ lang. Die Verteilung der Haftröhrchen unterscheidet sich von $A$. aculeatus insofern, als nur die hintere Körperhälfte mehr oder weniger regelmäßig verteilte Haftröhrchen trägt (zu etwa 4 Paaren, Länge 25-30 $\mu \mathrm{m}$ ), die Stellung der Haftröhrchen im vorderen Körperabschnitt aber ganz regellos erscheint.

\section{Macrodasyidae}

\section{Macrodasys caudatus Remane 1927 c (Abb. 1)}

Fundorte: Alberoni, S. Nicolo, Pta. Sabbioni; Caorle; Rovinj.

Untersuchtes Material: 314 Individuen.

Nordadriatische Exemplare wurden bereits eingehend beschrieben und kritisch verglichen mit früheren Angaben über diese Art (vgl. Schrom 1966b). Die bekannten Befunde über die innere Organisation können nun durch neue Beobachtungen an der 
Bursa copulatrix bereichert werden. Dieses Organ erwies sich bei annähernd gleichlangen Tieren als bemerkenswert verschieden ausgebildet, ein Umstand, der zur serienmäßigen Durchsicht eines zahlreichen Materials adulter Tiere von derselben Fundstelle führte. Dabei wurde eine Korrelation zwischen Form und Struktur der Bursa einerseits und der Ei-Anzahl in Ovar und Eilager andererseits festgestellt.

Die Bursa copulatrix von $M$. caudatus ist 90-115 $\mu \mathrm{m}$ lang und in zwei gleichlange Abschnitte gegliedert: die hintere Region, dem Antrum femininum angeschlossen, besitzt eine immer kräftig entwickelte Ringmuskulatur, unter der eine schwache Längsmuskelschicht an einem mehrfach gekrümmten, von feiner Granula umgebenen Gang entlang führt; dieser Gang ist vom Antrum weg meist durch die ganze hintere BursaRegion verfolgbar, in der vorderen Region war er nie mit Sicherheit zu erkennen. Diese vordere Region ist etwas schlanker als die hintere und läßt im wesentlichen vier, morphologisch deutlich trennbare Ausbildungsweisen erkennen, von denen Gestalt und Struktur der hinteren Region nur zu geringem 'Teil berührt werden.

Die in folgendem beschriebenen Bursa-Typen wurden während 3 aufeinanderfolgenden Tagen (Mitte Mai) an insgesamt 110 etwa gleich ausgewachsenen Individuen (aus dem oberen Eulitoral bei Alberoni) beobachtet und quantitativ erfaßt. An weiteren rund 80 Exemplaren konnten die Bursa-Verhältnisse qualitativ bestätigt werden (Ende Juni, Anfang August: oberes Eulitoral bei Alberoni; Ende März: Sublitoral bei Rovinj).
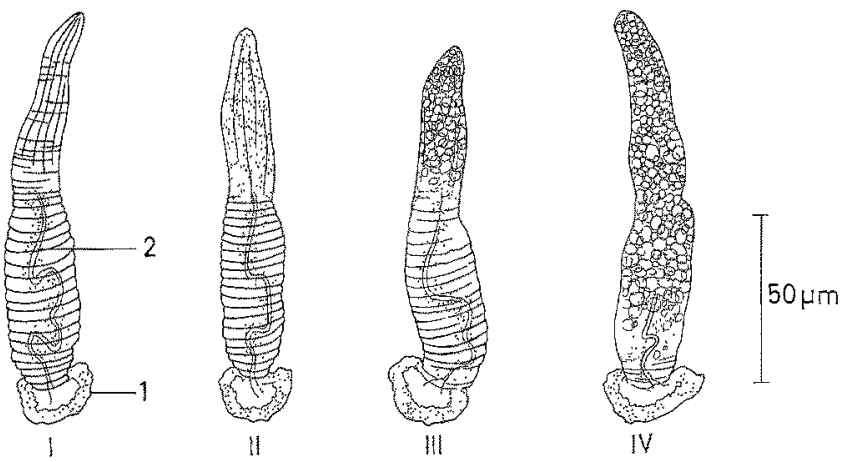

Abb. 1: Macrodasys candatus Remane 1927, Bursa-Typen I-IV; 1 Antrum femininum, 2 BursaGang

Typ I. Im Vorderteil der Bursa nimmt von hinten nach vorne die Stärke der: Ringmuskelschicht rasch $a b$, unter ihr hingegen die Stärke der Längsmuskelzüge in gleichem Maße rasch $z u$, so daß an der Bursaspitze die längsliegenden Muskelfasern dominieren, und die Ringmuskulatur oft völlig fehlt; der vordere Abschnitt der Bursa ist hell-durchsichtig, nur am Ubergang zum hinteren Bursateil, wo dessen zentraler Gang vermutlich endet, ist eine lockere Anhäufung feiner, dunkler Granula vorhanden. 4-5 unreife Eier, 1-2 reife Eier; 23 Individuen.

Ty p II. Sowohl Längs- wie Ringmuskulatur sind in der vorderen Bursa-Region beinahe gänzlich reduziert, dieser Abschnitt wird von feiner Granula in gleichmäßiger Dichte erfüllt. 3-4 unreife Eier, 3-4 reife Eier; 17 Individuen. 
Typ III. Längs- und Ringmuskulatur sind ebenfalls in der vorderen Bursahälfte nur durch wenige schwache Fasern angedeutet; feine Granula erfüllt nur das hintere Drittel dieser Region, deren übriger Raum bis zum Vorderende stark lichtbrechende Körner und Schollen in dichter Padkung enthält. Die Ringmuskulatur der hinteren Bursahälfte ist gegenüber den Typen I und II etwas schwächer ausgeprägt. 1-2 unreife Eier, 4-6 reife Eier; 26 Individuen.

Typ IV. Längs- und Ringmuskulatur der vorderen Bursahälfte fehlen. Dicht gepackte, stark lichtbrechende Schollen erfüllen nicht nur die vordere Bursa-Region zur Gänze, sondern auch die hintere zu etwa zwei Dritteln. Die Ringmuskulatur der hinteren Bursa-Region ist mit einigen schwachen Zügen nur in der Nähe des Antrums vertreten, der von diesem wegführende, zentrale Gang verliert sich nach ca. 20-30 $\mu \mathrm{m}$, dort, wo die dichte Packung der Schollen beginnt. 1-2 unreife Eier, 2-3 reife Eier; 35 Individuen.

An 9 Exemplaren ließen sich die Bursa-Strukturen zwar in die beschriebenen Typen eingliedern, gingen aber nicht einher mit der für die jeweilige Ausbildung typischen Anzahl unreifer und reifer Eier; 4 Tiere etwa, mit einer Bursa des Typs III, besaßen 1-2 unreife und 2 reife Eier.

\section{Urodasys viviparus WILKE 1954}

Fundort: Rovinj.

Untersuchtes Material: 18 Individuen.

Die nordadriatischen Exemplare entsprechen in ihren Maßen und in ihrer inneren und äußeren Morphologie der Erstbeschreibung. Auch die Entwicklung der Embryonen und die Geburt der Jungtiere durch Ruptur der Körperwand dorsal vor dem Rumpfende stimmen mit den Beobachtungen von WILKE (1954) überein.

\section{Turbanellidae}

Turbanella otti nov. spec. (Abb. 2)

Fundorte: Alberoni; Caorle.

Untersuchtes Material: 54 Individuen.

Adulte Tiere werden maximal $400 \mu \mathrm{m}$ lang, die meisten Individuen erreichen jedoch bloß eine Länge von 380-390 $\mu \mathrm{m}$. Die Pharynxlänge beträgt 140-150 $\mu \mathrm{m}$. Ab der Mundöffnung verbreitert sich der Körper rasch und trägt vor einer starken Einschnürung im ersten Drittel der Pharynxregion jederseits einen kräftigen, beweglichen Zapfen; die Spitzen der Zapfen sind in gespreiztem Zustand $55 \mu \mathrm{m}$ voneinander distanziert. Der übrige Körper ist bandförmig, 52-53 $\mu \mathrm{m}$ breit und vor den Schwanz-" lappen auf etwa $40 \mu \mathrm{m}$ verschmälert. Die Kopfzapfen sitzen ventrolateral und können in die hinter ihnen befindlichen Gruben eingeklappt werden, so daß der Körper, namentlich bei frisch gefangenen, voll bewegungstüchtigen Tieren, in der Pharynxregion eine durchgehend gerade Kontur zeigt. 
Jederseits 6 vordere Haftröhrchen befinden sich ventral auf der Höhe der vorderen Körpereinschnürung; sie sind mit 6-7 $\mu \mathrm{m}$ untereinander beinahe gleich lang und inserieren auf etwa $4 \mu \mathrm{m}$ langen, von kräftigen Muskelfasern durchzogenen Lappen. Die kleinsten der juvenilen Exemplare tragen 5 vordere Haftröhrchen. Die seitlichen Haftröhrchen bilden jederseits zwei deutlich getrennte Reihen; die laterale Reihe führt genau an der Körperkontur entlang, die dorsolaterale ist jeweils um $10 \mu \mathrm{m}$ mediad versetzt. In der lateralen Reihe werden maximal 15 Haftöhrchen gezählt; deren Zahl

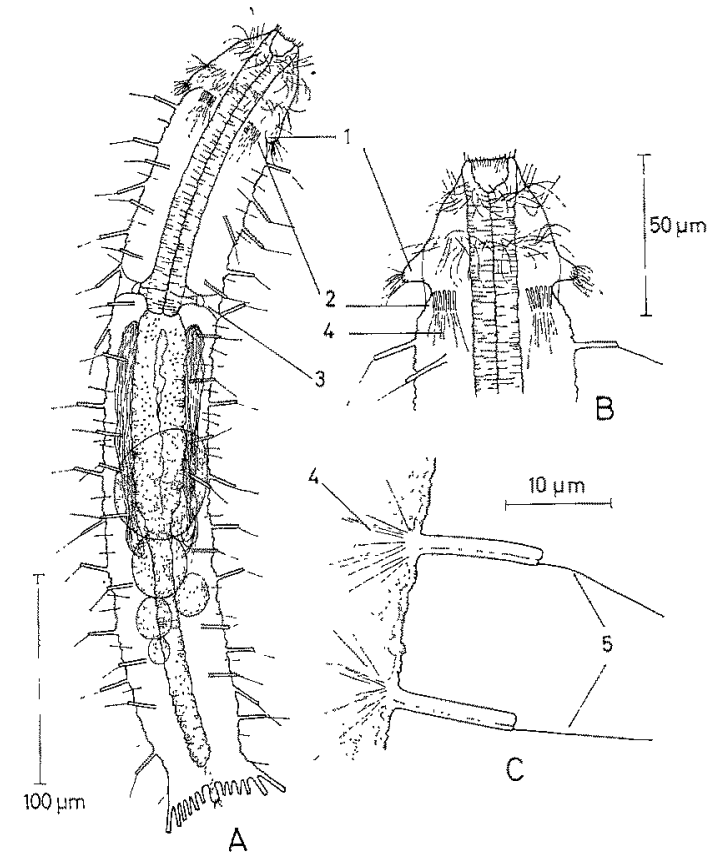

Abb. 2: Turbanella otti nov. spec. A Habitus, $B$ Vorderende, $C$ Haftröhrchen. 1 Kopfzapfen in $A$ angelegt, in $B$ gespreizt; 2 vordere Haftröhrchen; 3 Pharyngealpori; 4 Muskelfasern; 5 Wimpern

schwankt jedoch nicht nur intraspezifisch zwischen 10 und 15, sondern wird auch selten an ein und demselben Tier auf jeder Körperseite gleich angetroffen. Dorsolateral sind 10-12 Haftröhrchen vorhanden; auch diese gruppieren sich nicht zu serialen Paaren, sondern können auf einer Körperseite in regelmäßigen Abständen über beinahe die ganze Körperlänge stehen, auf der anderen sich in einer eng zusammengedrängten Gruppe auf eine kleine Körperregion beschränken. Während jedoch bei den lateralen Haftröhrchen das vorderste immer knapp nach der Kopfeinschnürung, das hinterste immer ein wenig vor der schmalen Stelle am Körperende steht, sind die vordersten und hintersten dorsolateralen Haftröhchen in ihrer Stellung keineswegs fixiert; ihre Reihe beginnt manchmal am Ende des ersten Körperdrittels und endet oft weit vor der hinteren Verschmälerung des Körpers. An den jüngsten gefundenen Tieren wurden nie weniger als 8 laterale und 6 dorsolaterale Haftröhrchen gezählt. T. otti trägt jederseits 
6 hintere Haftröhrchen. Sie inserieren auf der schrägen Hinterkante des auf jeder Seite spitz zulaufenden Schwanzlappens, werden von innen nach außen kontinuierlich länger $(5 \mu \mathrm{m}$ bis $12 \mu \mathrm{m})$ und bilden mit ihren Enden eine gerade Linie. Zwischen den beiden hinteren Haftröhrchengruppen befindet sich ein medianer Lappen von 5-8 $\mu \mathrm{m}$ Länge.

Die ventrale Bewimperung besteht aus zwei, durchgehend getrennten Bändern. Vom After bis auf den medianen Endlappen führt ein Band kürzerer Wimpern. Dorsal knapp hinter der Mundöffnung befindet sich ein querliegendes Wimperband, ebenso eines dorsal knapp vor den Kopfzapfen, die ihrerseits je ein Wimperbüschel tragen. Kurze Wimpern stehen an der Kopfkontur jederseits von der Mundöffnung bis zu den Kopfzapfen. Jedes der lateralen und dorsolateralen Haftröhrchen trägt eine etwa 10-15 $\mu \mathrm{m}$ lange, langsam schlagende Wimper. Diese Wimpern bewegen sich untereinander nicht synchron und stehen auch an frisch gefangenen Tieren zeitweise still. Eine solche Wimper entspringt einer knotigen Verdickung am distalen Ende des Haftröhrchens. Bis zu diesem kleinen Knoten führt ab der Basis des Haftröhrchens an dessen caudaler Kontur ein seperater Strang von geringem Durchmesser. Kurze, steife Tastborsten sind lateral und dorsolateral über den ganzen Rumpf verstreut, konzentrieren sich aber besonders um die Mundöffnung.

Die Mundöffnung neigt sich ein wenig ventrad und führt in eine halbkugelige Mundhöhle. Der Durchmesser des Pharynx mißt $15 \mu \mathrm{m}$. Die Pharyngeal-Pori befinden sich knapp vor dem Pharynxende, dort ist die Epidermis trichterförmig eingezogen und begegnet den die Pori einschließenden Pharynxzellen auf halbem Wege. Der Darm gliedert sich in zwei Abschnitte: in einen vorderen dickwandigen, drüsenreichen und in einen dünnwandigen Abschnitt, der ein deutliches Lumen erkennen läßt. Der vordere Abschnitt nimmt etwa $2 / 5$ der gesamten Darmlänge ein. Der After mündet ventral, die Verdauungsprodukte werden durch das kurze mediane Wimperband über den Endlappen wegbefördert.

Trotz eingehender Beobachtungen mit Phasenkontrast-Optik waren an T. otti keine Protonephridien zu finden.

Die paarigen Hoden erstrecken sich bei ausgewachsenen Tieren über die gesamte vordere Hälfte der Darmregion. Die Ovarien befinden sich paarig an den Seiten der hinteren Darmhälfte angeordnet, die reifen Eier liegen weiter vorne im Bereich der Hoden, zumeist dorsal des Darmes, manchmal seitlich verschoben.

Diskussion. T. otti ist am nächsten mit T. cornuta Remane 1925 verwandt. Oberflächlich betrachtet haben beide Arten die gleiche Körperform; die Lage der Gonaden ist identisch. Wesentliche Unterschiede ergeben sich aus den verschiedenen Maßen ( $T$. otti ist viel kleiner), aus der Zahl der Haftöhrchen ( $T$. cornuta trägt vorne und hinten, lateral und dorsolateral mehr als doppelt so viele Haftröhrchen) und aus der Länge der auf den lateralen und dorsolateralen Haftröhrchen inserierenden Wimpern (diese sind bei $T$. otti maximal bloß ein Drittel so lang wie bei $T$. comuta). Während die lateralen Kopfzapfen bei $T$. cornuta ziemlich spitze, große Kegel darstellen und dem Vorderende einen annähernd dreieckigen Umriß geben, treten sie bei $T$. otti nicht so stark hervor, sind mehr abgerundet, eher hoch-warzenförmig und überragen die Rumpfkontur nur wenig; das Vorderende erhält dadurch eine gestrecktere Form. Die Gestalt des Hinterendes ähnelt $T$, cornuta, ein Vergleich dieser Körperpartie kann jedoch nur wenig Aufschluß geben, da sich gerade diese Region mit wechselndem Deck- 
glasdruck und verschiedenem Kontraktionszustand der Tiere sehr stark verändert. Der vordere dickwandige Darmabschnitt ist bei $T$, otti mit etwa $2 / 5$ der gesamten Darmlänge ein wenig kürzer als bei $T$. cormuta.

In einen Vergleich müssen weiterhin einbezogen werden: T. plana GIARD 1904, T. mustela Wieser 1957, T. bocqueti Kaplan 1958 und T. byalina Schultze 1853. Letztgenannte Art teilt mit $T$. otti einige habituelle Grundzüge: die relativ kurzen lateralen Haftröhrchen mit kurzen Tastwimpern reichen bis in die Region der vorderen Haftröhrchen, die vorderen und hinteren Faftröhrchen sind nicht zahlreich, und das Fehlen von Kopfzapfen bei T. hyalina kann seit der Notiz von KARLING (1954) nicht mehr als gesichertes Merkmal gelten. Aber auch $T$. byalina ist wesentlich größer und mit Haftröhrchen reicher besetzt als $T$. otti. $T$. plana ist mit $T$. cornuta eng verwandt, Remane schließt eine Identität der beiden Arten nicht aus (vgl. Remane 1943). Ahnlichkeiten $z$ wischen $T$. otti und $T$. plana verstehen sich daher von selbst. T. mustela hält sich zwar im Größenbereich von T. otti und trägt ebenfalls rundum wenige Haftröhrchen, besitzt aber wesentlich größere Kopfzapfen und übertriff T. otti in den Abmessungen der Haftröhrchen, vor allem der lateralen, bei weitem. Remane vermutet eine zwischen T. byalina und T. cornuta stehende Art (Remane 1943, ferner Schrom 1966a, siehe Diskussion p. 101). T. otti schließt sich eng an T. cornuta und T. byalina an. Ich habe in zwei Arbeiten (Schrom 1966a, 1966b) nordadriatische Funde von T. cornuta behandelt; in beiden Fällen ist an deren Stelle T. otti zu setzen.

Diagnose. Turbanella-Art mit kleinen Kopfzapfen und jederseits 6 vorderen, 6 hinteren, maximal 15 lateralen und 12 dorsolateralen Haftröhrchen. Laterale und dorsolaterale Haftröhrchen bewimpert, Länge der Wimpern 10-15 $\mu \mathrm{m}$. Gonaden wie bei T. comuta. Gesamtlänge maximal $400 \mu \mathrm{m}$; Distanz der Kopfzapfen-Enden $55 \mu \mathrm{m}$; Rumpfbreite 52-53 $\mu \mathrm{m}$; Pharynxlänge 140-150 $\mu \mathrm{m}$.

Turbanella veneziana nov. spec. (Abb. 3)

Fundorte: Alberoni; Caorle.

Untersuchtes Material: 25 Individuen.

Die Gesamtlänge beträgt bei reifen Tieren meist $485-490 \mu \mathrm{m}$, maximal $500 \mu \mathrm{m}$; die Länge des Pharynx mißt 115-120 $\mu \mathrm{m}$, die Körperbreite etwa 57-59 $\mu \mathrm{m}$.

Das Vorderende erhält durch zwei Einschnürungen (eine schwache vordere und eine stärkere hintere) etwa birnenförmige Gestalt. Diese derart vom übrigen Körper abgesetzte vordere Region trägt keine seitlichen Zapfen. Rostrad ragt eine Mundröhre ein kurzes Stïck vor. Die Rumpfkontur ist leicht gerunzelt; der Körper verschmälert sich vor dem Schwanzlappen, der wiederum die Breite des Rumpfes erreicht.

Auf der Höhe der hinteren, das Vorderende abgrenzenden Einsdnürrung befinden sich jederseits 5 ventrale Haftröhrchen; das jeweils der Medianen zunächst stehende ist mit $6 \mu \mathrm{m}$ etwa halb so lang wie die übrigen. Sie inserieren direkt auf der Ventralseite des Körpers. In der ganzen Pharynxregion sind keine lateralen Haftröhrchen vorhanden; zu spitz-kegelförmigen Anhängen reduziert, bilden sie in der Darmregion jederseits eine Reihe von 5-7 Stück in annähernd gleichen Abständen. Dorsolaterale Haftröhrchen fehlen. Die Hälften des Schwanzlappens sind schmal und tragen jeweils 
4 Haftröhrchen, von denen die äußeren beiden auf einem verlängerten Anhang inserieren. Diese Verlängerung wird erst bei adulten Tieren gebildet, bei juvenilen Exemplaren stehen alle hinteren Haftröhrchen gemeinsam in einer schrägen Reihe. Median zwischen den hinteren Haftröhrchengruppen befindet sich ein kleiner Lappen, der jedoch nicht an allen Individuen deutlich ausgeprägt ist. Die lateralen Haftröhrchenrudimente sind etwa $10 \mu \mathrm{m}$ lang; von den hinteren Haftröhrchen messen die beiden äußeren $18 \mu \mathrm{m}$, die beiden inneren $10-12 \mu \mathrm{m}$.

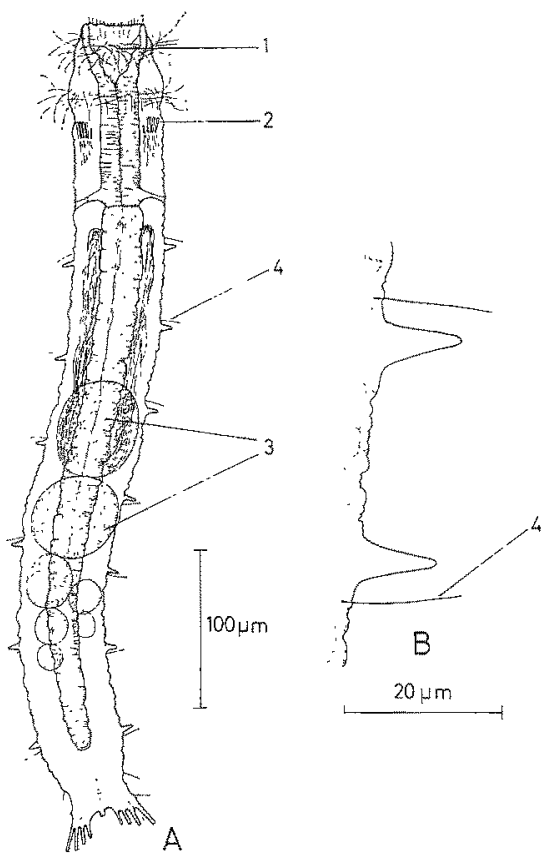

Abb. 3: Turbanella veneziana nov, spec. A Habitus, B Haftröhrchenrudimente. 1 Mundhöhle; 2 vordere Haftröhrchen; 3 reife Eier; 4 Wimpern

Die ventrale Bewimperung bildet $z$ wei in der Rumpfregion getrennte, unter dem Pharynx zusammenschließende Bänder. Vom After bis auf den hinteren medianen Endlappen führt ein schmales Wimperband. Die Bewimperung des Vorderendes besteht aus zwei querliegenden Wimperstreifen jeweils vor den Verschmälerungen; der hintere der beiden Streifen endet lateral jederseits in einem kräftigen Wimperbüschel. Der Rand der Mundröhre trägt kurze, starre, nach vorn gerichtete Borsten. Jedem lateralen Haftröhrchenrudiment ist eine freistehende, unbewegte Tastborste zugeordnet: bis zum 3. oder 4. Haftröhrchenrudiment inserieren sie knapp davor, bei den übrigen knapp dahinter; ihre Länge beträgt $14 \mu \mathrm{m}$. Ein Paar Tastborsten steht an der Verschmälerung des Körpers zum Schwanzlappen, ein weiteres Paar entspringt auf der verlängerten Basis der beiden jeweils äußersten hinteren Haftröhrchen.

Die Mundöffnung erweitert sich zweifach abgestuft zu einer großen Höhle, die $35 \mu \mathrm{m}$ tief ist, einen Durchmesser von $35 \mu \mathrm{m}$ besitzt und den rostralen Rand als dünn- 
wandiges Rohr ein wenig überragt. Der Durchmesser des Pharynx beträgt ein Stück hinter der Mundhöhle nur mehr $28 \mu \mathrm{m}$. Die Pharyngealpori befinden sich knapp vor dem Pharynxende. Der Darm verläuft gerade, der After mündet etwa $40 \mu \mathrm{m}$ vor dem medianen Endlappen.

Protonephridien wurden an keinem Exemplar gesehen. Hoden und Ovar wie bei T. cornuta Remane 1925: beiderseits der vorderen Darmhälfte Hoden, Ovar beiderseits der hinteren Darmhälfte, Eilager (2-3 große, dotterreiche Eier) dorsal in der mittleren Darmregion.

Diskussion. Ihren nächsten Verwandten findet $T$. veneziana in $T$. italica GERLACH 1953. Dieser Art fehlen ebenfalls Kopfzapfen und dorsolaterale Haftröhchen. Beide Arten besitzen rudimentäre laterale Haftröhrchen mit getrennt von diesen stehenden Tastborsten und sind auch in ihren Körpermaßen kaum verschieden. Im Gegensatz zu $T$. veneziana trägt $T$. italica in der Pharynxregion Haftröhrchenrudimente, die Haftröhrchen auf den Schwanzlappenhälften sind mit 7 gegen 4 wesentlich zahlreicher. Überdies wird von T. italica ein laterales Paar echter Haftröhrchen, in der hinteren Rumpfregion, beschrieben. Bei T. veneziana sind Hoden und Ovar viel weiter hinten angeordnet.

Diagnose. Turbanella-Art ohne Kopfzapfen, mit 5-7 lateralen Haftröhrchenrudimenten, die in der Pharynxregion fehlen. Jederseits 5 vordere und 4 hintere Haftröhrchen. Dorsolateral weder Haftröhrchen noch deren Rudimente. Laterale Tastborsten unbewegt und von den Haftröhrchenrudimenten getrennt stehend. Medianer Endlappen vorhanden. Gonaden wie bei $T$. cornuta. Gesamtlänge maximal $500 \mu \mathrm{m}$; Körperbreite 57-59 $\mu \mathrm{m}$; Pharynxlänge 115-120 $\mu \mathrm{m}$.

\section{Paraturbanella dobrni REMANE $1927 \mathrm{c}$}

Fundorte: Alberoni, Pta. Sabbioni.

Untersuchtes Material: 38 Individuen.

Die Exemplare werden mit $300 \mu \mathrm{m}$ geschlechtsreif und überschreiten $380 \mu \mathrm{m}$ Länge nie; der Pharynx wird etwa $110 \mu \mathrm{m}$ lang, das längere der beiden lateralen Haftröhrchen miß $20 \mu \mathrm{m}$. Der Habitus erweist sich völlig identisch mit den Angaben der Erstbeschreibung; die Zahl der vorderen, ventralen Haftröhrchen beträgt jederseits 5-8, meist 6-7, ebenso die der hinteren Haftröhrchen.

Oft werden in der hinteren Hälfte des Darmabschnittes kompakte Spermienknäuel gefunden, in diesen Fällen fehlt der linke oder der rechte Hoden in der vorderen Darmregion. Im Hoden messen die Spermien 90-120 $\mu \mathrm{m}$, jene aber, die in der hinteren Rumpfregion dicht aufgerollt und meist in starker Bewegung begriffen sind, werden bis zu $190 \mu \mathrm{m}$ lang. Die Lage der Ovarien konnte an den untersuchten Tieren nicht genau lokalisiert werden; das Eilager liegt dorsal am Ende der ersten Darmhälfte und beinhaltet, etwas seitlich verschoben, meist nur ein großes $\mathrm{Ei}$ (ca. $50 \times 25 \mu \mathrm{m}$ ) und ein bis $z$ wei etwas kleinere.

D is k u s s io n. In der Erstbeschreibung dieser Art sind keine Körpermaße, wohl aber die Länge des längeren lateralen Haftröhrchens, mit $30 \mu \mathrm{m}$, angegeben (vgl. REMANE 1927c). Vorausgesetzt, daß in der Abbildung des Habitus zur Erstbeschreibung 
(Fig. 9) die lateralen Haftröhrchen maßstabsgetreu gezeichnet sind, würde sich eine Körperlänge von 560-570 $\mu \mathrm{m}$ ergeben, die Pharynxlänge betrüge demnach etwa $180 \mu \mathrm{m}$. Swedmark (1956) mißr die Körperlänge von $P$. dohrni mit $600 \mu \mathrm{m}$, während die Angabe von Thane-Fenchel (1970), $340 \mu \mathrm{m}$, mit meinen Messungen übereinstimmt.

\section{Thaumastodermatidae}

\section{Thaumostoderma mediterranea ReMANE 1927c (Abb. 4)}

Fundort: Rovinj.

Untersuchtes Material: 13 Individuen.

Die Gesamtlänge adulter Tiere mißt $210-220 \mu \mathrm{m}$, der Pharynx erreicht eine Länge von 70-75 $\mu \mathrm{m}$. In der Pharynxregion ist der Körper ca. $35 \mu \mathrm{m}$ breit, $50 \mu \mathrm{m}$ in der hinteren Rumpfhälfte. Auf das gleichmäßig gerundete Vorderende folgt eine seichte laterale Einbuchtung, nach der die Körperkonturen bis zum Hinterende ziemlich gestreckt verlaufen.

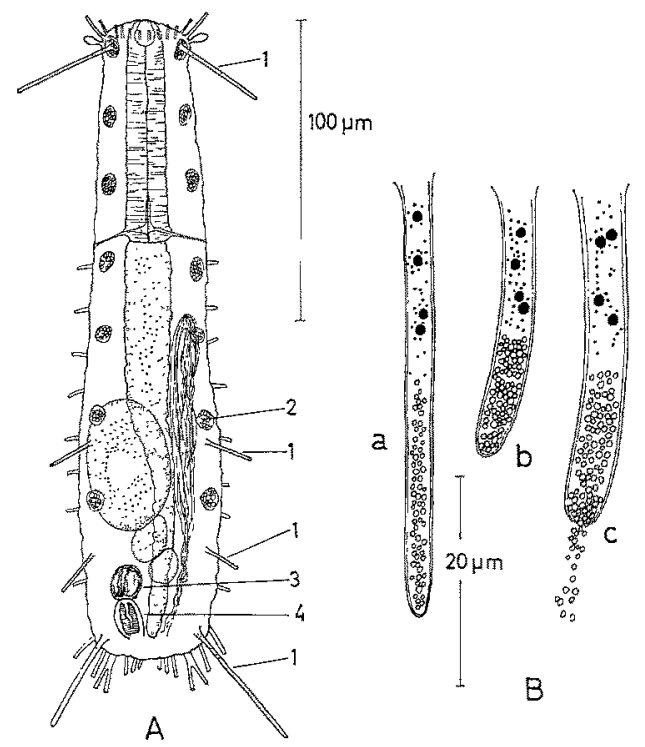

Abb. 4: Thaumastoderma mediterranea REMANe 1927. A Habitus dorsal, ohne VierhakerBedeckung, $B$ Cirrus: $a$ wenig, $b$ stark kontrahiert, $c$ stark gequetscht. 1 dorsolaterale Cirren; 2 Rückendrüsen; 3 Receptaculum; 4 Bursa

Die vorderen Haftröhrchen stehen knapp hinter dem Vorderende in einer geraden, querliegenden Reihe, die median keine Unterbrechung zeigt; ihre Länge nimmt von außen zur Medianen hin ab. Vom Ende der Pharynxregion bis zum Hinterende erstreckt sich jederseits eine ventrolaterale, unregelmäßige Abfolge von jeweils 8-10 kurzen Haftröhrchen. 
Das vorderste der 3 Kopftentakelpaare wird von kurzen, dünnen Stäbchen gebildet, die distal einen kugelförmigen Knopf tragen. Die Stäbchen des 2. Tentakelpaares sind doppelt so dick und doppelt so lang. Das 3. Kopftentakelpaar ist ovalspatelförmig, auf kurzen Stielen etwas dorsolateral angesetzt.

Die Cirren verteilen sich folgendermaßen: ein Paar langer Cirren etwa auf der Höhe der leichten Verschmälerung in der vordersten Pharynxregion, 2 Paare kurzer Cirren in der zweiten Hälfte der Darmgerion und ein Paar langer Cirren seitlich am Hinterende. Alle diese Cirren inserieren dorsolateral, sind beweglich und stark kontrahierbar, bis ca. auf die Hälfte ihrer normalen Länge, die bei den vorderen Cirren $35 \mu \mathrm{m}$, bei denen auf dem Hinterrumpf 15-20 $\mu \mathrm{m}$, am Hinterende bis $\mathrm{zu} 50 \mu \mathrm{m}$ beträgt. Die distale Hälfte einer Cirrus ist gleichmäßig dicht mit kleinen, stark lichtbrechenden Körnern erfüllt, in der proximalen Hälfte finden sich unregelmäßig verteilt 4-5 große dunkle Körner, die oft von feiner, dunkler Granula umgeben sind. Bei starker Quetschung der Tiere treten die kleinen, hellen Körner am distalen Ende des Cirrus aus.

Jederseits 7 große, hyalin granulierte Rückendrüsen liegen dorsolateral in ziemlich gleichen Abständen; die vorderste Rückendrüse befindet sich genau an der Wurzel des vordersten Cirrus, die hinterste ungefähr 50-60 $\mu \mathrm{m}$ vor dem Körperende.

Der Pharynx besitzt eine ovale Mundhöhle. Die Pharyngealpori führen vom Pharynxende schräg nach hinten zur Körperwand und werden von tütenartig bis zu den Pharynxzellen eingestülptem, epidermalem Gewebe gebildet.

Diskussion. Die nordadriatischen Exemplare sind um 40-60 $\mu \mathrm{m}$ kürzer als diejenigen, nach denen Remane (1927c) die Art errichtete. Die Form des Vorderendes, in der Abbildung von Remane (Fig. 14) trapezförmig, lehnt sich bei meinen Funden eher an T. swedmarki Levi 1950 und T. ramuliferum Crausen 1965 an. Die Stellung der vorderen Haftröhrchen beschreibt REMANE als jederseits zu dritt auf einer schräg verlaufenden Linie, mit einer medianen Unterbrechung; meine Exemplare weisen eine transversale, ununterbrochene Reihe von insgesamt 8 Haftröhrchen auf. Gleichsinnig mit $T$. beideri ReMane 1926 a sollte $T$. mediterranea, ,die von $T$. heideri . . nur geringfügige Abweichungen zeigt" (REMANE 1927c), etwa 16 ventrolaterale Haftröhrchen jederseits besitzen; die mir vorgelegenen Tiere tragen etwa halb so viele. Die Tentakel des vordersten Paares verschmälern sich nicht lang ausgezogen fadenförmig, sondern sind geknöpfte Stäbchen. Remane vermutet das Fehlen des, bei T. beideri vorhandenen, $z$ weiten vorderen Cirrenpaares; mit jederseits 4 Cirren und einer langen, cirrenfreien Region nach dem ersten Paar entsprechen die nordadriatischen Exemplare der Beschreibung Remanes.

Bei allen Thaumastoderma-Arten werden Lage und Bau der Gonaden als identisch, Körperformen, Körpermaße und Cirrenverteilung als annähernd gleich beschrieben. Das vorläufig wichtigste Merkmal zur Unterscheidung der Arten bleiben mithin die Form und der Verteilungsmodus der spatelförmigen Tentakel des Vorderendes. 
Tetranchyroderma boadeni nov. spec. (Abb. 5)

Fundort: Alberoni.

Untersuchtes Material: 10 Individuen.

Die Gesamtlänge beträgt 340-370 $\mu \mathrm{m}$, die Länge des Pharynx mißt $120 \mu \mathrm{m}$. Hinter der breiten Mundöffnung verschmälert sich der Körper, erreicht aber gleich darauf eine Breite von $30-32 \mu \mathrm{m}$; bis in die mitclere Körperregion wird diese Breite beibehalten, dann, im Bereich der Gonaden, steigt sie auf $35 \mu \mathrm{m}$. Das Hinterende ist wieder ein wenig schmäler und quer abgestutzt.

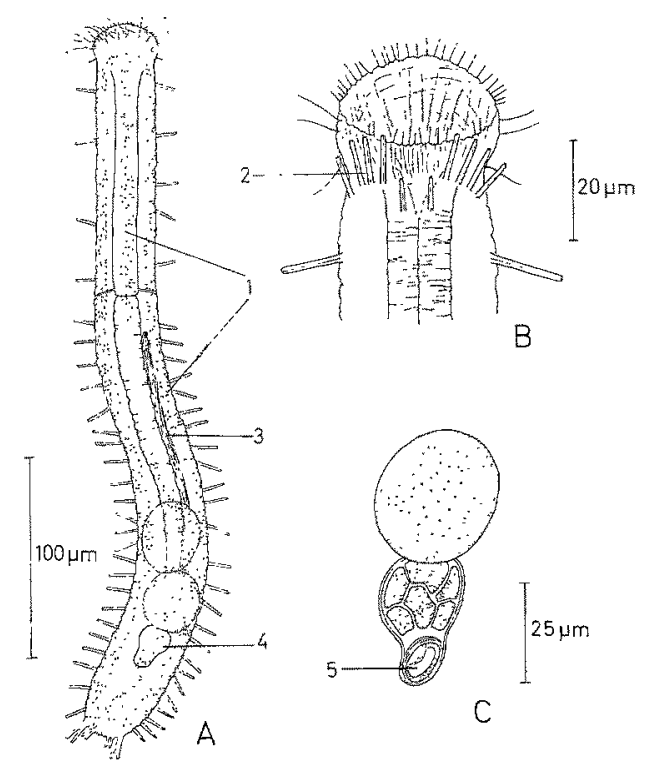

Abb. 5: Tetranchyroderma boadeni nov. spec. A Habitus dorsal, $B$ Vorderende ventral, $C$ Bursa mit hinterstem Ei. 1 punktierte Streifen: dorsale Vielhaker-Bedeckung; 2 vordere Haftröhrchen; 3 Hoden; 4 Bursa; 5 Antrum femininum

T. boadeni trägt Vierhaker, ist von diesen jedoch nicht vollständig bedeckt: dorsal ziehen, an der vorderen Körperverschmälerung beginnend, zwei nackte Streifen bis knapp vor das Hinterende. Vierhaker sind mithin nur in jeweils einem Streifen an den Körperflanken und in einem dorsomedianen Streifen vorhanden; dieser ist in der mittleren Körperregion jedoch unterbrochen, so daß hier die beiden nackten Flächen miteinander in Verbindung stehen. Die Vierhaker sind hinter der Mundöffnung etwa $2 \mu \mathrm{m}$ hoch, wachsen bis zur mittleren Körperregion auf über $4 \mu \mathrm{m}$ Höhe an und werden dem Rumpfende zu wieder etwas niedriger.

Jederseits 5 vordere Haftröhrchen inserieren in einem Halbkreis knapp hinter dem ventralen Mundrand. Das innerste Paar ist mit $6 \mu \mathrm{m}$ Länge halb so lang wie die übrigen und etwas caudad und gegen die Mediane versetzt. Lateral finden sich in der Pharynxregion 4-5 Haftröhrchen, die 12-14 $\mu \mathrm{m}$ lang sind. Wesentlich dichter stehen die lateralen Haftröhrchen in der Darmregion: ab dem Pharynx bis zu den Haft- 
röhrchen des Hinterendes finden sich 20-25 Stück in freier Verteilung; auch diese sind 12-14 $\mu \mathrm{m}$ lang. Die seitlichen Begrenzungen des Hinterendes bilden jeweils 2 Haftröhrchen auf einem verlängerten Basisstück. Dazwischen stehen 4 Haftröhrchen auf der Rumpfhinterkante, jederseits in einem Paar laterad an die Basis der äußeren Haftröhrchen gerückt.

Die ventrale Bewimperung ist homogen, dicht in der vorderen Körperhälfte, schütterer in der Genitalregion. Lange, schlagende Wimpern befinden sich dorsal und lateral der Mundöffnung. Auf dem dorsalen und lateralen Mundrand inserieren kurze, steife, Borsten; ventrolateral, knapp oberhalb der vorderen Haftröhrchen, stehen jederseits zwei etwas längere Tastborsten. Laterale Tasthaare sind über den ganzen Körper verstreut, etwas konzentrierter jedoch in den Regionen dichteren Haftröhrchenbesatzes.

Der Pharynx öffnet sich in eine große, trichterförmige Mundöffnung, deren Wände von einer kräftigen Ringmuskulatur durchzogen werden. Die Pharyngealpori befinden sich am Pharynxende, ihre Kanäle sind sehr dünn und erweitern sich nach außen nur wenig. An den von mir untersuchten Tieren endete der Darm unterhalb des Eilagers, ca. $80 \mu \mathrm{m}$ vor dem Rumpfende; ein After schien zu fehlen.

Protonephridien wurden nicht gefunden. Der Hoden liegt rechts neben dem vorderen Darmabschnitt und enthält etwa $120 \mu \mathrm{m}$ lange Spermien, deren durchgehend spiraliges Kopfstück 30-32 $\mu \mathrm{m}$ lang ist. Der Vas deferns ist deutlich bis in die Gegend des Darmendes verfolgbar. Die Tiere besitzen 2-3 reife Eier, das größte davon mit einer Länge von $35 \mu \mathrm{m}$; ein Ovar war nicht zu erkennen. Die Bursa legt sich eng an das hinterste reife Ei; sie besteht aus 6-8 dicht granulierten Schollen, die von 2 Muskellagen umhüllt werden. An der Berührungsstelle mit dem hintersten Ei scheint die muskulöse Umhüllung zu fehlen, zudem ist die Bursa hier stark eingedellt; sie öffnet sich 40-50 $\mu \mathrm{m}$ vor dem Rumpfende in ein großes, ventrales Antrum, dessen stark ausgeprägte Ringmuskulatur in die bursalen Muskelschichten überleitet. Ein Receptaculum seminis wurde nicht festgestellt.

Diskus sion. Einige Grundzüge teilt T. boadeni mit T. pugetensis WIESER 1957; diese Art ist etwa gleich groß, trägt ebenfalls Vierhaker, Zahl und Anordnung der Haftröhrchen sind ganz ähnlich. Unterschiede ergeben sich aus der dorsalen Verteilung der Vierhaker, denn $T$. pugetensis ist von diesen Kutikularelementen vollständig bedeckt, $T$. boadeni besitzt ausgedehnte nackte Flächen. Die Haftröhrchen sind bei $T$. boadeni wesentlich kürzer, die Vierhaker um vieles niedriger. WIESER beschreibt für T. pugetensis eine Kloake und ein daranschließendes zipfelförmiges Organ, das er als Receptaculum seminis bezeichnet (vgl. WIESER 1957, Fig. 5). Da aber einerseits an allen darauf untersuchten Tetranchyroderma-Arten After, männlicher und weiblicher Genitalporus getrennt münden, andererseits Lage und Form des Receptaculums bei T. pugetensis eher auf eine Bursa copulatrix hinweisen, dürtte in dieser Beschreibung das Antrum femininum einer "Kloake", die Bursa wohl dem "Receptaculum" entsprechen.

Das Fehlen eines Receptaculums an den von mir untersuchten T. boadeni-Exemplaren ist vermutlich nur altersbedingt; anderen Entwicklungsstadien darf deshalb dieses Organ nicht abgesprochen werden.

Diagnose. Tetranchyroderma-Art mit Vierhakern, auf der Dorsalseite 2 nackte 
Streifen. Jederseits 5 vordere, 25-30 laterale und 4 hintere Haftröhrchen. In der Pharynxregion jederseits nur 4-5 Haftröhrchen. Keine Cirren, keine Tentakel. Genitalapparat der Gattungsdiagnose entsprechend; ein Receptaculum fehlt (?). Gesamtlänge 340-370 $\mu \mathrm{m}$; Körperbreite in der vorderen Pharynxregion 30-32 $\mu \mathrm{m}$, in der Rumpfregion $35 \mu \mathrm{m}$; Pharynxlänge $120 \mu \mathrm{m}$.

\section{Tetranchyroderma spec. I (Abb. 6)}

Fundort: Alberoni.

Untersuchtes Material: 4 Individuen.

Die Tiere sind 260-270 $\mu \mathrm{m}$ lang, die Pharynxlänge mißt $70-80 \mu \mathrm{m}$. Das Vorderende ist $35 \mu \mathrm{m}$ breit, hinter der weiten Mundöffnung verschmälert sich der Körper und erreicht erst in seinem letzten Drittel eine Breite von 33-35 $\mu \mathrm{m}$. Das Hinterende ist quer abgestutzt.

Die Dorsalseite ist nicht vollständig mit Vierhakern bedeckt: zwei große, annähernd dreieckige Flächen im vorderen Körperdrittel, und zwei breite, parallele Streifen auf dem übrigen Körper sind nackt; nur schmale, von Vierhakern z. T. schütter bestandene Bänder grenzen die freien Flächen gegeneinander ab. In der Pharynxregion werden die dorsalen Vierhaker etwa $3 \mu \mathrm{m}$ hoch, die lateralen nicht ganz $4 \mu \mathrm{m}$; in der Darmregion erreichen die dorsalen Vierhaker über $4 \mu \mathrm{m}$ Höhe, die lateralen über $5 \mu \mathrm{m}$.

Die insgesamt 10 vorderen, ventralen Haftröhrchen stehen jederseits zu zweit laterad gewendet, $\mathrm{zu}$ zweit etwas weiter vorne gegen den Mundrand gerichtet, die mittleren beiden Haftröhrchen sind ein wenig caudad versetzt. In der Pharynxregion befinden sich lateral keine Haftröhrchen, dicht beieinander stehen sie jedoch am Anfang der Darmregion und von da bis zum Rumpfende etwas weiter auseinandergerückt in ziemlich regelmäßigen Abständen. Insgesamt beträgt ihre Zahl jederseits 18-22. Die vorderen Haftröhrchen sind $7 \mu \mathrm{m}$ lang, die lateralen 12-13 $\mu \mathrm{m}$. Am Hinterende inserieren jederseits $2 \mathrm{Haft}$ öhrchen auf verlängerter Basis, gemeinsam mit dieser mißt ihre Länge $15 \mu \mathrm{m}$. Auf der Hinterkante des Rumpfes befinden sich 6 Haftröhrchen.

Die Bewimperung der Ventralseite bilden quer verlaufende Bänder. Das Vorderende trägt dorsal knapp hinter dem Mundrand schlagende Wimpern. Auf dem dorsalen Mundrand selbst entspringen kurze Borsten. Jedem lateralen Haftröhrchen ist eine Tastborste zugeordnet.

Der Pharynxeingang öffnet sich zu einem weiten Trichter, der dorsale Mundrand ragt etwa $20 \mu \mathrm{m}$ über den ventralen vor. Die engen Pharyngealpori befinden sich am Pharynxende. Der Darm zeigt keine Besonderheiten.

Der rechtsliegende Hoden reicht vorne bis in die Nähe des Pharynxendes und geht hinten ohne deutliche Begrenzung in den Vas deferens über. In der mittleren Darmregion liegen zwei größere Eier, dahinter einige kleinere, deren Anzahl nicht genau festzustellen war. Form und Lage der Bursa und des Antrum femininums konnten nicht analysiert werden.

Diskussion. T. spec. I steht T. boadeni sehr nahe. Beide Arten tragen Vierhaker, die das Tier nur in schmalen Streifen bedecken. Die Anordnung der vorderen, 
lateralen und hinteren Haftröhrchen zeigen keine gravierenden Unterschiede, wohl aber die Körpergröße. Die nod. zu lückenhaft untersuchten Exemplare können vorläufig noch nicht zur Art erhoben werden.

Vorläufige Diagnose. Tetrancbyroderma-Art mit Vierhakern, die auf der Dorsalseite 2 etwa dreieckige, dahinter 2 parallele Flächen frei lassen. Jederseits 5 vordere, 18-22 laterale und 5 hintere Haftröhrchen. Keine Haftröhrchen in der Pharynxregion. Keine Cirren, keine Tentakel. Genitalapparat der Gattungsdiagnose entsprechend (?). Gesamtlänge 260-270 $\mu \mathrm{m}$; Körperbreite in der Pharynxregion $35 \mu \mathrm{m}$, in der hinteren Rumpfregion 33-35 $\mu \mathrm{m}$; Pharynxlänge 70-80 $\mu \mathrm{m}$.

\section{Tetranchyroderma spec. II (Abb. 7)}

Fundort: Alberoni.

Untersuchtes Material: 6 Individuen.

Die Gesamtlänge beträgt $280 \mu \mathrm{m}$, die Länge des Pharynx $122 \mu \mathrm{m}$. Gleich hinter der Mundöffnung befinden sich seitliche Lappen, die den hier $35 \mu \mathrm{m}$ breiten Körper jederseits um ca. $4 \mu \mathrm{m}$ überragen. In seiner hinteren Hälfte wird der Körper $43 \mu \mathrm{m}$ breit. Das Hinterende ist abgerundet.

Dorsal und lateral wird der Körper lückenlos von Vierhakern bedeckt.

In leicht gekrümmten Querreihen stehen jederseits 4 vordere, ventrale Haftröhrchen, deren Länge von innen nach außen zunimmt. In der Pharynxregion sind keine lateralen Haftröhrchen vorhanden. In der Darmregion bilden 6-10 Haftröhrchen eine ventrolaterale Reihe; 2 erhöht ansitzende, laterale Haftröhrchen finden sich in der Mitte der Darmregion. Das jederseits äußere Paar der hinteren Haftröhrchen besitzt einen Basislappen, direkt am Körperhinterrand inserieren insgesamt 4 Haftröhrchen. Die äußeren vorderen Haftröhrchen sind 6-8 $\mu \mathrm{m}$ lang, die inneren 3-4 $\mu \mathrm{m}$; die ventrolateralen Haftröhrchen messen 5-8 $\mu \mathrm{m}$, die lateralen $10-12 \mu \mathrm{m}$, die äußeren hinteren Haftröhrchen samt Basis etwa $12 \mu \mathrm{m}$, die mittleren am Rumpfhinterrand 5-6 $\mu \mathrm{m}$.

Die Ventralbewimperung konnte nicht genau beobachtet werden. Hinter dem dorsalen Mundrand inserieren ca. 30 schlagende Wimpern in einer Querreihe, auf den seitlichen Lappen des Vorderendes sind 5-7 Wimpern zu einem Büschel vereint. Starre Tasthaare von 20-25 $\mu \mathrm{m}$ Länge stehen lateral zu fünt in der Pharynxregion, 14 gleichmäßig verteilte in der Darmregion.

Die Mundöffnung ist groß, kann jedoch offenbar weder stark erweitert noch kontrahiert werden. Die Pharyngealpori zweigen vom Pharynxende ab. Der After befinder sich ca. $60 \mu \mathrm{m}$ vor dem Hinterende des Rumpfes.

Protonephridien wurden nicht beobachtet. Der rechtsliegende Hoden erstreckt sich längs der ganzen vorderen Darmhälfte. An den mir vorgelegenen Tieren waren nur 1 oder 2 kleine Eier dorsal hinter dem After zu finden; die Bursa, etwa $20 \mu \mathrm{m}$ lang und an ihrem Vorderende stark eingedellt, ist von einer dünnen Muskelschicht umgeben und enthält dicht gepackte Bläschen oder hyaline Körner. Das Antrum femininum befindet sich ca. $20 \mu \mathrm{m}$ vor dem Körperhinterrand. Neben der Bursa tritt ein ihr ähnlich strukturiertes, birnenförmiges Organ auf. Der gesamte Hinterkörper ist von großen Vakuolen erfüllt. 
Diskussion. Auch von T. spec. II sind die Kenntnisse zu gering, um die Aufstellung einer Art zu rechtfertigen. Die Körperform, die Verteilung der Haftröhrchen und der Besitz von Vierhakern nähern $T$. spec. II den beiden Arten T. pugetensis

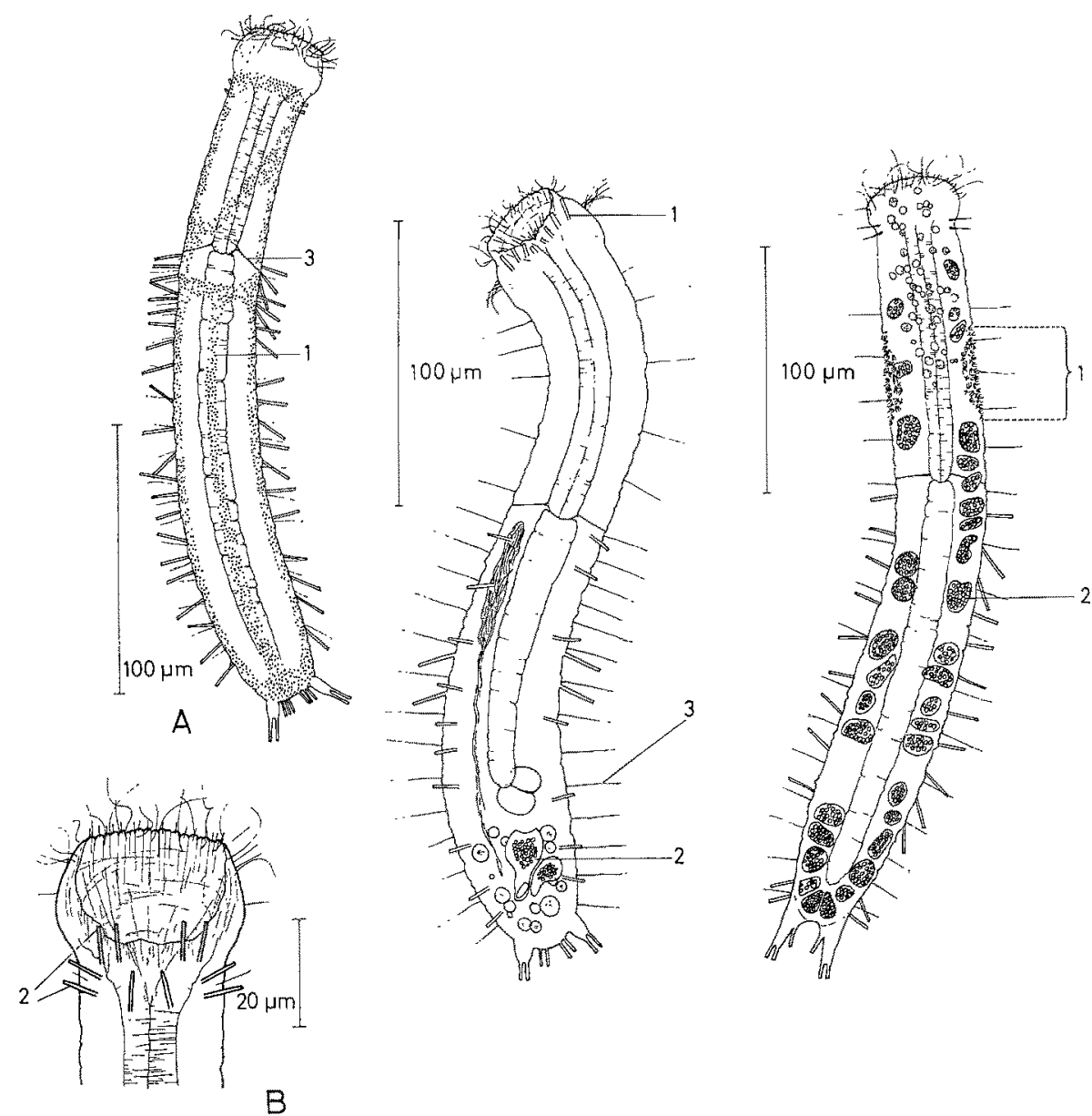

Abb. 6

Abb. 7

Abb. 8

Abb. 6: Tetranchyroderma spec. L. A Habitus dorsal, $B$ Vorderende ventral. 1 punktierte Streifen: dorsale Vierhaker-Bedeckung; 2 vordere Haftröhrchen; 3 Pharyngealpori

Abb. 7: Tetrancbyroderma spec. II. Habitus ventral. 1 vordere Haftröhrchen; 2 Bursa; 3 Tasthaare

Abb. 8: Tetranchyroderma spec. III. Habitus. 1 Vierhaker-Bedeckung; 2 Rückendrüsen

WIESER 1957 und T. boadeni, ihre Eigenständigkeit erweist sich jedoch durch die wesentlich geringere Anzahl der lateralen Haftröhrchen, durch die im Gegensatz zu $T$. boadeni völlige Bedeckung der Dorsalseite mit Vierhakern und durch die verschiedene Form des Vorderendes: ähnliche Lappen, die nicht durch die Erweiterung des Pharynx- 
einganges bedingt sind, zeigt andeutungsweise bloß die anschließend beschriebene Art, T. spec. III.

Vorläufige Diagnose. Tetranchyroderma-Art, von Vierhakern dorsal vollständig bedeckt. Jederseits 4 vordere, 6-10 ventrolaterale, 2 laterale und insgesamt 8 hintere Haftröhrchen. Keine Haftröhrchen in der Pharynxregion. Keine Cirren, keine Tentakel. Genitalapparat nicht vollständig bekannt. Gesamtlänge $280 \mu \mathrm{m}$; Körperbreite in der vorderen Pharynxregion $35 \mu \mathrm{m}$, in der hinteren Rumpfregion $43 \mu \mathrm{m}$; Pharynxlänge $122 \mu \mathrm{m}$.

Tetranchyroderma spec. III (Abb. 8)

Fundort: Alberoni.

Untersuchtes Material: 12 Individuen.

Die Gesamtlänge mißt 300-315 $\mu \mathrm{m}$, die Pharynxlänge $110 \mu \mathrm{m}$. Hinter der Mundöffnung ist der Körper ein wenig seitlich eingezogen, in der mittleren Pharynxregion $35 \mu \mathrm{m}$ breit, in der mittleren Darmregion ca. $40 \mu \mathrm{m}$.

Die Tiere sind beinahe vollkommen nackt, bloß etwa $60 \mu \mathrm{m}$ hinter dem dorsalen Mundrand befindet sich jederseits ein kleines Feld mit winzigen Vierhakern, dessen Längsausdehnung ungefähr $35 \mu \mathrm{m}$ beträgt. Nirgends sonst befinden sich auf dem Körper Kutikulargebilde.

Knapp hinter dem ventralen Mundrand stehen jederseits 4 ventrale Haftröhrchen. Laterale Haftröhrchen fehlen in der Pharynxregion, verteilen sich jedoch ziemlich regelmäßig zu 9-11 in der Darmregion, deren hinteres Viertel sie wiederum frei lassen; nur knapp vor den hinteren Haftröhrchen stehen noch 2 seitliche Paare. Die jederseits 3 hinteren. Haftröhrchen inserieren gemeinsam auf jeweils einen $20 \mu \mathrm{m}$ langen Basislappen; die Haftröhrchen an den Spitzen dieser Lappen sind $5 \mu \mathrm{m}$, die an den inneren Rändern derselben sind $10 \mu \mathrm{m}$ lang. Die lateralen Haftröhrchen messen etwa $12 \mu \mathrm{m}$.

Die ventrale Bewimperung führt in einem breiten Feld von den vorderen Haftröhrchen bis zum Körperende, ob sie von Querbändern gebildet wird, war nicht sicher zu erkennen. Hinter dem dorsalen Mundrand befindet sich eine Reihe langer, schlagender Wimpern. Der Mundrand trägt dorsal und ventral kurze Borsten. Jederseits ein Paar starrer Tastborsten entspringt dorsolateral an der vorderen Körpereinziehung. Diese Haare sind an ihrer Basis stark verdickt. 15-17 Tasthaare bilden jederseits eine regelmäßige Reihe vom vorderen Pharynxdrittel bis zu den hinteren Haftröhrchen.

Die Mundöffnung ist breit, die Pharyngealpori liegen am Pharynxende. Die Lage des Afters, wohl knapp vor dem Rumpfende, konnte nicht genau eruiert werden.

Die untersuchten Tiere sind ab der hinteren Pharynxregion bis zum Körperende reich an granulierten Rückendrüsen. Diese bilden jederseits einen, auf weiten Strecken manchmal unterbrochenen, dorsolateralen Streifen. Die Drüsen sind größtenteils unregelmäßig geformt und enthalten grobe Granula. Auf einer Körperseite werden maximal 20 Drüsen gezählt, mindestens 9 . Oberhalb der vorderen Pharynxhälfte befinden sich kleine Vakuolen (oder homogene Rückendrüsen); zwischen diese eingestreut liegen kleine, dunkel granulierte Drüsen. 
Protonephidien fehlten. An den untersuchten Exemplaren wurden keine Geschlechtsorgane beobachtet; nirgends in der Rumpfregion wurden Hoden, Ovarien, Eilager, Bursa, Receptaculum seminis oder deren Rudimente gefunden.

Diskussion. Die Form des Hinterendes erinnert an $T$. polyacantbus Remane $1927 \mathrm{c}$ (Echinodasys polyacanthus), vielleicht drücken auch die auffälligen GranulaBallungen von $T$. spec. III eine nähere Verwandtschaft zu jener Art aus (vgl. ForNERIs 1961). Für die Armut an epidermalen Kutikularelementen gibt es jedoch in der ganzen Gattung keine Parallelen. T. boadeni und T. spec. I besitzen lediglich nackte Streifen oder Flecken. Das vollständige Fehlen von Genitalorganen im Verein mit adult anmutenden Körperproportionen und Haftröhrchenbesatz stellt wohl kaum ein juveniles Merkmal dar, und zumal die dichten Granula-Anhäufungen als Sekretspeicherung später Altersstadien deutbar sind, darf eher ein bereits vollzogener Abbau aller Geschlechtsorgane angenommen werden.

Vorläufige Diagnose. Tetracbyroderma-Art, winzige Vierhaker nur in einem kurzen Abschnitt jederseits der mittleren Pharynxregion, der übrige Körper völlig nackt. Jederseits 4 vordere Haftröhrchen, 9-11 lateral in der Darmregion, hinten paarige Lappen mit jeweils 3 Haftröhrchen besetzt. Keine Haftröhrchen in der Pham rynxregion. Keine Cirren, keine Tentakel. Zahlreiche granulierte Rückendrüsen. Der Genitalapparat fehlte an den untersuchten Exemplaren. Gesamtlänge 300-315 $\mu \mathrm{m}$; Körperbreite in der Pharynxregion $35 \mu \mathrm{m}$, in der Rumpfregion $40 \mu \mathrm{m}$; Pharynxlänge $110 \mu \mathrm{m}$.

\section{Chaetonotoidea}

Xenotrichulidae

Xenotrichula lineata nov. spec. (Abb. 9)

Fundort: Alberoni.

Untersuchtes Material: 9 Individuen.

Die Tiere werden bis zu $145 \mu \mathrm{m}$ lang, an der schwachen Lappung der vordersten Pharynxregion $28 \mu \mathrm{m}$ breit und $31 \mu \mathrm{m}$ breit in der mittleren Rumpfregion. Der Körper ist am Ende der Pharynxregion leicht verschmälert, seine dorsoventrale Abplattung gering. Die Länge der Zehenbasis mißt $15 \mu \mathrm{m}$, die der Haftröhrchen $10 \mu \mathrm{m}$. Der Durchmesser der Zehenbasis beträgt $4-5 \mu \mathrm{m}$. Der Pharynx ist $40 \mu \mathrm{m}$ lang.

Ein Kephalion fehlt. Pharynxregion und Rumpf tragen dorsal keine Stielschuppen, wohl aber lateral. In einer breiten Fläche oberhalb des Pharynx liegen 16 feine Querlinien hintereinander, die seitlich in schräg gestellte, etwas stärker kutikularisierte Linien direkt überleiten, mithin gegen diese in der Längsrichtung nicht versetzt sind. Noch weiter lateral verlaufen in der Pharynxregion jederseits 3 Längsreihen punktförmiger Verdickungen, ihnen außen benachbart die lateralen Stielschuppen, die sich knapp $1 \mu \mathrm{m}$ über die Epidermis erheben; ob diese Stielschuppen mehr als eine Längsreihe bilden, ist ihrer geringen Größe wegen nicht zu erkennen. Das Querlinien-Feld auf der Dorsalseite der Pharynxregion verschmälert sich caudad, die Längsabfolge der stärker verdickten und das mediane Feld seitlich begrenzenden Linien biegt hier mit 
jederseits kürzer werdenden Elementen mediad ein, um gegen Ende der Pharynxregion in einer Reihe von jederseits 6-7 Punkten auszulaufen. Die dorsolateralen Punktereihen der Pharynxregion gehen ein Stück weiter auf den Rumpf über. Die vordere Rumpfregion wird dorsal von 10 Längsreihen kräftiger, 2-3 $\mu \mathrm{m}$ langer Querlinien bedeckt, die gegeneinander versetzt sind. In der mittleren Rumpfregion treten jederseits noch zwei Längsreihen hinzu, die weiter hinten wiederum laterad absinken.

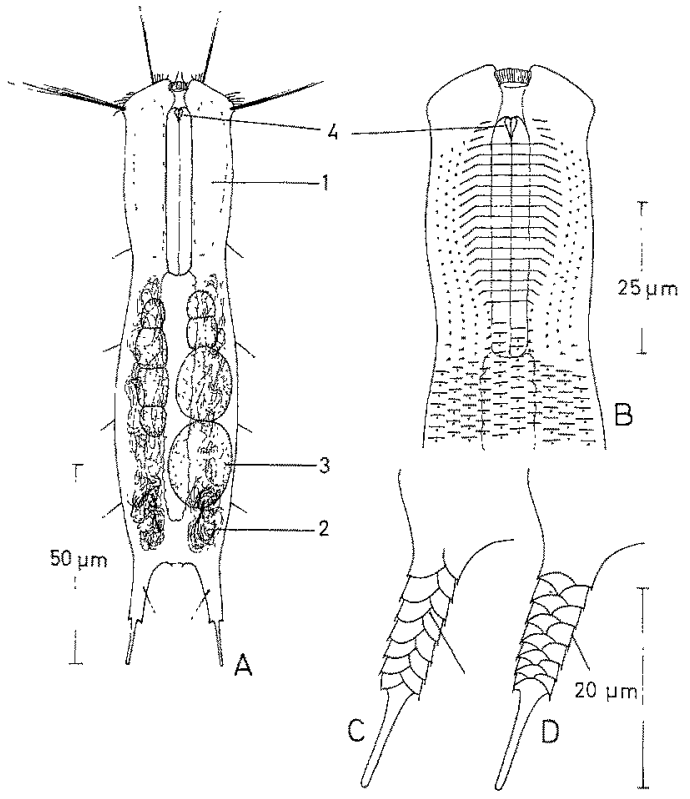

Abb. 9: Xenotrichula lineata nov. spec. A Habitus dorsal, ohne äußere Kutikularstrukturen, $B$ Vorderende dorsal, ohne Cirren und Sinnesborsten, $C$ linke Zehe dorsal, $D$ techte Zehe ventral. 1 vordere ventrale Cirrenfelder; 2 Spermienanhäufungen; 3 Eier; 4 kutikularisierte Hökker im Pharynxeingang

Während lateral in der gesamten Rumpfregion typische Stielschuppen stehen, mit kleiner runder Basis, mit Stiel und Endplatte, trägt hier die Dorsalseite nur querliegende Rippen, die der Epidermis direkt anliegen. Knapp hinter jeder dieser Rippen befindet sich eine punktförmige Verdickung. In der hinteren Hälfte des Rumpfes werden die Querlinien allmählich feiner, im letzten Rumpfdrittel verschwinden sie zur Gänze, die Punkte bleiben allerdings erhalten und führen die Reihen bis zum Rumpfende fort. Bei drei der untersuchten Tiere waren die Rippen bereits in der vordersten Rumpfregion sehr fein und fehlten auf uber zwei Drittel des Rumpfes.

Ventrolateral beginnt am Ende der Pharynxregion jederseits eine Reihe querstehender Schienen, die bis zu den Zehen führen. Diese Schienen sind sehr dünn und meist nur an ihren verdickten Hinterrändern kenntlich; unter günstigen Bedingungen sind auch die seitlichen Begrenzungen deutlich, selten die vorderen. Die Ventralseite des Körpers ist nackt. 
Die Zehenbasis ist rundum beschuppt. Die Elemente der beiden dorsalen Reihen greifen hier ventralwärts uber und decken z. T. noch die ventralen Schuppen, die nur eine Längsabfolge bilden. Die Klebdrüsen der Haftröhrchen ziehen etwa $10 \mu \mathrm{m}$ in den Rumpf ein.

Die ventralen Cirren bilden in der Pharynxregion getrennte Felder, die knapp hinter dem Vorderende beginnen und beinahe bis ans Ende der Pharynxregion reichen. Median lassen sie eine Fläche frei, deren Breite ungefähr dem Pharynxdurchmesser entspricht; laterad erstrecken sie sich bis zu den kleinen lateralen Stielschuppen. Die kleine paarige Gruppe der hinteren Bauchcirren befindet sich etwa am Ende des ersten Rumpfdrittels.

Ein Paar vorderer Tastcirren inseriert nahe dem Mundring, ein zweites Paar an der lateralen Lappung des Vorderendes. Zwischen den Cirren und neben dem Mundring stehen steife Borsten: zwischen dem Mundring und den rostralen Cirren sind sie $2 \mu \mathrm{m}$ lang, zwischen den rostralen und lateralen Cirren ca. $3 \mu \mathrm{m}$. Die lateralen Cirren bestehen aus 5-6 Haaren, die rostralen aus jeweils 3. Dorsolaterale Tasthaare, die oft geißelartig schlagen, befinden sich am Ende der Pharynxregion und zu 3 Paaren gleichmäßig verteilt auf dem Rumpf; ein mediad weisendes Paar inseriert auf den Zehenbasen.

Der stark geriefte Mundring ist $2 \mu \mathrm{m}$ hoch, $5 \mu \mathrm{m}$ weit, tief in das Vorderende eingesenkt und trägt zwei zueinander gebogene Borsten. Die Distanz zwischen dem Mundring und den vordersten Pharynxzellen überbrückt ein dünnwandiges, elastisches Rohr von etwa $5 \mu \mathrm{m}$ Länge. Im Pharynxeingang liegt ein Paar tropfenförmiger Kutikularhödker. Der Durchmesser des Pharynx beträgt $6 \mu \mathrm{m}$. Der gerade verlaufende Darm mündet etwa $10 \mu \mathrm{m}$ vor dem Rumpfende.

Bei allen untersuchten Tieren wurden paarig Spermienstränge über die gesamte Rumpflänge hin angetroffen; locker verteilt in deren vorderem Abschnitt, dichter geballt in deren hinterem Drittel, waren sie durch den Darm getrennt.

Diskussion. Innerhalb der Gattung teilt $X$. lineata nur mit $X$. pygmaea REMANE 1934 das Merkmal der Schuppenlosigkeit auf den Dorsalseiten von Pharynxund Rumpfregion. Der Mangel an Tentakeln, das Fehlen eines Kephalions, der Besitz ventrolateraler Schienen sowie die allgemein größeren Körperabmessungen rücken $X$. lineata aber von $X$. pygmaea weit ab. Dorsale Querlinien auf der dorsalen Pharynxregion wurden auch an $X$. subterranea REMANE 1934 gefunden, treten indes bei dieser Art gemeinsam mit Stielschuppen auf; zudem trägt auch $X$. subterranea Tentakel und Kephalion.

Die Ausbildung der vorderen Tastcirren, der Bauchcirren, der Zehenbeschuppung und die Geschlechtsverhältnisse stellen keine wesentlichen Gegensätze zu den meisten anderen Xenotrichula-Arten dar; $X$. lineata besitzt aber als bislang einzige Art der Gattung kutikulare Elemente im Lumen des vorderen Pharynxabschnittes.

Diagnose. Xenotrichula-Art ohne dorsale Stielschuppen, Stielschuppen nur rostral und lateral vorhanden. In der Pharynxregion in einem dorsomedianen Feld durchlaufende Querlinien, auf dem Rumpf kurze, gegeneinander versetzte Querlinien mit Stielrudimenten (?). Ventrolaterale Schienen vorhanden. Tentakel und Kephalion fehlen. Bauchcirren auf dem mittleren Rumpfabschnitt vorhanden. Im Pharynxeingang kutikulare Höcker. Hermaphroditisch. Gesamtlänge des Körpers 140-145 $\mu \mathrm{m}$, davon 
Länge der Zehenbasis $15 \mu \mathrm{m}$ und Länge der Haftröhrchen $10 \mu \mathrm{m}$; größte Körperbreite in der Pharynxregion $28 \mu \mathrm{m}$, in der Rumpfregion $31 \mu \mathrm{m}$; Pharynxlänge $40 \mu \mathrm{m}$.

\section{Chaetonotidae}

Chaetonotus angustus nov. spec. (Abb. 10)

Fundort: Alberoni.

Untersuchtes Material: 14 Individuen.

Die Gesamtlänge beträgt 122-126 $\mu \mathrm{m}$. Auch reife Tiere sind in der Pharynxregion breiter $(23 \mu \mathrm{m})$ als in der Rumpfregion $(21 \mu \mathrm{m})$. Der Körper ist am Ende der Pharynxregion kaum verschmälert. Der Rumpf läuft hinten in einen stark abgeflachten,

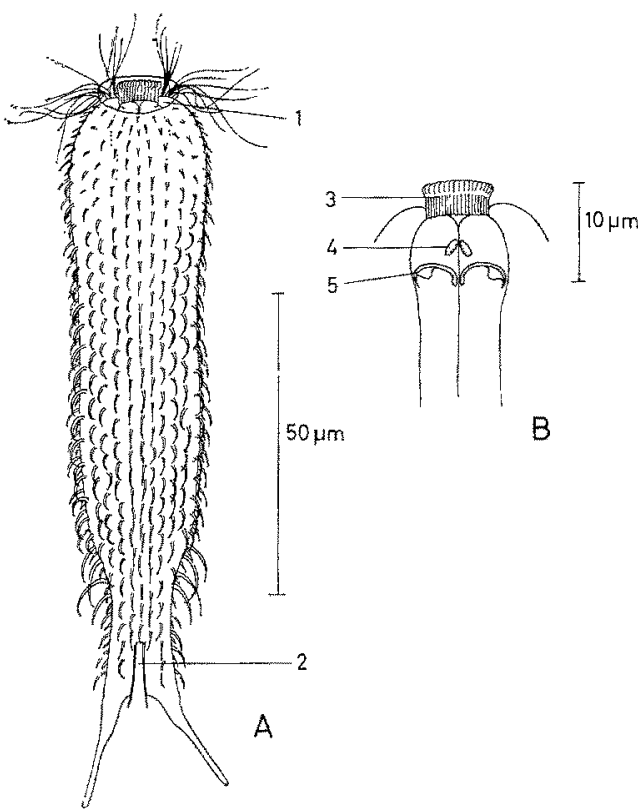

Abb. 10

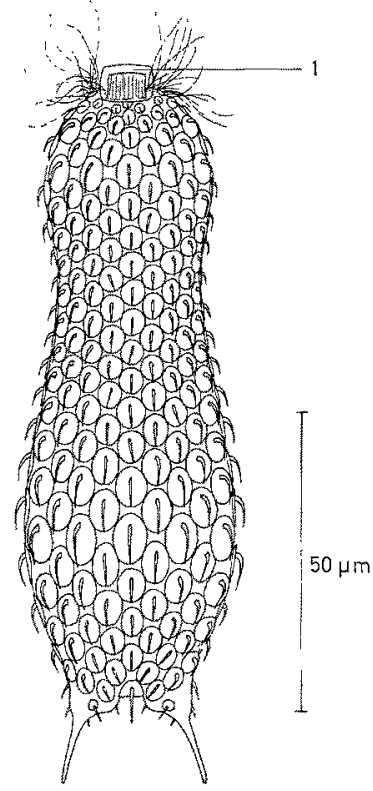

Abb. 11

Abb. 10: Chaetonotus angustus nov. spec. A Habitus dorsal, $B$ vorderer Pharynxabschnitt. 1 Kephalion; 2 caudaler Spalt; 3 Mundring; Mundbewaffnung: 4 Höcker, 5 Spangen

Abb. 11: Chaetonotus aequispinosus nov. spec., Habitus dorsal. 1 Kephalion

etwa $17 \mu \mathrm{m}$ langen Lappen aus, der an seiner Basis $10 \mu \mathrm{m}$ breit ist und bis $\mathrm{zu}$ den Ansatzstellen der Haftröhrchen um $4 \mu \mathrm{m}$ Breite zunimmt. Die dïnnen, leicht auswärts gebogenen Haftröhrchen messen $19 \mu \mathrm{m}$ in der Länge, inklusive der $6 \mu \mathrm{m}$ langen Zehenbasen, die innen knotig erweitert sind. Der Schwanzlappen ist an seinem Hinterende durch einen etwa $10 \mu \mathrm{m}$ langen Spalt geteilt, dessen Wände von kutikularen, caudad ca. $2 \mu \mathrm{m}$ überragenden Schienen ausgekleidet werden. Der Pharynx wird $35 \mu \mathrm{m}$ lang. 
Das Kephalion ist $14 \mu \mathrm{m}$ lang, $6 \mu \mathrm{m}$ breit und ragt über das Vorderende um 1,5-2 $\mu \mathrm{m}$ hinaus. Die hintere Hälfte des Kephalions überdeckt die vordersten dorsalen Stacheln. Pleuren fehlen.

In der Pharynx- und Rumpfregion verlaufen 9 dorsale Stachelreihen, die jederseits von je einer dorsolateralen Reihe flankiert werden. Unterhalb der lateralen Reihe befindet sich noch eine ventrolaterale. Auf dem Schwanzanhang werden nur die mittleren 5 dorsalen Reihen mit wenigen Stacheln fortgesetzt. In der dorsomedianen Reihe, wie auch in der jederseits lateralen stehen 24 Stacheln bis zur Basis des Schwanzlappens; dort sind die äußeren dorsalen Reihen durch die Verschmälerung des Rumpfes um 2-3 Stacheln verkürzt, die lateralen und ventrolateralen Reihen ziehen sich bis zu den Zehenbasen hin.

An den dorsalen Stacheln sind keine Basisschuppen zu sehen. Die lateralen Stacheln erweitern sich an ihrer Basis zu kleinen, schwach kutikularisierten Plättchen. In der Pharynxregion sind die dorsalen Stacheln kurz (ca. $2 \mu \mathrm{m}$ ) und stehen beinahe senkrecht vom Körper ab; die lateralen Stacheln (3-4 $\mu \mathrm{m}$ Länge) krümmen sich hier sichelförmig caudad, ebenso wie alle übrigen Stacheln der Rumpfregion (dorsal und lateral 6-6,5 $\mu \mathrm{m}$ lang). Knapp vor der Verschmälerung zum Schwanzlappen steht jederseits eine Gruppe von 3-5 längeren Stacheln $(8-10 \mu \mathrm{m})$ in den lateralen Reihen. Die Stacheln auf der Dorsalseite des Schwanzlappens sind 4-5 $\mu \mathrm{m}$ lang.

Im 2. Drittel der Pharynxregion beginnt ein von 7-8 Kielreihen bedecktes, ventrales Zwischenfeld; die Kiele messen unter dem Pharynx $3 \mu \mathrm{m}$, werden unter dem Darm länger $(4-4,5 \mu \mathrm{m})$ und erreichen auf der Ventralseite des caudalen Lappens $5 \mu \mathrm{m}$ Länge.

Die ventralen Wimperbänder schließen in der vorderen Pharynxregion aneinander, mit schütter stehenden Wimpern reichen sie bis in die hintere Rumpfregion. Die Tastwimpern inserieren dicht zusammengedrängt seitlich des Mundringes unter dem vorragenden Teil des Kephalions; sie bilden 2 verschieden gerichtete Büschelpaare: ein seit- und rückwärtsschlagendes von 20-25 $\mu \mathrm{m}$ langen Wimpern und ein neben dem Mundring nach vorne weisendes, das aus etwa $10 \mu \mathrm{m}$ langen Wimpern besteht.

Die Höhe des Mundringes mißt 3,5 $\mu \mathrm{m}$, der Durchmesser $7 \mu \mathrm{m}$; sein Vorderrand ist zu einem kräftigen Wulst versteift, seine Wand durch Längsleisten verfestigt. Der Durchmeser des Pharynx beträgt $8 \mu \mathrm{m}$, vordere und hintere Bulbusbildungen sind mit 9-10 $\mu \mathrm{m}$ schwach ausgeprägt. Der vordere Bulbus birgt eine kutikularisierte Mundbewaffnung: wenig hinter dem Mundring liegt in der Ländsachse ein Paar länglicher, rostrad sich berührender Höcker; ein Stück dahinter befindet sich ein Paar Spangen, die den dorsalen Wänden der beiden oberen Pharynxfalten angelagert sind, in der Medianen mit knotigen, caudad weisenden Verdickungen aneinanderstoßen, außen mit dünnen Flügeln in die Pharynxmuskulatur eindringen und in dieser mit spitzen Haken verankert sind. Der Darm durchzieht den Rumpf in einer leicht S-förmigen Krümmung. Der After befindet sich knapp vor dem Schwanzlappen. Protonephridien wurden nicht gefunden. Die reifen Tiere tragen $1 \mathrm{Ei}(\mathrm{ca} .30 \times 20 \mu \mathrm{m})$ in der mittleren Rumpfregion.

Diskussion. Da Stacheln und Stachelschuppen den Körper gleichmäßig bedecken und in keiner Region Stacheln besonders verlängert sind, fügt sich diese Art am ehesten in die maximus-Gruppe der Gattung Chaetonotus. Innerhalb dieser Gruppe 
hat $C$. angustus wegen der eigentümlichen Körperform und Mundbewaffnung keinen näheren Verwandten. Das Merkmal größtenteils basisschuppenloser, jedoch homogen über den Körper verteilter Stacheln erinnert an die formosus-Gruppe; deren Angehörige tragen aber wenigstens ein Pleurion und nur ein laterales Wimperbüschel (vgl. Remane 1936), beides im Gegensatz zu C. angustus. Die Art sei daher, zumindest vorläufig, der weniger streng abgegrenzten maximus-Gruppe zugeordnet.

Diagnose. Chaetonotus-Art aus der maximus-Gruppe. Rumpf hinter dem After in einen schmalen Schwanzanhang verlängert, der die Haftröhrchen trägt. Dorsal 9 Längsreihen basisschuppenloser, kurzer Stacheln. Laterale Stacheln mit Basisschuppen. 3-5 wenig verlängerte Stacheln an der Verschmälerung des Rumpfes zum Schwanz. Pharynxbewaffnung aus zwei paarigen Elementen bestehend. Parthenogenetisch. Gesamtlänge des Körpers 122-126 $\mu \mathrm{m}$, davon Zehenlänge $19 \mu \mathrm{m}$; größte Körperbreite in der Pharynxregion $23 \mu \mathrm{m}$, in der Rumpfregion $21 \mu \mathrm{m}$; Pharynxlänge $35 \mu \mathrm{m}$.

Chaetonotus aequispinosus nov. spec. (Abb. 11)

Fundorte: Alberoni, S. Nicolo.

Untersuchtes Material: 16 Individuen.

Die Tiere werden $120 \mu \mathrm{m}$ lang, wovon $13 \mu \mathrm{m}$ auf die Zehen entfallen. Die Pharyxnregion ist maximal $28 \mu \mathrm{m}$ breit und an ihrem Ende durch eine Verschmälerung auf $24 \mu \mathrm{m}$ deutlich vom Rumpf abgesetzt. Die breiteste Stelle des Rumpfes (36 $\mu \mathrm{m})$ liegt in seinem 2. Drittel. Die Pharynxlänge mißt $32 \mu \mathrm{m}$. Pleuren fehlen. Das Kephalion überragt den rostralen Rand um 2-3 $\mu \mathrm{m}$, ist kräftig kutikularisiert und besitzt die Form eines leicht abgerundeten Rechteckes $(9,5 \times 6 \mu \mathrm{m})$.

Die Dorsalseite des Körpers wird von ovalen Schuppen mit kurzen, erhabenen Stacheln bedeckt, die über alle Körperregionen hin identisch geformt und, je nach der Region größer oder kleiner, in durchlaufend 9 Längsreihen angeordnet sind. In der dorsomedianen Reihe stehen 19 Schuppen, die Terminalschuppe eingerechnet. Jederseits zieht eine laterale Reihe der Körperkontur entlang. Je zwei kleine Schuppen mit verlängerten Stacheln sitzen auf den breiten Zehenbasen. Die Beschuppung der Ventralseite des Rumpfes ist auffallend ausgedehnt: Jederseits eines schuppenlosen Feldes verlaufen hier 5 Reihen, von denen die jeweils äußerste in der vorderen Pharynxregion beginnt und bis auf die Höhe der ventralen Terminalschuppen führt. Die jederseits 4 inneren Schuppenreihen erstrecken sich vom 1. Darmdrittel ebenfalls bis zu den 4 groBen Terminalschuppen und mit den letzten Elementen zweier Reihen noch weiter bis auf die Ventralseiten der Zehenbasen.

Alle dorsalen Basisschuppen sind oval und überdecken sich nirgends; immer aber stoßen die Ränder der Schuppen benachbarter Längsreihen aneinander, dadurch bleiben die aufeinander folgenden Schuppen einer Längsreihe getrennt und umschließen gemeinsam mit den versetzten Schuppen der jeweils benachbarten Reihe eine kleine, nackte Fläche. Die caudad gebogenen Stacheln inserieren im 1. Drittel ihrer Basisschuppen, über die sich etwa $2 \mu \mathrm{m}$ erheben, deren Hinterrand sie aber nicht überragen. Bloß die Terminalschuppe der dorsomedianen Reihe trägt einen über ihren abgestutz- 
ten Hinterrand verlängerten Stachel. Die Maße der dorsalen Schuppen: in der Pharynxregion etwa $6 \mu \mathrm{m}$ Länge und 3,5 $\mu \mathrm{m}$ Breite, am Öbergang zum Rumpf $4 \mu \mathrm{m}$ Länge und $4 \mu \mathrm{m}$ Breite, auf der breitesten Stelle des Rumpfes $8 \mu \mathrm{m}$ Länge und 4,5 $\mu \mathrm{m}$ Breite. Gegen das Körperende zu sind die Schuppen wieder etwas kleiner. Die Schuppen auf den Zehenbasen sind rund.

Die ventrolateralen Schuppen besitzen etwa die gleichen Abmessungen wie die dorsalen Schuppen der gleichen Körperregion, nehmen aber die Form abgerundeter Dreiecke ein. Ihre Stacheln sind kräftig, inserieren im 2. Drittel der Schuppe und überragen deren Hinterrand um ca, die Hälfte ihrer jeweiligen Länge. Die inneren, ventralen Schuppen sind mit $2 \mu \mathrm{m}$ Länge sehr klein; auch hier sind die Stacheln über den Schuppenhinterrand hinaus verlängert, ebenso die Stacheln der zu 2 Paaren angeordneten ventralen Terminalschuppen, die in Form und Größe den dorsalen Elementen entsprechen. Die hintersten 3-4 Schuppen der beiden von den ventralen Schuppenfeldern bis auf die Zehenbasen vordringenden Reihen besetzen mit 3-4 $\mu \mathrm{m}$ langen Elementen den Raum $z$ wischen den ventroterminalen und hintersten lateralen Schuppen.

Die ventrale Bewimperung ist auf die Pharynxregion beschränkt und bildet ein großes, homogenes Feld. Die Tastwimpern am rostralen Rand inserieren jederseits des Mundringes in einem eng begrenzten, einheitlichen Streifen; sie sind $12 \mu \mathrm{m}$ lang, etwas länger jene, die leicht gebündelt knapp neben dem Mundring entspringen.

Der Mundring mißt $6 \mu \mathrm{m}$ im Durchmesser, $4 \mu \mathrm{m}$ in der Höhe. Der Pharynx ist an seinen Enden $z u$ schwachen Bulbi erweitert. Unter dem vorderen Bulbus liegt ein Hypostomion, dessen caudad abgewinkelte Vorderkante kräftig kutikularisiert ist. Der Darm verläuft gerade. Der After mündet vor dem 1. Paar der ventralen Terminalschuppen. Protonephridien wurden nicht beobachtet. Ein großes Ei füllt die Rumpfregion beinahe zur Gänze aus.

$D$ is $\mathrm{k}$ u s s i o n. Die gleichmäßige Verteilung der in allen Körperregionen identisch geformten Stachelschuppen ordnet die Art der maximus-Gruppe zu, mit deren marinen Vertretern sie allerdings kaum mehr als die Merkmale der Gattungs- und Gruppendiagnose teilt.

D i a g n o s e. Chaetonotus-Art aus der maximus-Gruppe. Kephalion und Hypostomion vorhanden. Dorsale Stachelschuppen in 9 Längsreihen, in der dorsomedianen Reihe 19 Elemente. Dorsale und laterale Basisschuppen oval, ventrolaterale Basisschuppen abgerundet dreieckig; die Schuppen überdecken sich nirgends und stoßen nur auf der Dorsalseite mit ihren Rändern aneinander. Keine stark verlängerten Stacheln in der hinteren Körperregion. Parthenogenetisch. Gesamtlänge des Körpers $120 \mu \mathrm{m}$, davon Zehenlänge $13 \mu \mathrm{m}$; Körperbreite in der Pharynxregion $28 \mu \mathrm{m}$, in der Rumpfregion $36 \mu \mathrm{m}$; Pharynxlänge $32 \mu \mathrm{m}$.

Diskussion der $m a x$ imus-Gruppe. In diese Sammelgruppe werden alle jene Chatonotus-Arten gestellt, „... deren Stachelkleid ziemlich gleichmäßig den Körper bedeckt, also auf dem Rücken oder an den Seiten nicht Gruppen stark verlängerter Stacheln enthält..." (Remane 1936); im übrigen wird die maximus-Gruppe nur dadurch zusammengehalten, daß ihre Merkmale oder Merkmalskombinationen anderer Chaetonotus-Gruppen fehlen; ihre Abgrenzung beruht mithin auf negativen Merkmalen und unscharf definierten Kriterien, die zur Einordnung zahlreicher, vor allem limnischer Arten führten. Mit bislang 6 Arten ist die Gruppe im Meer vertreten: C. balticus Remane 1926b, C. parthenopeius WILKE 1954, C. testiculopborus Hummon 
1966, C. schoepferi Thane-Fenchel 1970 und die beiden neuen Arten C. angustus und C. aequispinosus.

C. balticus ist vorläufig nur nach einem Exemplar bekannt. Auch C. parthenopeius wurde nach einem einzigen Exemplar kurz beschrieben; allerdings will D'HONDT (1966 und 1968) diese Art wiedergefunden haben, vermag indes mit der Skizze eines Hinterendes (1966, p. 16) nicht zu überzeugen; und zumal nicht nur diese Darstellung mit der Habitus-Zeichnung von WILKE (1954, p. 533, Abb. 23) wenig gemeinsam hat, sondern auch bei WILKe die Anzahl der dorsalen Stachelschuppen-Längsreihen mit 16 angegeben wird, während D'HONDT „... le nombre, par file longitudinale, est de 19 comme l'avait déjà reconnu WILKE" findet, empfehlen sich Zweifel an der D'HondTschen Bestimmung.

In einigen habituellen Merkmalen stimmt C. testiculophorus mit C. parthenopeius ibberein: mit einer starken Verbreiterung in der Rumpfregion und mit den bestachelten, weit über den After frei nach hinten verlängerten seitlichen Rumpfpartien, an denen die Haftröhrchen inserieren, besitzen beide Arten fast die gleiche Körperform. Sehr ähnlich sind überdies die Körpermaße und die Anzahl der Längsreihen der dorsalen Stachelschuppen.

C. angustus steht in der maximus-Gruppe ziemlich isoliert durch die eigentümliche Körperform und die auf der Dorsalseite basisschuppenlosen Stacheln. C. aequispinosus wäre, dem System von REMANE (1936) folgend, am ehesten in die Untergruppe b/2 einzugliedern, wo C. brevispinosus ZELINKA 1889 als Verwandter in Frage kommt.

\section{Chaetonotus jucundus nov. spec. (Abb. 12)}

Fundort: Rovinj.

Untersuchtes Material: 18 Individuen.

Die Gesamtlänge erwachsener Tiere beträgt 265-282 $\mu \mathrm{m}$, die Zehenlänge 41 bis $47 \mu \mathrm{m}$, die Länge des Pharynx 68-70 $\mu \mathrm{m}$. Der Körper ist stark dorsoventral abgeplattet. Ungequetscht erreicht die Pharynxregion eine Breite von etwa $60 \mu \mathrm{m}$, der Rumpf von über $80 \mu \mathrm{m}$. Die Distanz zwischen den Zehenbasen mißt ca. $35 \mu \mathrm{m}$.

Pleuren und Kephalion fehlen. In der Pharynxregion verlaufen 7 dorsale Längsreihen von Stachelschuppen. Etwa in der Mitte der Pharynxregion ist die mediane Reihe nach ihrer dritten Schuppe unterbrochen; hier ist eine freie Stelle zu erkennen, so groß wie die Fläche, die eine Basisschuppe dieser Region einnehmen würde. Am Ende der Pharynxregion enden die beiden der Medianen benachbarten Reihen mit ihrer jeweils 5. Schuppe, worauf die wiederum jederseits zunächst gelegene Reihe mediad einbiegt und mit ihrer schräg einwärts liegenden und vergrößerten 6. Schuppe den freiwerdenden Raum zu besetzen beginnt. Da diese mediad gerichtete Schwenkung von der, gegen die Körperseiten zu, letzten dorsalen Reihe kaum mitvollzogen wird, befinden sich in der ersten Hälfte des Rumpfes nur 5 Längsreihen auf der Dorsalseite. Erst bei der Verbreiterung des Körpers in der mittleren Rumpfregion rückt die bis dahin laterale Reihe jederseits ein wenig dorsad auf. Doch erreicht weder sie, noch die beiden zwischen ihr und der Medianen verlaufenden Reihen das Rumpfende: die innere dorsale Reihe endet mit ihrer 13., die äußere mit der 10., und die ab der Rumpfmitte dorsolaterale Reihe mit ihrer 13. Schuppe. Vor den Zehenbasen entsteht also 
jederseits eine nackte Fläche, die von den letzten zwei Stacheln der Medianreihe und den beiden laterad verschobenen der ventrolateralen Reihe seitlich begrenzt wird. Die ventrolaterale Reihe beginnt jederseits in der zweiten Häfte der Pharynxregion und besteht jeweils aus 12 Stachelschuppen. Ventral etwas hinter dem After inseriert ein Paar kurzer Stacheln auf unregelmäßig gerundeten Basisschuppen. Das Feld zwischen den beiden ventralen Wimperbändern ist nackt.

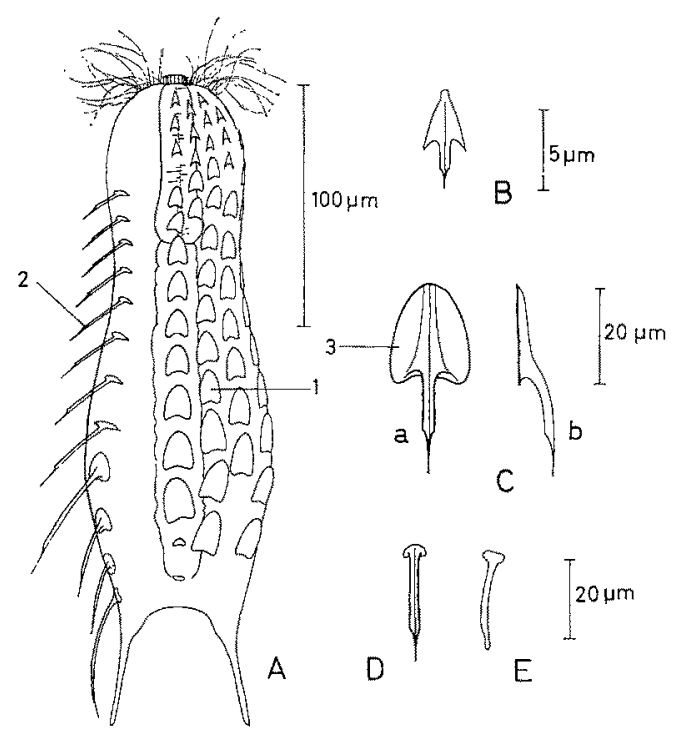

Abb. 12: Cbaetonotus jucundus nov. spec. $A$ Habitus, äußere Kutikularelemente vereinfacht. Dorsomediane Stachelschuppen: $B$ vordere Pharynxregion; $C$ hintere Rumpfregion: $a$ in Aufsicht, $b$ in Seitenansicht; $D$ vorletzter, $E$ letzter Stachel. 1 Ansatzflächen dorsaler Stachelschuppen; 2 ventrolaterale Stacheln; 3 Basisschuppe

Im wesentlichen können 3 verschiedene Formen der Stachelschuppen unterschieden werden: die dorsalen der vorderen Pharynxregion, die dorsalen des übrigen Körpers und die ventrolateralen. Die knapp hinter dem Vorderende zu dritt in jeder Längsreihe stehenden Stachelschuppen legen sich flach dem Körper an. Es ist daher nicht sicher, ob die beiden als Nebenspitzen des Hauptstachels deutbaren Fortsätze, die zudem wesentlich schwächer kutikularisiert sind als jener, nicht etwa die caudalen, spitzen Enden von Basisschuppen darstellen (wie sie in ähnlicher Form schon gleich dahinter, allerdings mehr oder weniger abgerundet, zu finden sind); zumindest verjüngt sich der 10-13 $\mu \mathrm{m}$ lange Hauptstachel nicht kontinuierlich, sondern erst knapp vor seiner Spitze.

Die Basisschuppen der dorsalen Rumpfstacheln sind leicht gewölbt und vorne oval abgerundet; ihr Hinterrand ist verschieden stark eingedellt. Der Stachel liegt vorerst als scharfkantiger Kiel beinahe der ganzen Länge der Schuppe an, erst knapp vor deren Hinterrand erhebt er sich frei in einer kräftigen Krümmung. In allen Körperregionen bleiben jedoch die Neigungswinkel der dorsalen und lateralen Stacheln sehr flach gegenüber der Körperoberfläche, von der sich daher auch die Stachelspitzen nie weiter als 
etwa $5 \mu \mathrm{m}$ (in der hinteren Pharynxregion) bis etwa $8 \mu \mathrm{m}$ (in der hinteren Rumpfregion) distanzieren. Von der hinteren Pharynxregion bis zum Rumpfende besitzen die dorsalen und lateralen Stacheln einen dreieckigen Querschnitt. Bloß der hinterste Stachel der dorsomedianen Reihe ist rund.

Der Querschnitt der ventrolateralen Stacheln ist in der Pharynx- und vorderen Rumpfregion schwer festzustellen, in der mittleren Rumpfregion scheinen die ventrolateralen Stacheln eine scharfe, vom Körper abgewandte Kante zu haben, die an der Verjüngungsstelle des Stachels in eine schwach angedeutete Nebenspitze ausläuft. Aber auch die beiden körperseitigen Kanten der dorsalen und lateralen Stacheln bilden an der Verjüngungsstufe zur feinen Stachelspitze keine deutlichen Nebenspitzen.

In der dorsomedianen Reihe nimmt die Länge der Basisschuppen von der 4. Schuppe $(10 \mu \mathrm{m})$ bis zur 12. Schuppe $(20 \mu \mathrm{m})$ kontinuierlich $z u$, ebenso die Länge der Stacheln $(18-41 \mu \mathrm{m})$; die beiden letzten Stacheln dieser Reihe sind wieder kürzer (26 $\mu \mathrm{m}$ und $22 \mu \mathrm{m}$ ) und inserieren auf kleinen, unregelmäßig geformten Basisschuppen. Die ventrolaterale Reihe besteht jederseits aus einer Abfolge gleichmäßig länger werdender Stacheln (1. Stachel $17 \mu \mathrm{m}, 8$. Stachel $35 \mu \mathrm{m}$ ) auf quer zur Körperachse liegenden Basen, die länglich oval und gegen die Mediane leicht zugespitzt sind. Der 9. Stachel der ventrolateralen Reihe ist $50 \mu \mathrm{m}$ lang, seine Basis ähnlich den dorsalen Basisschuppen ausgebildet; die beiden nächsten Stacheln sind kürzer $(30 \mu \mathrm{m}$ und $27 \mu \mathrm{m})$, der hintere steht auf einer kleinen, beinahe runden Basisschuppe und ist laterad gerückt. Der letzte Stachel der ventrolateralen Reihe besitzt als Basis nur eine unregelmäßige Verdickung, er entspringt ca. $12 \mu \mathrm{m}$ vor den Zehen, deren Enden er mit seiner Länge von $54 \mu \mathrm{m}$ beinahe erreicht. Die ventrolateralen Stacheln sind wenig gekrümmt und überragen die Körperkontur wesentlich mehr als die lateralen.

Die ventralen Wimperbänder vereinen sich unter dem Pharynx. Die jederseits 10-12 vorderen Tastwimpern stehen frei verteilt auf der rostralen Kontur; sie sind alle etwa gleich lang, abgesehen von 2-3 kürzeren in der Nähe des Mundringes, und zeigen seitlich eine nur schwache Bündelung.

Der Durchmesser des Mundringes beträgt $10 \mu \mathrm{m}$, der des vorderen Pharynxabschnittes $16 \mu \mathrm{m}$. Der Pharynx erweitert sich nur hinten zu einem schwachen Bulbus, dessen Wandzellen ca. $10 \mu \mathrm{m}$ hoch werden. Ein Hypostomion fehlt. Der Darm verläut gerade und ohne erkennbare Sonderbildungen. Der After mündet ungefähr 18-20 $\mu \mathrm{m}$ vor dem Hinterrand des Rumpfes. Ein Paar Protonephridien liegt in der vorderen Rumpfhälfte. Reife Tiere tragen ein Ei, das etwa zwei Drittel der Rumpfregion einnimmt.

$\mathrm{D}$ iskussion. Chaetonotus jucundus ist vorläufig der größte Vertreter der schultzei-Gruppe. Nur C. neptuni WILKE 1954 kommt an seine Abmessungen heran, besitzt aber eine andere Körperform: C. neptuni ist schlanker und vor allem vor den Haftröhrchen stark verschmälert. Bei beiden Arten beträgt die Pharynxlänge $1 / 4$ der Gesamtlänge, ähnlich ist ebenso die Relation zwischen der Haftröhrchenlänge und der Gesamtlänge mit $1: 6$. Leider finden sich in der Erstbeschreibung von C. neptuni keine Angaben über die Anordnung der dorsalen Stachelschuppen. Der längste laterale Stachel ist bei C. jucundus der letzte seiner Reihe, bei C. neptuni der drittletzte. Die zur Körperachse quergestellten Basisschuppen der ventrolateralen Stacheln sind bei $C$. iucundus, C. neptuni, C. atrox WruKe 1954 und C. dispar WILKE 1954 gleichermaßen vorhanden. Gegenüber C. neptuni sind die dorsalen Stachelschuppen von $C$. jucundus 
durchwegs größer und haben im Verhältnis zu den Stacheln kleinere Basisschuppen; die Basisschuppen laufen überdies bei $C$. jucundus an ihrem Hinterrand in abgerundeten Lappen aus, bei C. neptuni in paarigen Spitzen. C. neptumi trägt im ventralen Mittelfeld Stacheln, C. jucundus ist hier nackt. Abweichungen ergeben sich weiterhin in der Verteilung der vorderen Tastwimpern, indem diese bei $C$. jucundus nicht in scharf getrennten Büscheln stehen, sondern sich frei verteilen und eine schwache Bündelung nur lateral erkennen lassen.

Diagnose. Chaetonotus-Art aus der schultzei-Gruppe. Mit bis zu $282 \mu \mathrm{m}$ Gesamtlänge der bislang größte Vertreter der Gruppe. Kephalion, Pleuren und Hypostomion fehlen. Dorsomediane Reihe der Stachelschuppen nach der 3. Schuppe unterbrochen. Die jederseits nächst der dorsomedianen verlaufende Reihe endet mit der 5 . Stachelschuppe noch in der Pharynxregion. In der hinteren Rumpfregion fallen jederseits 2 dorsale Reihen aus. Die beiden letzten Basisschuppen der dorsomedianen Reihe rudimentär. Letzter Lateralstachel stark verlängert, er erreicht beinahe die Zehenspitzen. Parthenogenetisch. Gesamtlänge des Körpers 265-282 $\mu \mathrm{m}$, davon Zehenlänge $41-47 \mu \mathrm{m}$; Körperbreite in der Pharynxregion $60 \mu \mathrm{m}$, in der Rumpfregion $80 \mu \mathrm{m}$; Pharynxlänge 68-70 $\mu \mathrm{m}$.

Chaetonotus serenus nov. spec. (Abb. 13)

Fundorte: S. Nicolo; Rovinj.

Untersuchtes Material: 35 Individuen.

Die Tiere werden $145 \mu \mathrm{m}$ lang, die Länge der Zehen beträgt $17 \mu \mathrm{m}$, die Pharynxlänge $38 \mu \mathrm{m}$. Die Körperbreite mißt in der Pharynxregion $30 \mu \mathrm{m}$, in der Rumpfregion $35 \mu \mathrm{m}$; der Habitus ist schlank, der Körper nur geringfügig dorsoventral abgeplattet.

Pleuren und Kephalion fehlen. Von der vorderen Pharynxregion bis zum Rumpfende verlaufen die Stachelschuppen in 5 dorsalen, exakt geradlinigen Längsreihen und in jederseits einer lateralen Reihe. Jede dorsale und die jewreils laterale Reihe wird von 11 Stachelschuppen gebildet. Ventrolateral beginnt jederseits eine Stachelreihe am Ende der Pharynxregion und führt mit 17 Elementen bis zu den Zehenbasen. Ventral vor dem Hinterrand des Rumpfes stehen 4 Stacheln in einer leicht geschwungenen Querreihe. Die Verteilung der Stacheln zeigt in allen Körperregionen große Regelmäßigkeit. In der vorderen Pharynxregion können allerdings 1-3 Stacheln zwischen die streng geführten Längsreihen eingestreut sein. Das ventrale $Z$ wischenfeld ist in der gesamten Darmregion von 7-8 Reihen feiner Kiele bedeckt.

In jeder der 5 dorsalen Längsreihen besitzt der jeweils 1 . Stachel hinter dem rostralen Rand keine Basisschuppe und verzweigt sich schon an seiner Insertion in 3, gleich stark kutikularisierte Spitzen; die mittlere Spitze ist etwa $5 \mu \mathrm{m}$ lang, die leicht gekrümmten Nebenspitzen sind um 2-3 $\mu \mathrm{m}$ kürzer. Dem Typus dieser Stacheln entsprechen auch jene maximal zu dritt in der vorderen Pharynxregion zwischen den Längsreihen liegenden Elemente.

Ganz anders, untereinander jedoch völlig identisch, sind alle anderen dorsalen Schuppenstacheln geformt: auf einer kleinen, unregelmäßigen, selten runden, meist etwas quer ausgezogenen Basisschuppe steht ein dünner Stachel von mehr oder weniger dreikantigem Querschnitt. Ab seiner Basis verbreitert er sich ein wenig, im letzten Vier- 
tel seiner Länge verjüngt er sich zur kurzen Endspitze. Die Nebenspitzen sind sehr subtil differenziert und manchmal kaum zu erkennen. In den dorsalen Reihen nimmt die Länge der Stacheln kontinuierlich von vorne nach hinten zu; so mißt der 2. dorsomediane Stachel $6 \mu \mathrm{m}$, der letzte dieser Reihe $18 \mu \mathrm{m}$. Die Stacheln der jederseits lateralen Reihe tragen keine Nebenspitzen und ähneln den dorsalen nur insoweit, als sie sich in ihrem letzten Viertel ziemlich rasch zu einer Spitze verjüngen. Im übrigen entsprechen sie dem Typus der Lamellenstacheln, da die dem Körper abgewandte Kante

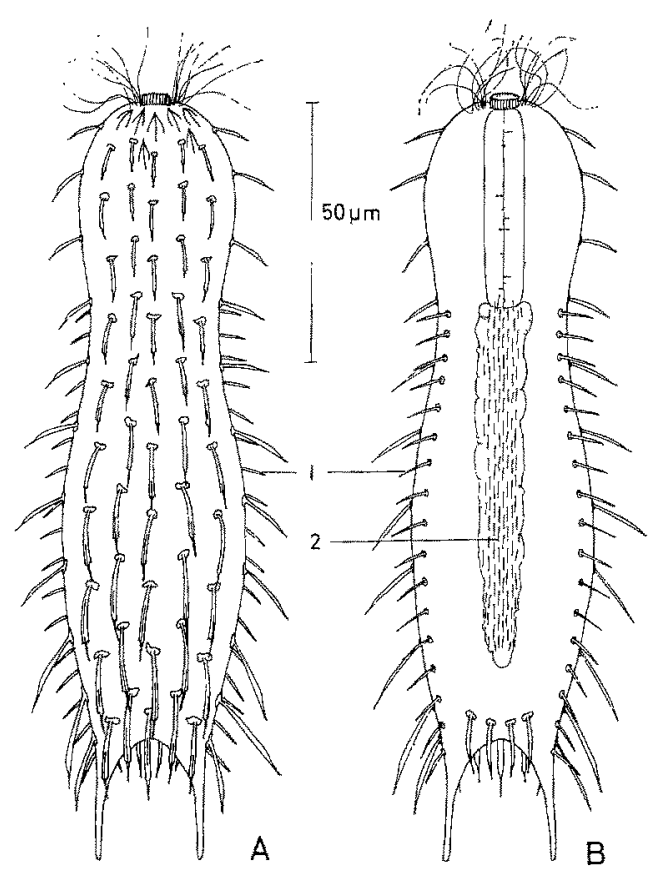

Abb. 13: Chaetonotus serenus nov, spec. $A$ Habitus dorsal, $B$ Habitus ventral. $I$ ventrolaterale Stacheln; 2 ventrale Kielbedeckung

hoch ausgezogen ist; die Elemente der ventrolateralen Reihe sind gleichartig geformt, jedoch noch schwächer kutikularisiert. Die laterale Reihe beginnt mit einem $6 \mu \mathrm{m}$ langen Stachel, ihr vorletzter wird $18 \mu \mathrm{m}$ lang, der letzte $13 \mu \mathrm{m}$. Die ventrolateralen Stacheln messen in allen Körperregionen ca. $7 \mu \mathrm{m}$.

Die ventralen Wimperbänder bilden unterhalb des Pharynx ein gemeinsames Feld und ziehen getrennt bis ins letzte Rumpfdrittel. Etwa 8 gleichlange Tastwimpern stehen jederseits des Mundringes in einem schmalen Streifen; sie sind nicht zu Büscheln zusammengefaßt.

Der Mundring mißt $5 \mu \mathrm{m}$ im Durchmesser; der Pharynx ist durchgehend $7 \mu \mathrm{m}$ dick und weder vorne noch hinten zu einem Bulbus erweitert. Ein Hypostomion fehlt. Der Darm verläuft gerade, der After mündet etwa $15 \mu \mathrm{m}$ vor dem Rumpfende. Ein Paar Protonephridien liegt im 1. Drittel der Rumpfregion. Reife Individuen tragen ein Ei. 
D is k u s sion. Diese Art zählt zu den kleineren der schultzei-Gruppe. C. atrox WILKE 1954 wird zwar ungefähr gleich groß, besitzt aber einen wesentlich längeren Pharynx, längere Zehen und trägt etwa doppelt so viele Längsreihen dorsaler Stachelschuppen; annähernd gleich sind jedoch die Form der Stacheln und deren Maße. Die unregelmäßige Form der Basisschuppen von $C$. serentus läßt sich besser mit den entsprechenden Bildungen bei C. modestus n. sp. und C. bilarus n. sp. vergleichen. Gegenüber diesen Arten sehr verschieden gestaltet sind die ventrolateralen Stacheln; gegenüber allen anderen Angehörigen der Gruppe hebt sich die Anordnung der dorsalen Stachelschuppen deutlich hervor.

$\mathrm{D}$ i a g n o s e. Chatonotus-Art aus der schultzei-Gruppe. Pleuren, Kephalion und Hypostomion fehlen. 5 Längsreihen dorsaler Stachelschuppen, in der medianen Reihe 11 Elemente. Dorsale Stacheln mit sehr kleinen Nebenspitzen; lateral und ventrolateral Lamellenstacheln. Typus der „Kopfstacheln“ (im Sinne WILKE 1954) nur an 6-8 Elementen verwirklicht. Basisschuppen in allen Körperregionen unregelmäßig. Keine verlängerten Stacheln am Hinterende. Parthenogenetisch. Gesamtlänge des Körpers $145 \mu \mathrm{m}$, davon Zehenlänge $17 \mu \mathrm{m}$; Körperbreite in der Pharynxregion $30 \mu \mathrm{m}$, in der Rumpfregion $35 \mu \mathrm{m}$; Pharynxlänge $38 \mu \mathrm{m}$.

\section{Chaetonotus modestus nov. spec. (Abb. 14)}

Fundort: Rovinj.

Untersuchtes Material: 22 Individuen.

Die Tiere erreichen eine Gesamtlänge von $145 \mu \mathrm{m}$, die Zehen werden $22 \mu \mathrm{m}$ lang, der Pharynx $36 \mu \mathrm{m}$. Die größte Breite in der Pharynxregion beträgt $35 \mu \mathrm{m}$, in der Rumpfregion ca. $43 \mu \mathrm{m}$. Der Abstand der Zehenbasen mißt $27 \mu \mathrm{m}$.

In der Pharynxregion verlaufen 7 dorsale Längsreihen der für die meisten Arten der schultzei-Gruppe typischen, schon an ihrer Insertion dreifach verzweigten Stacheln; 5 dieser Stacheln in der medianen Reihe, 4-5 in den anderen Reihen; die jederseits der Körperkontur nächste dorsale Reihe besteht aus nur 3 Elementen und wird ab der Mitte der Pharynxregion nicht weiter caudad fortgesetzt. Auf dem Rumpf verlaufen 5 , streckenweise unregelmäßig geführte Längsreihen. Die jederseits laterale Reihe beginnt mit leicht dorsad gerückten Stachelschuppen in der mittleren Pharynxregion, sinkt bis zur mittleren Rumpfregion an die Körperkontur ab und steigt in der hinteren Rumpfregion wieder ein wenig dorsad an; der letzte Stachel dieser Reihe inseriert jeweils knapp vor den Zehenbasen und ist mediad gerichtet. Außer den für die Pharynxregion typischen Stacheln zählt die dorsomediane Reihe 7, die anderen dorsalen Reihen jeweils 8 Stachelschuppen; 11 stehen in der lateralen Reihe. C. modestus besitzt jederseits 2 ventrolaterale Stachelreihen. Die jeweils äußere Reihe beginnt im 1. Drittel der Pharynxregion und besteht aus 11 Stachelschuppen, die jeweils innere Reihe beginnt am Ende des 2. Pharynxdrittels und wird von 20-22 sehr feinen Stacheln gebildet. Beide ventrolateralen Reihen führen bis in die hinterste Rumpfregion. Zwei Paare kräftiger Stacheln inserieren hintereinander ventral vor dem Hinterende, das sie mit ihren Spitzen ein kleines Stück überragen. Jederseits ventral vor den Zehenbasen liegen 3 parallele, mediad geneigte Schienen. Im ventralen $Z$ wischenfeld verlaufen 5 Reihen feiner Kiele vom Pharynxende bis zu den ventralen Endstacheln. 
Die mittleren Spitzen der dorsalen Stacheln in der vorderen Pharynxregion sind 3-8 $\mu \mathrm{m}$ lang; Basisschuppen fehlen. In der mittleren Pharynxregion sind einige Stacheln an ihrer Basis etwas verdickt, an manchen Individuen besitzen 1-2 dorsomediane Stacheln der hinteren Pharynxregion sogar ein kurzes Stammstück, mithin ist hier ein Übergang zu den viel kräftigeren Stacheln der Rumpfregion angedeutet.

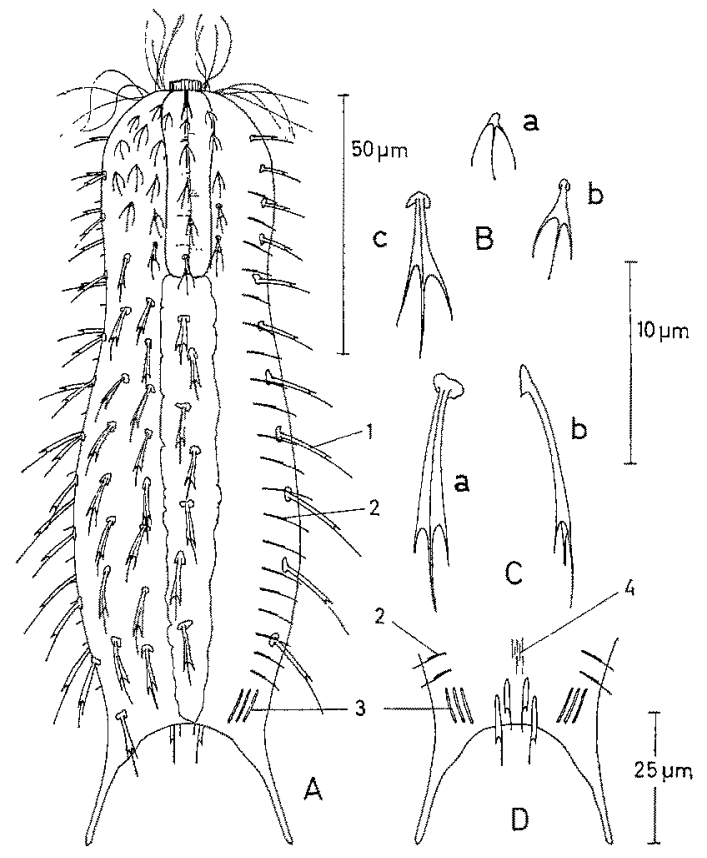

Abb. 14: Chaetonotus modestus nov. spec. A Habitus, dorsale Stacheln in der rechten Körperhälfte nicht eingezeichnet. Dorsomediane Stacheln: $B$ Pharynxregion: $a$ vordere, $b$ mittlere, $c$ hintere; $C$ mittlere Rumpfregion: $a$ Aufsicht, $b$ Seitenansicht. Ventrolaterale Stacheln: 1 äußere Reihe, 2 innere Reihe; 3 Schienen; 4 ventrale Kiele

Alle dorsalen und lateralen Stacheln des Rumpfes sind gleich geformt: das Stammstiick verbreitert sich distad ein wenig und trägt 2 kurze, jedoch prägnante Nebenspitzen; die Hauptspitze nimmt etwa ein Drittel der gesamten Stachellänge ein. Die Stacheln sind leicht abgerundet dreikantig. Die Basisschuppen zeigen sehr verschiedene Formen: manche sind wappenschildförmig, manche gleichen querliegenden Halbmonden, andere wiederum stellen nur eine keulenförmige, proximale Verdickung des Stachels dar. In der dorsomedianen Reihe beträgt die Länge des vordersten Rumpfstachels (oberhalb dem Pharynxende) $8 \mu \mathrm{m}$, die Länge des hintersten Stachels $12 \mu \mathrm{m}$. Die lateralen Stacheln sind in jedem Rumpfabschnitt ebenso lang wie die Dorsalstacheln derselben Region.

Die Stacheln der jederseits äußeren ventrolateralen Reihe besitzen als Basalteile nur unregelmäßige Verdickungen; sie tragen an ihrer körperabgewandten Kante eine Nebenspitze, sind ein wenig gekrümmt und in jeder Körperregion etwa um die Hälfte länger als die entsprechenden Dorsalstacheln: Schon die vordersten Stacheln dieser 
Reihe messen $8 \mu \mathrm{m}$, gegen Ende der Pharynxregion sind sie etwa 10-11 $\mu \mathrm{m}$ lang; der drittletzte Stachel, der am Anfang der 2. Rumpfhälfte inseriert, wird $19 \mu \mathrm{m}$ lang.

Die 2. weiter median verlaufende ventrolaterale Reihe bilden sehr fein kutikularisierte Stacheln mit 1 Nebenspitze, die schon auf der halben Stachellänge entspringt; Basisschuppen fehlen. Diese Stacheln messen in der Pharynxregion $6 \mu \mathrm{m}$, werden in der mittleren Rumpfregion $10 \mu \mathrm{m}$ lang und wiederum $6 \mu \mathrm{m}$ in der Region der 3 paarigen, ventralen Schienen. Auch die 4 terminalen Stacheln auf der Ventralseite des Rumpfes sind schwach kutikularisiert, tragen eine Nebenspitze und sind paarweise $11 \mu \mathrm{m}$ sowie $13 \mu \mathrm{m}$ lang.

Die ventralen Wimperbänder schließen sich in der Pharynxregion zu einem gemeinsamen Feld. Die vorderen Tastwimpern inserieren auf engem Raum und bilden jederseits 2 Büschel, von denen das dem Mundring nähere nach vorne weist, das andere seitwärts absteht und jeweils 4 oder 5 Wimpern enthält.

Der Mundring mißt $6 \mu \mathrm{m}$ im Durchmesser. Der Pharynx erweitert sich vorne zu einem schwachen Bulbus (Durchmesser $10 \mu \mathrm{m}$ ), dessen Lumen eine feine kutikulare Auskleidung erkennen läßt. Wohl wächst der Pharynxdurchmesser caudad wieder ein wenig an, ein abgesonderter Bulbus wird jedoch nicht gebildet. Der Darm verläuft gerade, der After befindet sich am Rumpfhinterrand. Ein Paar Protonephridien ist vorhanden. Zwei nebeneinander liegende Eier erfüllen den Rumpf ausgewachsener Tiere beinahe zur Gänze.

$\mathrm{D}$ is kus sion. C. modestus ist plumper als andere etwa gleichlange Vertreter der schultzei-Gruppe; keine der verwandten Arten besitzt im Verhältnis zur Gesamtlänge derart weit auseinandergerückte Zehenbasen. In der Verteilung der dorsalen Stachelschuppen nimmt C. modestus eine Mittelstellung ein zwischen den Arten mit streng geometrisch geordneten Längsreihen (wie etwa $C$. serenus $\mathrm{n}$. $\mathrm{sp}$. und $\mathrm{C}$. atrox WILKE 1954) und C. hilarus n. sp., dessen Stachelschuppen auf dem Rumpf beinahe regellos angcordnet sind. Die eigenartigen ventralen Schienen am Rumpfende besitzt innerhalb der schultzei-Gruppe nur C. modestus. Die dorsalen Stacheln dieser Art und jene von C. bilarus n. sp. sind einander ziemlich âhnlich, Unterschiede ergeben sich nur in der Form der Basalteile und durchgehend im Verhältnis der Länge des Stammstückes zur Länge des frei ausgezogenen Hauptstachels.

$\mathrm{D}$ i a g n o se. Chaetonotus-Art aus der schultzei-Gruppe. Körperform gedrungen, Distanz $z$ wischen den Zehenbasen besonders groß. Pleuren, Kephalion und Hypostomion fehlen. Dorsale Stachelschuppen in der Pharynxregion zu 7 Längsreihen, zu 5 auf dem Rumpf. Die dorsomediane Reihe zählt ab der hinteren Pharynxregion 7 Stacheln. Jederseits 2 ventrolaterale Stachelreihen. Ventral vor dem Hinterende 3 Paar Schienen. Parthenogenetisch. Gesamtlänge des Körpers $145 \mu \mathrm{m}$, davon Zehenlänge $22 \mu \mathrm{m}$; Körperbreite in der Pharynxregion $35 \mu \mathrm{m}$, in der Rumpfregion $43 \mu \mathrm{m}$; Pharynxlänge $36 \mu \mathrm{m}$.

Chaetonotus bilarus nov. spec. (Abb. 15)

Fundorte: Alberoni, S. Nicolo.

Untersuchtes Material: 23 Individuen.

Die Tiere werden $125 \mu \mathrm{m}$ lang, die Zehenlänge beträgt 16-18 $\mu \mathrm{m}$, die Pharynx- 
länge $32 \mu \mathrm{m}$. Die größte Breite in der Pharynxregion miß ca. $30 \mu \mathrm{m}$, die Breite des Rumpfes etwa $32 \mu \mathrm{m}$.

Die Stacheln bilden in der Pharynxregion 8 dorsale Längsreihen. Durch die regelmäßige, symmetrische Anordnung der in gerader Anzahl vorhandenen Reihen bedingt, ist die Medianlinie von keiner Reihe besetzt. Dieses strenge Gleichmaß der Stachelverteilung verliert sich jedoch gegen Ende der Pharynxregion, Längsreihen sind hier

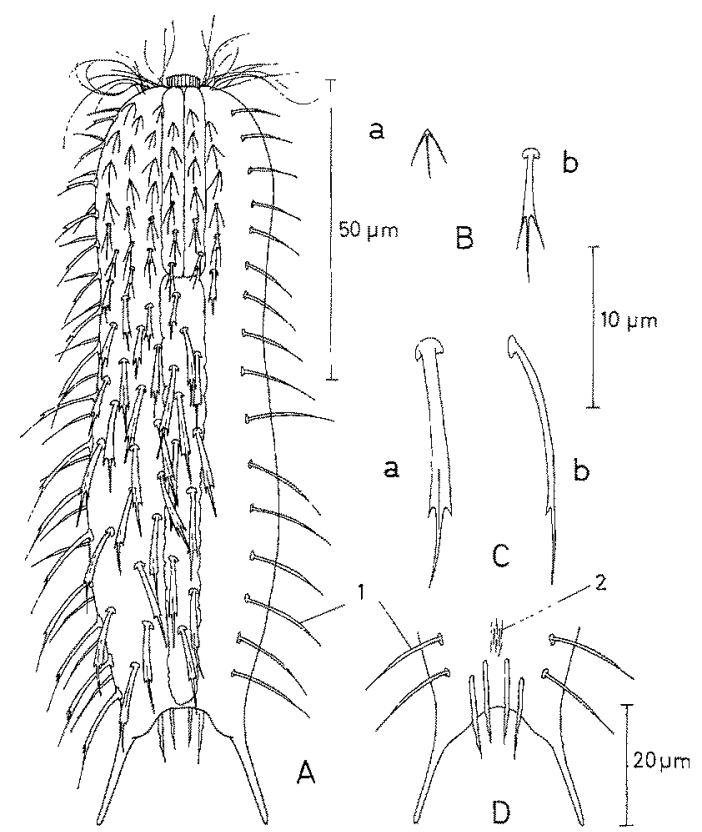

Abb. 15: Chatotonotus bilarus nov. spec. A Habitus, dorsale Stachelbedeckung in der rechten Körperhälfte nicht eingezeichnet. Dorsomediane Stacheln: $B$ Pharynxregion: $a$ vordere, $b$ hintere; $C$ mittlere Rumpfregion: $a$ Aufsicht, $b$ Seitenansicht. 1 ventrolaterale Stacheln; 2 ventrale Kiele

nicht mehr verfolgbar, an manchen Exemplaren bleiben hier weite Flächen nackt oder sind regellos von wenigen Stacheln bestanden. Wegen der ungeordneten Stellung der dorsalen Stacheln lassen sich auch auf dem Rumpf getrennte Reihen kaum unterscheiden. Einige Individuen mit etwas regelmäßigerem Stachelbesatz besaßen ungefähr 6-7 Längsreihen auf dem Rumpf. Immer ist jedoch jederseits eine völlig geradlinig geführte laterale und ventrolaterale Stachelreihe zu finden.

In der Pharynxregion beinhalten die beiden mittleren Reihen jeweils 6 Stacheln, die mehr lateral liegenden meist bloß 5 oder 4 Stacheln, da nicht jede Reihe schon an der rostralen Kontur beginnt, immer aber bis ans Ende der Pharynxregion gefüht wird. Auf dem Rumpf besteht eine annähernd gerade Längsabfolge aus etwa 8-10 Stacheln; sie inserieren in der ersten Rumpfhälfte dichter beieinander, gegen das Rumpfende zu etwas schütterer. Jederseits bilden 16-17 Stacheln eine laterale Reihe, die von der vorderen Pharynxregion bis zu den Zehenbasen führt. Uber die gleiche 
Distanz zieht jederseits eine ventrolaterale Reihe mit ebenfalls 16-17 Stacheln. Das ventrale $\mathrm{Z}$ wischenfeld ist von 5 Kielreihen bedeckt, die sich ab dem Pharynxende bis vor 2 terminale Stachelpaare erstrecken.

Die Stacheln in der vorderen Pharynxregion besitzen keine Basisschuppen und verzweigen sich an ihrer Insertion dreifach. Der mittlere Stachel ist etwa $3 \mu \mathrm{m}$ lang. In der hinteren Pharynxregion besitzen diese Stacheln bereits ein kurzes, verdicktes Stammstïck und werden mit diesem bis zu $6 \mu \mathrm{m}$ lang. Die Stacheln auf dem Rumf sind nicht deutlich dreikantig und tragen in der vorderen und mittleren Rumpfregion kleine Nebenspitzen, die im 2. Drittel der Stachellänge entspringen; die Nebenspitzen sind an den Stacheln der hinteren Rumpfregion sehr schwach ausgeprägt, an den Lateralstacheln aber immer gut erkennbar. Die ventrolateralen Stacheln sind schwach kutikularisiert, lamellenförmig und tragen keine Nebenspitzen. Die 4 terminalen Stacheln verjüngen sich in 2 Stufen zu einer feinen Spitze. Die Basalteile der Rumpfstacheln sind klein, annähernd halbkreisförmig und stellen, wie es vor allem die lateralen Stacheln gut erkennen lassen, nur proximale Verdickungen der Stacheln dar.

Am Ende der Pharynxregion sind die Dorsalstacheln rund $8 \mu \mathrm{m}$ lang, werden in der vorderen Rumpfregion $15 \mu \mathrm{m}$ lang und behalten dieses Maß bis zum Rumpfende bei. Die Lateralstacheln sind bei den meisten Tieren jeweils um 2-3 $\mu \mathrm{m}$ länger als die Dorsalstacheln der gleichen Körperregion. Die Länge der ventrolateralen Stacheln beträgt in der Pharynxregion $8-10 \mu \mathrm{m}, 15-16 \mu \mathrm{m}$ ab der mittleren Rumpfregion bis zum Körperende. Die 4 terminalen Stacheln sind $14 \mu \mathrm{m}$ lang.

Die beiden ventralen Wimperbänder schließen unter dem Pharynx zusammen und reichen getrennt bis ins hintere Rumpfdrittel. Die vorderen Tastwimpern inserieren eng beieinander und bilden ein seitwärts abstehendes Büschel. Einige Wimpern neben dem Mundring weisen jedoch immer nach vorne.

Der Durchmesser des Mundringes beträgt $5 \mu \mathrm{m}$. Der Pharynx ist weder vorne noch hinten zu einem Bulbus erweitert und mißt im Durchmesser $7 \mu \mathrm{m}$. Der Darm verläut gerade durch den Rumpf. Ein Paar Protonephridien ist vorhanden. Reife Tiere tragen ein Ei.

Einer intraspezifischen Variabilität waren an den untersuchten Tieren vor allem Lage und Form der äußeren kutikularen Merkmale unterworfen. Besonders die Anzahl der Stacheln in der Pharynxregion erwies sich als sehr variabel: bei etwa der Hälfte der Individuen fehlten Stacheln auf dem rostralen Rand gänzlich, 2 der Tiere trugen jederseits des Mundringes 3 Stacheln, die übrigen Exemplare besaßen rostral insgesamt 1-2 Stacheln. An beinahe allen Individuen waren 2 oder 3 dorsale Längsteihen auf dern Vorderende durch das Fehlen von 1-2, selten 3 Stacheln streckenweise unterbrochen. Die Positionen der Stacheln am Ende der Pharynxregion und auf dem Rumpf sind nicht von Tier zu Tier festgelegt, ihre Anzahl variiert jedoch wenig: größere nackte Stellen entstehen zumeist nicht durch schwächeren Stachelbesatz, sondern ergeben sich aus verschieden orientiertem Zusammenrücken der Stachelbasen. Die beiden Paare ventraler Terminalstacheln inserieren entweder hintereinander, oder waren bei etwa einem Drittel der Tiere in einer Querreihe nebeneinander stehend anzutreffen. Abgesehen von der Vielgestaltigkeit der basalen Stachelverdickungen erweist sich die Ausprägung der Nebenspitzen an den Stacheln als unterschiedlich: Vor allem in der hinteren Rumpfregion, und hier wiederum am ehesten an den dorsalen Stacheln, 
sind alle Variationen zwischen prägnant ausgezogenen Nebenspitzen und kontinuierlichen Verminderungen des Stacheldurchmessers verifiziert.

D is k us sio n. C. hilarus ist die bislang kleinste Art der scbultzei-Gruppe. Der bedeutendste Unterschied zu den anderen Arten der Gruppe ergibt sich aus den in der Pharynxregion in gerader Anzahl vorhandenen und in voneinander gleichen Abständen verlaufenden Stachellängsreihen. Die Form der Stacheln findet sich ähnlich bei C. modestus n. sp. (siehe D is k u s s i o n von C. modestus n. sp.).

D i a g n o s e. Chaetonotus-Art aus der schultzei-Gruppe. Pleuren, Kephalion und Hypostomion fehlen. Längsreihen der dorsalen Stacheln in der Pharynxregion in gerader Anzahl (8 Reihen); Stacheln auf dem Rumpf unregelmäßig verteilt. 1 ventrolaterale Reihe jederseits. Parthenogenetisch. Gesamtlänge des Körpers $125 \mu \mathrm{m}$, davon Zehenlänge 16-18 $\mu \mathrm{m}$; Körperbreite in der Pharynxregion $30 \mu \mathrm{m}$, in der Rumpfregion $32 \mu \mathrm{m}$; Pharynxlänge $32 \mu \mathrm{m}$.

\section{Chaetonotus dispar WILKE 1954}

Fundort: Rovinj.

Untersuchtes Material: 3 Individuen.

Von dieser Art aus der schultzei-Gruppe lag mir nur ein unbeschädigtes Exemplar vor, die Indentifizierung mit C. dispar kann daher nicht als völlig gesichert gelten.

Die Körpermaße meines Fundes entsprechen der Erstbeschreibung, nur der Pharynx ist mit $39 \mu \mathrm{m}$ um $5 \mu \mathrm{m}$ kürzer. Pharynx- und Rumpfregion sind mit 7 Stachellängsreihen bedeckt; dieses Merkmal wird in den Angaben von Whke (1954, p. 350) nicht eindeutig bezeugt, die Autorin erwähnt lediglich, daß die Anordnung der Stacheln zwischen C. atrox. WILKE 1954 und C. dispar keine Unterschiede erkennen ließe: Auch C. dispar müßte daher in der Pharynxregion 9, auf dem Rumpf sogar 11 Längsreihen besitzen. Solche Ergebnisse können jedoch bei stärkerer Quetschung der Tiere zustande kommen. Fraglich bleibt allerdings, ob nicht in der Abbildung zur Originalbeschreibung (Wilke 1954, Abb. 20 b) die ventrolateralen Stacheln zu den lateral inserierenden hinzugezählt wurden, da an den von mir untersuchten Tieren 13 Stacheln lateral und etwa 10 oder 11 sublateral standen, während WILKE 22 an den Körperseiten entspringende Stacheln skizziert. An meinen Exemplaren sind die lateralen Stacheln stark sichelförmig gekrïmmt. Die Form der dorsalen Stacheln entspricht der Erstbeschreibung. Ein Paar Protonephridien befindet sich seitlich des ersten Darmdrittels.

Diskussion der scbultzei-Gruppe. Bereits Schultze (1853) beschreibt und zeichnet (Tafel VI, Fig. 4, 5 und 6) eine Chaetonotus-Art, an der er „.. die Borsten an ihrer Basis jede mit 2 Nebenspitzen ..." findet, diese beiden Nebenspitzen in den sehr eindeutigen Abbildungen jedoch auf halber Länge des Stachels entspringen läßt und keineswegs mit den, überdies nicht eingezeichneten, Basisschuppen in Verbindung bringt. Gleichwohl vermutet $\mathrm{er}$ in ihr eine schon von EHRENBERG (1832) als C. maximus beschriebene Form. Metschnikoff (1865) erkennt die Eigenständigkeit der Art und gibt ihr den Namen C. scbultzei. Bei der Gliederung der zahlreichen Chatonotus-Arten errichtete Remane (1936) für diese Art eine Gruppe, als deren bindendes Charakteristikum der Autor "Ausgezeichnet durch Schuppenstacheln, die $2 \mathrm{Ne}$ - 
benspitzen tragen" hervorhebt. Durch WrLke (1954) wurde die Gruppe um drei Arten bereichert: C. atrox, C. dispar, C. neptuni.

Nun, da in vorliegender Arbeit weitere 4 neue Arten beschrieben werden, erscheint eine zusammenfassende Diskussion der Gruppe und ihrer Merkmale angemessen. Den yon mir untersuchten Arten (C. jucundus n. sp., C. serenus n. sp., C. modestus n. sp., C. bilarus n. sp. und C. dispar WILKE 1954) fehlen Kephalion und Pleuren. Auch ein Hypostomion ist nirgends vorhanden; die Beobachtung WILKEs (1954) an C. atrox, „... daß die Cuticula ventral hinter der Mundöffnung leicht verdickt ist, ..." triff für keine meiner Arten zu.

Die Stachelformen der einzelnen Körperregionen sind untereinander sehr verschieden. Bereits WhLKE erkennt diese Unterschiede und bezeichnet z. B. die dorsalen Stacheln der vorderen Pharynxregion von C. atrox sogar als Stielschuppen, da die Stacheln „... dort, wo sie inserieren, ... rechtwinkelig geknickt ...“ sind, und „.. . zwischen den drei Spitzen noch eine feine Lamelle..." wahrzunehmen ist; den Beschreibungen folgend gilt dies auch für C. neptuni (bei C. dispar werden diese Charakteristika nicht erwähnt). Bei den von mir gefundenen Arten bestehen die Dorsalstacheln der vorderen Pharynxregion aus 3 gemeinsam inserierenden Spitzen: 2 Nebenspitzen und einer mittleren Spitze, die ein wenig verlängert ist; zwischen diesen Spitzen sind keine Lamellen vorhanden. WrLKE beschreibt nur von C. neptuni Basisschuppen an den vorderen Dorsalstacheln, bei $C$. atrox und $C$. dispar inserieren sie direkt an der Epidermis, ebenso bei meinen Arten; bei C. jucundus sind die Spitzen an ihrer Insertionsstelle lediglich etwas knotig verdickt. Als Stielschuppen (im Sinne der Verhältnisse bei den Gattungen Xenotrichula und Aspidiophorus) fand ich an keiner Art die vorderen Dorsalstacheln ausgeprägt, die 3 Spitzen liegen der Körperoberfläche dicht an, eine distinkte Basisschuppe fehlt ebenso, wie eine als Stil verstehbare Struktur. Zur Form der auf dem Rumpf durchgehend repräsentierten Dorsalstacheln bestehen kaum Ubergänge. Wohl sind bei C. modestus und C. bilarus einige Stacheln der hinteren Pharynxregion ein wenig verdickt, ihre Nebenspitzen distaler angesetzt und damit den caudad folgenden Rumpfstacheln ähnlich, alle übrigen Arten aber entbehren solcher struktureller Angleichungen.

Die dorsalen Rumpfstacheln sind bei allen von mir untersuchten Arten scharf oder mehr abgerundet dreikantig und sitzen nur bei $C$. jucundus auf flächig ausgedehnten Basisschuppen. Die Nebenspitzen sind bei manchen Arten kaum zu sehen, werden bei C. modestus und C. hilarus von den ausgezackten Enden der beiden körperseitigen Kanten des Stachels gebildet, sind bei C. jucundus, ähnlich wie bei C. neptuni WruKE 1954, nur als eckig gestufte Zäsur erkennbar und bei C. serenus auf eine jähe seitliche Verjüngung im letzten Drittel des Stachels reduziert.

Die Form der lateralen Stacheln ist nicht leicht zu analysieren, unterscheidet sich von jener der dorsalen Rumpfstacheln aber mindestens insoweit, als sie nur eine Nebenspitze zu tragen scheinen, die sich zudem von der dem Körper abgewandten Kontur des Stachels abspaltet; dies triff allerdings nur für die lateralen und ventrolateralen Stacheln bei $C$. modestzts und C. bilarus zu und ähnelt der einfachen Stachelverzweigung von C. similis Zelinka 1889. Bei C. modestus verläuft eine zweite, noch weiter median angeordnete ventrolaterale Stachelreihe, ihre Elemente sind genauso geformt wie die Lamellenstacheln gleicher Position einiger Halichaetonotus-Arten.

Eine Trennung der rostralen Tasthaare in ein vorderes und ein hinteres Büschel 
konnte ich nicht feststellen: Die Wimpern bilden zu beiden Seiten des Mundringes ein geschlossenes Feld, das sich mehr oder weniger laterad ausdehnt. Die Insertionsstellen liegen ziemlich gleichmäßig verteilt, manchmal etwas konzentrierter in der Nähe des Mundringes. Durch freie Stellen scharf getrennte Büschel in der Weise, wie sie WILKE für die Arten C. atrox, C. neptuni und $C$. dispar angibt, sind bei keiner der mir vorliegenden Arten verifiziert; bloß ab und zu sind einige verlängerte Wimpern paarig gebündelt, aber auch dies in intraspezifisch sehr variablem Ausmaß.

Das charakteristische Merkmal der schultzei-Gruppe, die frei vom Hauptstachel abstehenden paarigen Nebenspitzen, ist wohl schon seit den Funden von WILKE als plastischer aufzufassen; und die Dreikantigkeit der dorsalen Rumpfstacheln findet sich auch bei vielen Arten anderer Chaetonotus-Gruppen, die auf hinten quer abgestutzten oder symmetrisch dreilappigen Basisschuppen kräftig entwickelte Stacheln tragen. Für die Einheit der Gruppe bürgen vorderhand nur mehr: die einander nie berührenden Basisschuppen und die in jeweils eine einfache Spitze auslaufenden drei Kanten der Dorsalstacheln, wobei wohl die dem Körper zugewandten beiden Kanten fallweise abgerundet sind und keine distinkten Spitzen bilden, aber die mediane, dem Körper abgewandte Kante (oder der auch hier abgerundete Stachel) immer in einer einfachen Spitze endet. Durch diese Stachelform unterscheidet sich die schultzei-Gruppe eindeutig von einigen sonst verhältnismäßig ähnlich beschuppten Arten der spinulosus-Gruppe (etwa C. bystrix Metschnikoff 1865, C. macrochaetus ZeLINKA 1889 und C. persetosus ZELINKA 1889) sowie auch von dem bereits erwähnten C. similis (aus der maximusGruppe): obschon deren dorsale Stacheln dreikantig sind, verjüngen sich diese kontinuierlich ohne seitliche Spitzen oder Stufung bis zur Endspitze, und diese ist dann senkrecht zur Körperoberfläche in eine Haupt- und eine mediane Nebenspitze gespalten.

Gerade dies triff auch für C. woodi THANE-Fenchel $1970 \mathrm{zu}$ (p. 128): „Each scale has a median spine which is distally split into two pointed spines and two lateral, somewhat shorter spines." Letztere sind indessen keine freien Nebenspitzen des Hauptstachels, sondern, wie die Autorin auch in ihrer Abbildung $11 \mathrm{C}$ einwandfrei zeigt, die beiden der Basisschuppe anliegenden Kiele, die ebenmäßig in die lateralen Stachelkanten übergehen und den Stachel gegen die hintere Hälfte seiner Schuppe abstützen.

Da diese Struktur nicht der distalen Stufung oder Ausspitzung der beiden seitlichen Kanten des Stachels entspricht, dieser vielmehr eine unpaare, seiner dem Körper abgewandten Kante entspringende Spitze trägt, soll diese Art nicht der schultzeiGruppe, sondern, allen ihren Merkmalen entsprechend, besser der maximus-Gruppe zugeordnet werden.

\section{Halichaetonotus (REMANE 1936) nov. gen.}

Ex subgen. Chaetonotus (Halichaetonotus) Remane 1936. Typus der Gattung: Halichaetonotus pleuracanthus (REMANE 1926b).

Zur Gattung Halichaetonotus zählen die Arten: H. pleuracanthus (Remane 1926b), H. decipiens (REMANe 1929), (Heterolepidoderma dubium ReMANE 1926b), H. paradoxus (Remane 1927), H. aculifer (GerLach 1953), H. parous (WILKe 1954). $H$. riedli nov. spec., $H$. swedmarki nov. spec.; ferner die Formen $H$. decipiens var. spinosus (D'HONDT 1966 b) und H. aculifer f. adriatica nov. $f$. 
Das Subgenus Halichaetonotus wird eingezogen und in den Rang einer Gattung erhoben. Den geltenden Regeln entsprechend, bleibt REMANE der Autor, H. pleuracanthus der Typus der Gattung.

Halichatonotus riedli nov. spec. (Abb. 16)

Fundort: Alberoni.

Untersuchtes Material: 3 Individuen.

Bei einer Gesamtlänge von 125-128 $\mu \mathrm{m}$ werden die Tiere in der Pharynxregion maximal $30 \mu \mathrm{m}$ breit, in der Rumpfregion $34 \mu \mathrm{m}$; an Ende der Pharynxregion ist der Körper nur wenig verschmälert und insgesamt stark dorsoventral abgeplattet. Die Zehen sind $10 \mu \mathrm{m}$ lang und werden von den Tieren beim Kriechen weit gespreizt.

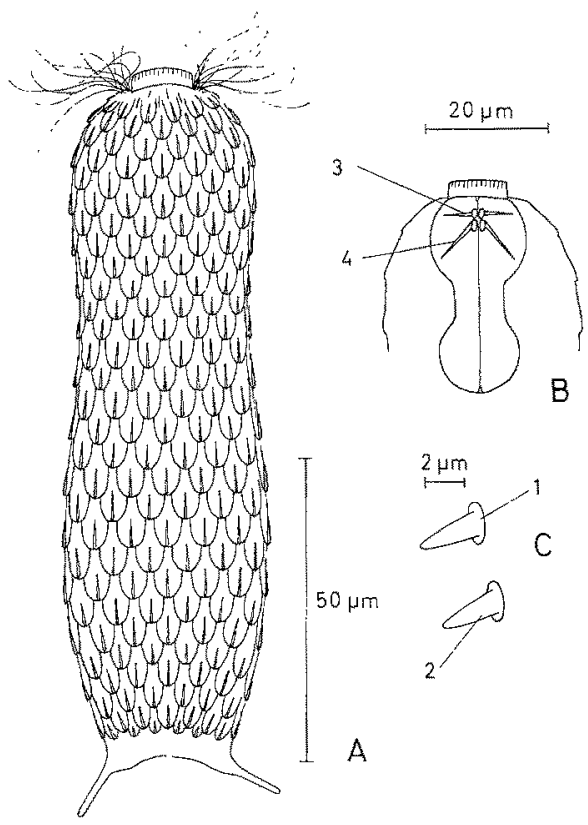

Abb. 16: Halichaetonotus riedli nov. spec. A Habitus dorsal, $B$ Pharynx, $C$ ventrolaterale Lamellenschuppen. 1 Basisschuppe, 2 Lamellenstachel; Mundbewaffnug: 3 vorderes, 4 hinteres Spangenpaar

Weder Kephalion noch Pleuren sind vorhanden. Die gekielten Schuppen bilden 11 dorsale, nahe zusammengerückte Längsreihen, die Schuppen einer Längsreihe sind aber weit voneinander entfernt. Die dorsomediane Reihe besteht aus 14 Schuppen. Das Verteilungsbild der kutikularen Elemente ist in allen Körperregionen gleich und regelmäßig. Kielschuppen verlaufen jederseits in einer lateralen Reihe vom rostralen Rand bis zu den Zehenbasen. Etwa $6 \mu \mathrm{m}$ von der lateralen Körperkontur ventrad eingerückt befindet sich jeweils eine Reihe von etwa 12 sehr schwach kutikularisierten Lamellen- 
schuppen. Das Körperende ist auf seiner Ventralseite nackt, auch das ventrale Zwischenfeld enthält keine kutikularen Bildungen.

Die Form der Schuppen ist dorsal und lateral in allen Körperregionen halboval, da eine vordere Begrenzung der Schuppe fehlt. Die Kiele verdicken sich caudad und enden mit dem Hinterrand der Basisschuppe. Die Kiellänge der dorsomedianen Reihe mißt in der Pharynxregion 3,5 $\mu \mathrm{m}, 2,5 \mu \mathrm{m}$ auf dem Ubergang zum Rumpf und etwas über $4 \mu \mathrm{m}$ auf dem Rumpf selbst. Die ventrolateralen Lamellenstacheln sind sehr dünn, ihre Form abgerundet dreieckig; ihre ovalen Basisschuppen neigen sich schräg nach vorne gegen die Körperachse; die Höhe der Lamellen beträgt ca. $3 \mu \mathrm{m}$, die Länge der Basisschuppe $2 \mu \mathrm{m}$.

Die ventralen Wimperbänder treffen sich unter dem Pharynx zu einem gemeinsamen, dichten Feld und reichen getrennt bis ins 2. Rumpfdrittel zurück. Die vorderen Tastwimpern besetzen den kleinen Raum jederseits zwischen dem Mundring und den weit nach vorne reichenden lateralen Schuppen. Die Wimpern sind 15-18 $\mu \mathrm{m}$ lang und bilden jederseits zu 6-8 ein lebhaft schlagendes Büschel.

Der Mundring ist schwach kutikularisiert, seine zahlreichen Längsversteifungen bilden eine feine Riefelung. Er mißt $10 \mu \mathrm{m}$ im Durchmesser und ist $2 \mu \mathrm{m}$ hoch. Der Pharynx ist sehr kräftig entwickelt; der Durchmesser des vorderen Bulbus beträgt $17 \mu \mathrm{m}$, der des hinteren etwa $13 \mu \mathrm{m}$. Im mittleren Pharynxabschnitt werden die Wandzellen aber kaum höher als $4 \mu \mathrm{m}$. Zwei Paare kutikularisierter Spangen liegen in den dorsalen Lumina des vorderen Bulbus. Beide Paare stoßen mit tropfenförmigen Verdickungen median zusammen; die vorderen Spangen liegen quer zur Körperachse, mit der die hinteren einen. Winkel von etwa $45^{\circ}$ bilden. Die Bewegungen dieser Elemente während des Schluckvorganges konnten nicht beobachtet werden. Der Darm verläuft gerade, der After mündet am Körperhinterrand. Protonephridien scheinen zu fehlen. Ein $\mathrm{Ei}$ ist vorhanden.

$\mathrm{D}$ is $\mathrm{k}$ u s s i n. Der Besitz von dorsalen Kielschuppen und ventrolateralen Lamellenstacheln ordnet diese Art der Gattung Halichaetonotus zu. Die Form und Lage der Schuppen, die besonders kräftig entwickelten Pharynxbulbi und die aus 2 Spangenpaaren bestehende Pharynxbewaffnung sind $z$. T. sehr verschieden von den entsprechenden Elementen und Strukturen der anderen Gattungsmitglieder.

$\mathrm{D}$ i a g n o se. Halichaetonotus-Art ohne Pleuren und Kephalion. Hypostomion fehlt. Dorsale Kielschuppen halboval, in 11 Längsreihen; in der dorsomedianen Reihe 14 Kielschuppen. Ventrolaterale Lamellenstacheln sehr fein kutikularisiert. Keine hinteren Tastborsten auf dem Rumpf. Keine ventroterminalen Elemente. Pharynx vorne und hinten mit kräftigen Bulbi; im vorderen Bulbus 2 Paare kutikularer Spangen. Parthenogenetisch. Gesamtlänge des Körpers 125-128 $\mu \mathrm{m}$, davon Zehenlänge $10 \mu \mathrm{m}$; Körperbreite in der Pharynxregion $30 \mu \mathrm{m}$, in der Rumpfregion $34 \mu \mathrm{m}$; Pharynxlänge $33 \mu \mathrm{m}$.

Halichaetonotus steedmarki nov. spec. (Abb. 17)

Fundort: Rovinj.

Untersuchtes Material: 4 Individuen.

Die Tiere werden $84 \mu \mathrm{m}$ lang, inklusive der $18 \mu \mathrm{m}$ langen Zehen. An kaum gequetschten Exemplaren wurde die Breite der Pharynxregion mit $20 \mu \mathrm{m}$, die Breite des 
Rumpfes mit $24 \mu \mathrm{m}$ gemessen. Der Körper ist gegen Ende der Pharynxregion geringfügig verschmälert.

Die rostrale Kontur ist gleichmäßjig gerundet und wird vom Kephalion nicht überragt. Das Kephalion ist nur durch seinen stark gekrümmten Vorderrand markiert, eine hintere Begrenzung ist nicht $\mathrm{zu}$ sehen; es liegt dem rostralen Rand wohl nur als schmale, weit laterad reichende Spange an. Ein Paar Pleuren wölbt sich von ventrolateral nach lateral auf, greit jedoch nicht auf dorsolateral über.

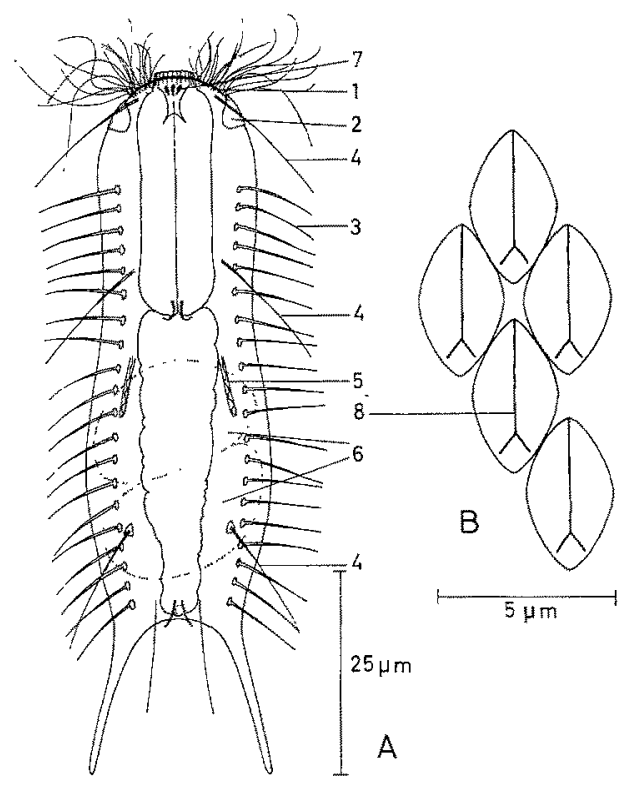

Abb. 17: Halichaetonotus swedmarki nov. spec. A Habitus, ohne dorsale Kielschuppen, $B$ dorsale Kielschuppen aus der mittleren Rumpfregion. 1 Kephalion; 2 Pleuren; 3 ventrolaterale Stacheln; 4 dorsale Tastborsten; 5 Protonephridien; 6 Eier; 7 Mundbewaffnung: kutikularisierte Höcker; 8 Kiel

Die Kielschuppen bilden 17 dorsale Längsreihen, die gleichmäßig über den gesamten Körper verlaufen. Kielschuppen bilden auch jederseits eine laterale Reihe. Die dorsomediane Reihe zählt 19 Schuppen. Jederseits ventrad eingerückt verläuft eine Reihe von Lamellenstacheln, die auf kleinen ovalen Basisschuppen stehen. Diese Reihe beginnt im 2. Drittel der Pharynxregion und endet knapp vor den Zehenbasen. Ventral neben dem After inserieren 2 feine Borsten, die mit einer Länge von etwa $14 \mu \mathrm{m}$ bis zur hinteren Hälfte der Haftröhrchen reichen. Das ventrale Zwischenfeld ist nackt.

Alle dorsalen und lateralen Schuppen sind rhombisch mit leicht abgerundeten Ekken und tragen niedrige Kiele, die an ihrem hinteren Ende gegabelt sind. In der Pharynxregion überdecken sich die Schuppen ein wenig, so daß die Gabelung des Kieles mit dem Vorderrand der nachfolgenden Schuppe zusammenfällt. Ob letztere überdeckt wird oder umgekehrt selbst die nächste vordere Schuppe ihrer Reihe bis zur Kielgabelung überdeckt, konnte nicht entschieden werden. Die dorsalen Schuppen sind mit $4,2 \mu \mathrm{m}$ Länge und 2,5 $\mu \mathrm{m}$ Breite in allen Körperregionen gleich groß, bloß die beiden 
ersten Querreihen hinter dem Kephalion sind etwas kleiner. Die ventrolateralen Lamellenstacheln sind $10 \mu \mathrm{m}$ lang.

Unter der vorderen Pharynxhälfte bildet die ventrale Bewimperung ein geschlossenes Feld, von hier bis zum Rumpfende getrennte Bänder. Die vorderen Tastwimpern entspringen im Raum zwischen Mundring und Pleuren unterhalb des Kephalions. Thre Länge nimmt von frontal nach lateral zu: die neben dem Mundring stehenden sind $5 \mu \mathrm{m}$ lang, $15 \mu \mathrm{m}$ die den Pleuren benachbarten. Dorsal etwas vor den Pleuren inseriert ein Paar starrer Tastborsten ohne Basisschuppen. Tastborsten finden sich ferner dorsolateral in der hinteren Pharynxregion und, auf dreieckigen Schuppen stehend, etwa $15 \mu \mathrm{m}$ vor den Haftröhrchenbasen. Alle Tastborsten sind ungefähr $18 \mu \mathrm{m}$ lang.

Der Durchmesser des Pharynx beträgt $9 \mu \mathrm{m}$, die Bulbusbildungen sind schwach. Gegen den Mundring zu ist das Pharynxlumen erweitert, und die Wandungen seiner dorsalen Falten an dieser Stelle kutikularisiert. Die ventrale Falte des Pharynxlumens verbreitert sich zum Pharynxeingang und beherbergt 3 nebeneinanderliegende, tropfenförmige Höcker. Am hinteren Pharynxende befindet sich eine kutikulare Versteifung, deren Form nicht genau zu analysieren war. Der Darm verläuft gerade bis zum terminal gelegenen After, der durch eine versteifte Tüte mündet.

Neben der vorderen Darmregion befindet sich ein Paar Protonephridien mit $8 \mu \mathrm{m}$ langen Geißelkolben; diese sind von einem stark granulierten Gewebe umgeben. Über dem Darm liegen hintereinander 2 Eier.

$\mathrm{D}$ is kus i o n. Gegenüber den anderen Arten der Gattung unterscheidet sich H. swedmarki durch den Besitz von Pleuren, rhombischen Basisschuppen und gegabelten Kielen. Auch die dorsal knapp vor den Pleuren inserierenden Tastborsten stellen für die Gattung ein Novum dar. Mithin geht die Ubereinstimmung von $H$. swedmarki mit den anderen Mitgliedern der Gattung kaum über die Forderungen der Gattungsdiagnose hinaus. Die 3 kräftigen Höcker im Pharynxeingang erinnern entfernt an die Zahnbildungen, wie sie Remane (1936, Abb. 66c) für Aspidiopborus paradoxus (Vorgt 1902) abbildet.

D i a g n o se. Halichaetonotus-Art mit Kephalion und Pleuren. Kein Hypostomion. Rhombische Schuppen mit gegabelten Kielen; Kielschuppen in 17 dorsalen Längsreihen, in der dorsomedianen Reihe 19 Schuppen. Tastborsten: jeweils ein Paar dorsal vor den Pleuren, dorsolateral in der hinteren Pharynxregion und vor den Zehenbasen. Im Pharynxeingang 3 kutikulare Höcker. Parthenogenetisch. Gesamtlänge des Körpers $84 \mu \mathrm{m}$, davon Zehenlänge $18 \mu \mathrm{m}$; Körperbreite in der Pharynxregion $20 \mu \mathrm{m}$, in der Rumpfregion $24 \mu \mathrm{m}$; Pharynxlänge $28 \mu \mathrm{m}$.

\section{Halichaetonotus aculifer (GeRLACH 1953) (Abb. 18)}

Fundorte: Alberoni, Pta. Sabbioni.

Untersuchtes Material: 32 Individuen.

Reife Tiere erreichen eine Gesamtlänge von 120-146 $\mu \mathrm{m}$. Die Form der äußeren kutikularen Elemente unterscheidet sich teilweise von den Angaben der Erstbeschreibung. Deshalb und zum Vergleich mit der im folgenden beschriebenen forma adriatica soll die Form der dorsalen Schuppen vom (nordadriatischen) Typus der Art rekapituliert werden: In der vorderen Hälfte der Pharynxregion sind die Schuppen seitlich 
eingedellt, vor dieser Eindellung abgerundet dreieckig, hinter ihr leicht oval gerundet; in der hinteren Pharynxregion sind die seitlichen Dellen eingeebnet, der Vorderrand der Schuppe undeutlich dreieckig bis rund, womit ein Übergang zu den längsovalen Schuppen der Rumpfregion besteht; am Ende der Pharynxregion liegt in der jederseits zweiten paramedianen Reihe (von der Mediane gerechnet) eine frontal eingedellte, in die Breite gezogene Schuppe.

Halichatonotus aculifer $\mathrm{f}$. adriatica nov. forma (Abb. 18)

Fundort: Alberoni.

Untersuchtes Material: 6 Individuen.

Die genaue Durchsicht des Materials erbrachte regelmäßig Individuen, die wohl in ihren Abmessungen und in der Anordnung der Schuppenreihen von $H$. aculifer nicht zu unterscheiden sind, bei überdies gleichen Schuppenmaßen jedoch eine andere Schuppenform in der Pharynxregion aufweisen: hier sind alle Schuppen gleichmäßig längsoval, sowie queroval in einer kleinen mehr lateral stehenden Gruppe. Die Form der Kiele ist die gleiche wie bei dem Typus der Art, jedoch tragen die beiden vordersten ventrolateralen Stacheln keine Lamellen; die ventralen Schuppen am Rumpfende werden nur

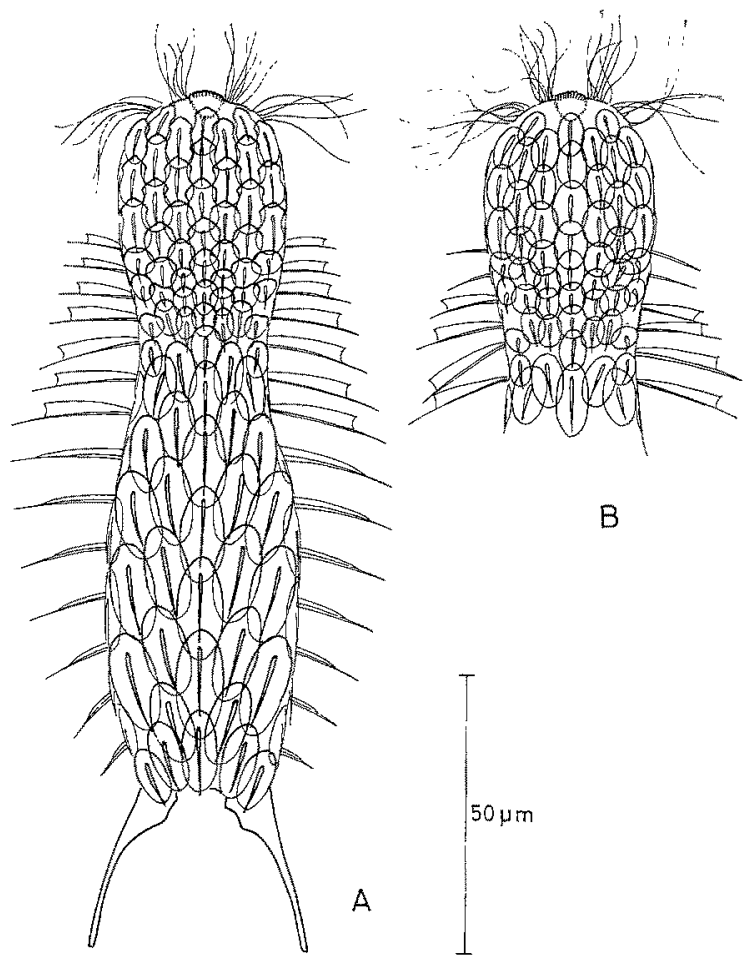

Abb. 18: A Halichaetonotus aculifer (GerLACH 1953), Habitus dorsal; B Halicbaetonotus aculifer forma adriatica nov. f., vordere Körperhälfte dorsal. ( $A$ aus ScHrom 1966b) 
halb so lang. Ein schwach kutikularisiertes Kephalion ist entwickelt, das dem Typus fehlt. In allen übrigen Merkmalen ist die forma adriatica mit dem Typus von $H$. aculifer identisch.

Diskussion der Gattung Halichaetonotus. Remane (1936) hat die Untergattung Halichaetonotus errichtet, um vom übrigen Artenvolumen der Gattung Cbaetonotus jene 3 Arten deutlich abzurücken, die sowohl dorsale Kielschuppen als auch jederseits eine ventrolaterale Reihe von Lamellenstacheln tragen: C. pleuracantbus Remane 1926b, C. decipiens Remane 1929 und den etwas abseits stehenden C. paradoxus Remane 1927d, dessen dorsale und laterale Kiele in hohe, segelförmige Lamellen ausgezogen sind. Später wurde für 2 weitere Arten die Zugehörigkeit zu diesem Subgenus befunden: GERLACH (1953) reihte den von ihm beschriebenen C. aculifer hier ein, da diese Art außer den fein zugespitzten dorsalen Kielen auch eine ventrolaterale Reihe von Lamellenstacheln besitzt; WILKE (1954) fand an C. parvus ventrolaterale Lamellenstacheln und dorsale Kiele, hielt die Art für verwandt mit C. aculifer und stellte sie in die Halichaetonotus-Gruppe.

Als weiteres Merkmal dieser Formen führt Remane (1936) das Fehlen von Kephalion und Pleuren an; die Erstbeschreibung von C. pleuracanthus enthält jedoch bloß die Bemerkung: "Nur das schwer erkennbare Kephalion und Hypopleurion sowie die vorderen und hinteren lateralen Wimperbüschel deuten die Fünflappigkeit des Kopfes der meisten Chaetonotus-Arten an. "Während $H$. riedli tatsächlich Kephalion und Pleuren vermissen läßt, sind diese Bildungen bei $H$. swedmarki deutlich ausgeprägt; durch ventrolaterale Stacheln und dorsale Kiele ist die Stellung dieser Art innerhalb der Gattung jedoch gesichert. Interessanterweise trägt auch $H$. aculifer f. adriatica ein Kephalion, obwohl diese Form dem Typus der Art, die kein Kephalion besitzt, sehr nahe steht. Kephalion und Pleuren stellen mithin nur Merkmale zweiten Ranges dar. Ähnlich verhält es sich mit den vorderen Wimperbüscheln, deren Anzahl REMANE auch für die Untergattung Halichaetonotus definitorischen Gehalt beimißt: "Wimperbüschel ... in normaler Zahl und Anordnung. " $H$. pleuracanthus, $H$. decipiens, $H$. paradoxus und $H$. aculifer besitzen 2 Paare vordere Wimperbüschel, bei $H$. parvus entspringt ein 3. Paar nahe am Mundring. Bei $H$. swedmarki sind die vorderen Wimpern nicht gebündelt, sie bilden ein homogenes Feld; die Wimpern von $H$. riedli bilden nur ein Büschel jederseits.

Den 5 bisher bekannten Arten dieser Gruppe sind große ventrolaterale Terminalschuppen gemein; für $H$. paradoxus wurden sie von WILKE (1954) nachgewiesen, wiewohl bezweifelt werden muß, ob der Autorin tatsächlich diese Art vorgelegen hat, da sie die Anzahl der dorsalen Schuppenreihen mit 15 angibt, während die genaue Zeichnung von Remane (1927d sowie 1936, Fig. 180) nur 7 Längsreihen erkennen läßt. Die 2 neuen Arten tragen ventral terminale Kiele ohne Basisschuppen. Dorsale Tastborsten auf dem Kopf und vor den Zehen sind an $H$, decipiens gefunden worden, mit ihnen homologisierbar sind die kräftigen vorderen und hinteren dorsalen Borsten von $H$. swedmarki. Für $H$. pleuracanthus und $H$. paradoxus sind nur hintere Tasthaare beschrieben. An $H$. aculifer, $H$, aculifer $f$ adriatica, $H$. parous und $H$. riedli fehlen aber diese Elemente.

Die dorsalen, den Körper durchgehend bedeckenden Kielschuppen bilden gemeinsam mit den ventrolateralen Stacheln oder Lamellenstacheln eine Merkmalskombination, die innerhalb der Gattung Chaetonotus nur für die Arten der bislang als Unter- 
gattung Halichaetonotus gefuhrten Gruppe zutrifft. Durch den Zuwachs an neuen Arten begïnstigt, soll dieses Subgenus daher von der umfangreichen Sammelgattung Cbatonotus getrennt und in den Rang einer selbständigen Gattung erhoben werden.

Halichaetonotus steht der Gattung Heterolepidoderma sehr nahe. Tatsächlich ist der Besitz ventrolateraler Stachel- oder Lamellenreihen nunmehr das einzige Kriterium, das Halichaetonotus von Heterolepidoderma unterscheidet. Kein anderes Merkmal der Kutikularstrukturen findet sich ausschließlich bei einer der beiden Gattungen. Denn einer hohen Schuppenzahl, wie sie Remane (1936) für Heterolepidoderma als charakteristisch fordert, weichen bereits 2 sichere Heterolepidoderma-Arten aus, nämlich $H$. armatum ScHrom $1966 \mathrm{~b}$ und $H$. istrianum n. sp.: sie tragen ähnlich viele dorsale Längsreihen und Schuppen in einer Reihe wie die meisten Halichaetonotus-Arten; umgekehrt besitzt Halichaetonotus swedmarki mehr als doppelt so viele KielschuppenLängsreihen wie die meisten Arten dieser Gattung. Ebenso wenig würden die Kielformen eine Trennung der beiden Gattungen rechtfertigen, denn in beiden Genera kommen direkt der Basisschuppe anliegende Kiele vor, und auch solche, die mittels einer niedrigen Lamelle mit ihrer Basis verbunden sind. Ferner sind Kephalion und Pleuren nun auch für Halichaetonotus bekannt geworden. Dorsale Tastborsten sind fast allen Heterolepidoderma-Arten eigen; aber auch 4 von den 7 Halichaetonotus-Arten lassen dieses Merkmal nicht vermissen.

Remane (1936) vermutet den Anschluß von Chaetonotus an Heterolepidoderma über die Arten Chaetonotus elegans Konsuloff 1923 und C. elegantulus Remane 1936. Von letzterer Art existiert leider nur eine sehr kurze Beschreibung; aber C. elegans zählt wohl eindeutig zu Chatonotus: sein Körper ist von kurzen, doch von den Basisschuppen deutlich abstehenden Stacheln bedeckt.

Diagnose der Gattung Halichaetonotus. Gattung aus der Familie Chaetonotidae. Dorsale Schuppen gekielt; der Kiel stellt eine mediane Kutikularleiste dar, die über ihre ganze Länge der Basisschuppe direkt, oder mittels einer dünnen, immer sehr niedrigen Lamelle anliegt und über den Schuppenhinterrand hinaus in eine feine, kurze Spitze verlängert sein kann. Jederseits entlang des Körpers eine ventrolaterale Reihe von Stacheln oder Lamellenstacheln.

Heterolepidoderma istriantum nov. spec. (Abb. 19)

Fundort: Rovinj.

Untersuchtes Material: 12 Individuen.

Die Tiere erreichen eine Gesamtlänge von $126 \mu \mathrm{m}$, wovon $17 \mu \mathrm{m}$ auf die Zehen entfallen. Der Pharynx nimmt mit $35 \mu \mathrm{m}$ nicht ganz ein Drittel der Gesamtlänge ein. In ungequetschtem Zustande ist die Pharynxregion $26 \mu \mathrm{m}$, der Rumpf $35 \mu \mathrm{m}$ breit.

Das Kephalion ist breit, frontal stark kutikularisiert und überragt die rostrale Körperkontur. Die Pleuren bestehen jederseits aus einer leicht gewölbten, schwach kutikularisierten lateralen Platte; sie greifen auf die Ventralseite ein wenig über, nicht aber auf die Dorsalseite der vorderen Pharynxregion.

In allen Körperregionen liegen die niedrigen Kiele direkt der epidermalen Kutikula an; weder dorsal noch lateral oder ventrolateral sind die Umrisse von Basis- 
schuppen zu erkennen. In der Pharynxregion ist die Stellung der Kiele nicht durchgehend regelmäßig. Zwischen den geradeverlaufenden 12-13 Längsreihen sind stellenweise 4-5 Kiele regellos eingestreut, oder der Verlauf einer Reihe wird von kiellosen Flächen unterbrochen. Auf dem Ubergang von der Pharynxregion zum Rumpf neigen sich beinahe alle Kiele gegen die Mediane; die Längsreihen rücken eng aneinander und

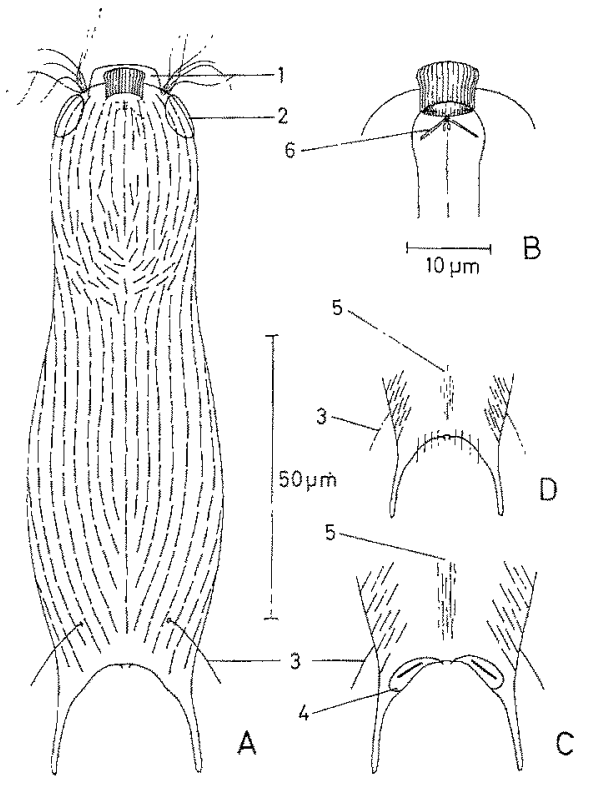

Abb. 19: Heterolepidoderma istrianum nov. spec. $A$ Habitus dorsal, $B$ vorderer Pharynxabschnitt, $C$ Hinterende ventral, D Heterolepidoderma armatum Schrom 1966b, Hinterende ventral. 1 Kephalion; 2 Pleuren; 3 Tastborsten; 4 terminales Kielschuppen-Paar; 5 ventrale Kiele; 6 Mundbewaffnung

ermöglichen damit einigen lateralen Reihen dorsad aufzusteigen; da hier außerdem einige mittlere Reihen mit quergestellten Kielen enden, können die aufgestiegenen Reihen bis zur Rückenmitte vordringen und schon ab der ersten Hälfte der Darmregion die Kielbedeckung des Rumpfes bilden. Auf dem Rumpf verlaufen 15 Längsreihen exakt parallel und nur $2,5 \mu \mathrm{m}$ voneinander distanziert. Die dorsomediane Reihe des Rumpfes enthält 13 Kiele; die Kiele sind auch in ihrer Längsabfolge eng zusammengerückt. In der 2. Rumpfhälfte enden jederseits 2-3 paramediane Reihen, wie am Ende der Pharynxregion steigen auch hier laterale Reihen dorsad auf und besetzen den freiwerdenden Raum. Ventrolateral verlaufen jederseits 3 Reihen schräg geneigter Kiele über die ganze Körperlänge. Den Köperhinterrand sclließen 2 querliegende ventrale Schuppen ab, die leicht gekrümmt und mediad zugespitzt sind und stark kutikularisierte, gerade Kiele tragen. In der hinteren Häfte des ventralen $Z$ wischenfeldes liegen 5-7 Reihen langer, feiner Kiele. Die Längenmaße der Kiele betragen: in der Pharynxregion etwas über $4 \mu \mathrm{m}$, am Ende der Pharynxregion 2,5-3 $\mu \mathrm{m}$, auf dem Rumpf etwa $5 \mu \mathrm{m}$. 
Die ventralen Wimperbänder sind von vorne bis hinten getrennt. Jederseits steht ein vorderes Wimperbüschel zwischen den Seitenrändern des Kephalions und den Pleuren; es wird aus jeweils 5-6 Wimpern gebildet. Ein Paar langer Tastborsten inseriert ca. $10 \mu \mathrm{m}$ vor den Zehenbasen auf winzigen Basisschuppen, die zwischen der 3. und 4 . Kielreihe liegen (von lateral gerechnet).

Die Pharynx ist vorne zu einem etwas stärkeren, hinten zu einem schwachen Bulbus erweitert. Im vorderen Bulbus ist den dorsalen Wänden des Pharynxlumens ein Paar schräg nach vorne zusammenlaufender Leisten angelagert; hinter deren proximalen Enden liegen winzige kutikulare Höcker. Während des Schluckvorganges bewegen sich diese Elemente genauso wie jene von $H$. armatum ScHrom 1966b. Der Darm verläuft gerade und mündet zwischen den querliegenden Terminalschuppen am Hinterrand des Rumpfes. Die Protonephridien befinden sich seitlich des vordersten Darmabschnittes. Reife Exemplare tragen 2 nebeneinanderliegende Eier.

D is kus s io n. Diese Art steht H, armatum ScHrom 1966b nahe: sehr ähnlich ist die Anordnung der dorsalen Kielreihen, auch deren Anzahl ist nur wenig verschieden: auf der dorsalen Rumpfpartie stehen bei $H$. armatum 17 Längsreihen, bei $H$. istrianum 15; das Kephalion ist gleich geformt, die Pleuren sind aber bei $H$. armatum größer.

Systematisch wichtige Unterschiede zwischen den beiden Arten ergeben sich durch die großen, quergestellten ventralen Terminalschuppen von $H$. istrianum ( $H$. armatum zeigt an dieser Stelle nur jederseits 4 feine Borsten), durch die allgemeinen Abmessungen ( $H$. istrianum ist größer) und in der Mundbewaffnung, die bei $H$. istrianum zwar die gleichen Elemente wie bei $H$. armatum zeigt, jedoch wesentlich schwächer kutikularisiert ist. Ferner lassen die dorsalen Kiele an H. istrianum keine Basisschuppen erkennen, die bei $H$. armatum, wenn anch schwach kutikularisiert, so doch immer vorhanden sind.

Di a $\mathrm{g}$ n o s e. Heterolepidoderma-Art mit Kephalion und Pleuren. Kein Hypostomion. Kiele ohne Basisschuppen. Ventroterminal neben dem After ein Paar großer, querstehender Kielschuppen. Kiele auf dem Rumpf in 15 Längsreihen, die mediane Reihe besteht auf dem Rumpf aus 13 Kielen. Hintere Tastborsten vorhanden. Im vorderen Pharynxbulbus eine schwach kutikularisierte Mundbewaffnung aus 1 Paar Spangen und 1 Paar kleiner Höcker. Parthenogenetisch. Gesamtlänge des Körpers $126 \mu \mathrm{m}$, davon Zehenlänge $17 \mu \mathrm{m}$; Körperbreite in der Pharynxregion $26 \mu \mathrm{m}$, in der Rumpfregion $35 \mu \mathrm{m}$; Pharynxlänge $35 \mu \mathrm{m}$.

\section{Heterolepidoderma spec. (Abb. 20)}

Fundort: Alberoni.

Untersuchtes Material: 4 Individuen.

Von dieser neuen Art haben mir nur juvenile Exemplare vorgelegen. Eine endgültige Benennung muß daher unterbleiben.

Die Tiere maßen 80-87 $\mu \mathrm{m}$ in der Länge, inklusive der $10 \mu \mathrm{m}$ langen Zehen. Die Pharynxlänge wurde mit 30-31 $\mu \mathrm{m}$ gemessen. Mit $21 \mu \mathrm{m}$ waren Pharynx- und Rumpfregion gleich breit. Pleuren fehlten. Die Querausdehnung des Kephalions betrug 
$10 \mu \mathrm{m}$, es überragte den Körper rostrad um etwa $2 \mu \mathrm{m}$. Die Anzahl der Kielreihen war in allen Körperregionen gleich: mithin lagen die 7 Längsreihen je nach ihrer Entfernung von der Mediane mehr oder weniger parallel zur Körperachse oder zur Körperkontur. Die dorsomediane Reihe bestand aus 16 Kielen. Ventrolateral waren keine

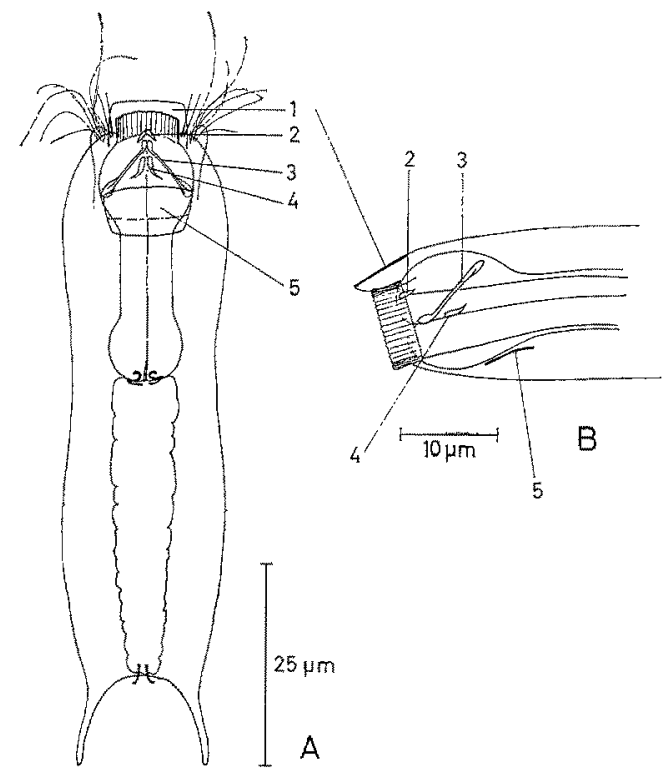

Abb. 20: Heterolepidoderma spec. A Habitus, ohne Kielbedeckung, $B$ vorderer Pharynxabschnitt seitlich gesehen, Kielbedeckung und Bewimperung weggelassen. 1 Kephalion; Mundbew affnung: 2 Winkel, 3 Leisten, 4 Höcker; 5 Hypostomion

Kiele vorhanden, das ventrale $Z$ wischenfeld war nadkt. Die Kiele einer Längsreihe schlossen knapp aneinander, besaßen keine Basisschuppen, erhoben sich nach hinten zu lamellenartig und liefen in eine kurze Spitze aus.

Die Ventralbewimperung bildete unter der vorderen Pharynxhälte ein geschlossenes Feld, $a b$ da bis zum Rumpfende 2 getrennte Bänder. Dem Mundring benachbart inserierten 2 Paare kurzer, steifer Borsten; seitlich von diesen befanden sich mehrere lange, schlagende Wimpern. Knapp neben den Seitenrändern des Kephalions stand jederseits eine lange, wenig bewegte Wimper, die sich dorsad zurückbog. Etwa $8 \mu \mathrm{m}$ vor den Zehenbasen inserierten die hinteren Tastborsten, denen Basisschuppen fehlten.

In den Pharynx führte ein $3 \mu \mathrm{m}$ hoher Mundring, dessen Durchmesser $8 \mu \mathrm{m}$ betrug. Mit einem Durchmesser von $12 \mu \mathrm{m}$ war der vordere Pharynxbulbus stark erweitert; er enthielt eine kräftig kutikularisierte Murdbewaffnung: 1 Paar $8 \mu \mathrm{m}$ langer, leicht geschwungener Leisten zieht in die dorsalen Pharynxlumina ein und liegt deren dorsalen Wänden an. Die kolbig verdickten Vorderenden der Leisten treffen in Ruhestellung mediad knapp hinter dem Pharynxeingang zusammen, die blattartig verbreiterten Hinterenden scheinen über das Lumen hinaus ein Stück in die Pharynxmuskulatur zu dringen. Knapp vor den vorderen, kolbigen Enden der Leisten liegt ein 
unpaarer, kutikularer Winkel den dorsalen Pharynxzellen an, median uber der ventralen Pharynxfalte. Hinter den Vorderenden der langen Leisten liegt ein Paar 3,5 $\mu \mathrm{m}$ langer, vorne aufeinandertreffender Höcker, deren hintere Enden spitz auslaufen. $\mathrm{Ob}$ diese Bildungen den dorsalen oder ventralen Wänden der beiden oberen Pharynxfalten angelagert sind, konnte nicht sicher beurteilt werden. Die Bewegungen dieser Elemente waren nicht genau zu verfolgen, dürften aber übereinstimmen mit den Bewegungen der gleich gelagerten Kutikularstrukturen von $H$. armatum Sснвом 1966 b. Unter dem vorderen Pharynxbulbus befindet sich ein Hypostomion in der Form eines leicht abgerundeten Trapezes, dessen längere Kanten $11 \mu \mathrm{m}$ und $8 \mu \mathrm{m}$, dessen Seitenkanten etwa $5 \mu \mathrm{m}$ lang waren; diese dünne Platte ist um eine Querachse leicht geknickt. Der hintere Pharynxbulbus erweiterte sich wesentlich weniger als der vordere und mündete in den Darm mit einer kutikularen Versteifung. Der Darm verlief gerade, der After lag am Rumpfhinterrand. Protonephridien wurden nicht beobachtet.

D is $\mathrm{k}$ us s i n. Wiewohl die von mir gefundenen Exemplare nicht adult waren, darf ihre Zugehörigkeit zu einer neuen Heterolepidoderma-Art als sicher gelten. Da nämlich die postembryonale Entwicklung der Chaetonotidae meist nur die Rumpfregion betriff, die Pharynxregion hingegen bei dem Heranreifen der Tiere geringere Veränderungen erfährt (vgl. u. a. REMANE 1936), repräsentieren die signifikanten Merkmale in der vorderen Körperregion dieser juvenilen Heterolepidoderma spec. mit großer Sicherheit die Verhältnisse, wie sie auch bei adulten anzutreffen wären. Deshalb stellt die Mundbewaffnung wohl das hervorragendste Charakteristikum dar; homologisierbare, jedoch z. T. weit weniger differenzierte Bildungen sind bekanntgeworden von $H$. armatum, $H$. istrianum n. sp. und von $H$. hermaphroditum WILKe 1954; aber keine dieser Arten besitzt ein Hypostomion. Der Mangel an Pleuren bei Heterolepidoderma spec. kann kaum als juveniles Merkmal gelten; $H$. armatum und $H$. istrianum besitzen jedoch diese Elemente. Durchaus möglich ist allerdings, daß adulte Heterolepidoderma spec. dorsale Basisschuppen, ventrolaterale Kielreihen, Kiele im ventralen Zwischenfeld und Kielschuppen ventral vor dem Körperhinterrand entwickelt haben.

Heterolepidoderma loricatum nov. spec. (Abb. 21)

Fundort: Alberoni.

Untersuchtes Material: 5 Individuen.

Die Tiere werden 105-110 $\mu \mathrm{m}$ lang, in der Pharynxregion $25 \mu \mathrm{m}$ breit, $30 \mu \mathrm{m}$ breit in der Rumpfregion. Die Zehenlänge beträgt $14 \mu \mathrm{m}$, die Pharynxlänge $31 \mu \mathrm{m}$.

Das Kephalion ist $11 \mu \mathrm{m}$ breit; sein Vorderrand überragt den Mundring nur wenig, sein Hinterrand ist nicht erkennbar. Der vorderen Pharynxregion liegt jederseits ein stark kutikularisiertes, leicht gewölbtes Pleurion an, das etwas mehr ventrad als dorsad übergreift.

Die Kielschuppen bedecken alle Körperregionen mit 9 Längsreihen, die dorsomediane Reihe enthält 20 Schuppen. Jeweils eine laterale Reihe erstreckt sich von den Pleuren bis $z u$ den Zehenbasen. Jederseits verlaufen 2 ventrolaterale und 2 ventrale Reihen kleiner Kielschuppen von der vorderen Pharynxregion bis zu den 6 ventralen Terminalschuppen. Die leicht einwärts gekrümmten Zehen sind stark kutikularisiert. 
Thre Basen tragen dorsal kräftige, annähernd rhombische Platten, deren Innenränder verdickt sind. Diese flachen Elemente überdecken die Seitenränder der dorsomedianen Terminalschuppe, sowie Teile der jederseits letzten Schuppen anderer dorsaler Reihen und werden bei den Spreiz- und Schließbewegungen der Zehen um einen, etwa in ihrem
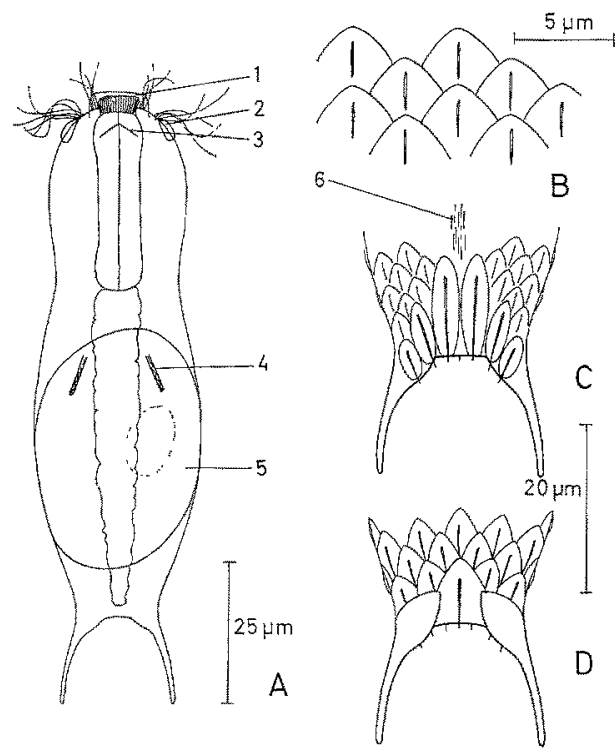

Abb. 21: Heterolepidoderma loricatum nov. spec. A Habitus, ohne Kielschuppenbedeckung, $B$ Kielschuppen aus der mittleren Pharynxregion, $C$ Hinterende ventral, $D$ Hinterende dorsal. 1 Kephalion; 2 Pleuren; 3 Mundbewaffnung; 4 Protonephridien; 5 Ei; 6 ventrale Kiele

Zentrum liegenden Punkt mitgedreht. Sie sind also mit ihren Hinterrändern den Zehen angelagert und vermutlich mit deren Kutikula fest verwachsen. Ab dem Ende der Pharynxregion bis zum inneren Paar der Terminalschuppen erstreckt sich ein ventrales Zwischenfeld, das von 5 Kielreihen bedeckt ist.

Die Schuppen der Dorsalseite nehmen alle die Form abgerundeter Rhomben ein. Sie sind flach und tragen auf etwa 2 Drittel threr Länge wenig erhabene Kiele, die den Schuppen der Pharynxregion zur Gänze anliegen, auf den Schuppen des Rumpfes aber in eine feine Spitze ausgezogen sind, die noch ein wenig über die nachfolgende Schuppe ragt. Der Hinterrand jeder Schuppe wird von den nachfolgenden Schuppen der beiden jeweils benachbarten Reihen überdeckt und ist so schwach kutikularisiert, daß er bloß an den relativ großen Rumpfschuppen zu erkennen ist. Die vordersten Schuppen der Pharynxregion bilden eine unregelmäßige Querreihe längsgezogener, gekielter Elemente, die nicht in einer Linie mit den darauffolgenden Längsreihen stehen. Sie sind $3 \mu \mathrm{m}$ lang. Signifikante Schuppenmaße der dorsomedianen Reihe: die 3. Schuppe (in der Pharynxregion) wird etwas über $4 \mu \mathrm{m}$ lang, die 8 . Schuppe (auf dem Ubergang zum Rumpf) bloß knapp $3 \mu \mathrm{m}$, die 13. Schuppe (auf der vorderen Rumpfhälfte) beinahe $6 \mu \mathrm{m}$, die 16. Schuppe (auf der hinteren Rumpfhälfte) etwa $7 \mu \mathrm{m}$. Bis zu den hintersten dorsalen Schuppen nimmt die Länge kaum mehr ab, die dorsomediane Terminal- 
schuppe aber wird mit $8 \mu \mathrm{m}$ am größten; ihr Kiel ist iiber den leicht gestutzten Hinterrand in eine Spitze verlängert. Die ventrolateralen und ventralen Schuppen entsprechen in allen Körperregionen in Form und Größe den Schuppen der Pharynxregion. Sie tragen kurze Kiele, ihre Hinterränder sind sehr dünn und stellenweise nicht sichtbar. Manchmal fehlen in der innersten ventralen Reihe jederseits einzelne Schuppen; diese Reihe wird in der Pharynxregion nur durch feine, kurze Kiele repräsentiert. Die ovalen ventralen Terminalschuppen liegen schräg hintereinander gestaffelt. Das innerste Paar ist mit $12 \mu \mathrm{m}$ Schuppenlänge das größte; seine kräftigen Stacheln überragen ein wenig den abgestutzten Hinterrand. Das nächste Paar mißt $8 \mu \mathrm{m}$, das hinterste, das schon den Zehenbasen ventral anliegt, etwa $5 \mu \mathrm{m}$.

In der ganzen Pharynxregion bilden die ventralen Wimperbänder ein geschlossenes Feld, mit sehr schmalen Streifen verlaufen sie auf dem Rumpf. Die Tastwimpern inserieren eng beieinander in Raum zwischen Mundring und Pleuren. Noch unter dem Kephalion stehen jederseits 3-5 kürzere Haare, in der Nähe der Pleuren entspringen längere Wimpern in einer büschelförmigen Gruppe.

Der Mundring ist $3 \mu \mathrm{m}$ hoch und hat einen Durchmesser von $7 \mu \mathrm{m}$. Der Pharynx mißt $8 \mu \mathrm{m}$ im Durchmesser, vorne und hinten ist er schwach bulbös erweitert. Im vorderen Bulbus finden sich feine Leisten, die in die oberen Falten des Pharynxlumens einziehen. Der Darm zeigt keine Sonderbildungen, der After mündet zwischen den ventralen Terminalschuppen.

Ein Paar Protonephridien liegt lateral des 1. Darmdrittels. Reife Exemplare tragen ein großes $\mathrm{Ei}$, das die Rumpfregion beinahe völlig erfüllt.

$\mathrm{D}$ iskus $\mathrm{s}$ io n. Seine nächsten Verwandten innerhalb der Gattung findet $H$. loricatum in den anderen, große Schuppen tragenden Arten; nahe steht vor allem $H$. clipeatum n. sp. Beide Arten tragen ähnlich geformte Kielschuppen in gleich viel Längsreihen, sogar die Anzahl der Kielschuppen in der dorsomedianen Reihe ist gleich. Kephalion und Pleuren gemeinsam finden sich bei einigen anderen Arten, bei $H$. clipeatum fehlt das Kephalion. Eigenständigkeit in der Gattung wird für H. loricatum hauptsächlich gesichert durch: ventrolaterale Kielschuppen, die beweglichen Platten auf den Zehenbasen, die 6 ventralen Schuppen auf dem Rumpfhinterrand. (Über die Frage, ob große Kielschuppen tragende Arten zu Heterolepidoderma gestellt werden sollen, siehe Diskussion der Gattung Heterolepidoderma.)

$\mathrm{D}$ i a $\mathrm{g}$ o s e. Heterolepidoderma-Art mit großen rhombischen Kielschuppen. Kephalion und Pleuren vorhanden. Ein Hypostomion fehlt. Kielschuppen auf dem ganzen Körper in 9 dorsalen Längsreihen, in der dorsomedianen Reihe 20. Am Rumpfhinterrand 3 verschieden große Schuppenpaare. Mit den Zehenbasen verwachsene, die Bewegung der Zehen zwangsläufig mitvollziehende Platten. Tastborsten fehlen. Parthenogenetisch. Gesamtlänge des Körpers $105-110 \mu \mathrm{m}$, davon Zehenlänge $14 \mu \mathrm{m}$, Körperbreite in der Pharynxregion $25 \mu \mathrm{m}$, in der Rumpfregion $30 \mu \mathrm{m}$; Pharynxlänge $31 \mu \mathrm{m}$. 
Fundort: Rovinj.

Untersuchtes Material: 12 Individuen.

Die Gesamtlänge mißt $125 \mu \mathrm{m}$, der Pharynx ist $36 \mu \mathrm{m}$ lang. Die Breite der Pharynxregion beträgt durchgehend etwa $26 \mu \mathrm{m}$ und verringert sich am Übergang zum Rumpf nur wenig. Der Rumpf wird nach hinten zu langsam breiter, seine größte Breite von $35 \mu \mathrm{m}$ erreicht er erst in seinem letzten Drittel; bis zu den Zehenbasen verschmälert er sich auf $24 \mu \mathrm{m}$. Die stark einwärts gekrümmten Zehen sind $21 \mu \mathrm{m}$ lang, wovon etwa $4 \mu \mathrm{m}$ auf die leicht knotig erweiterten Zehenbasen entfallen.

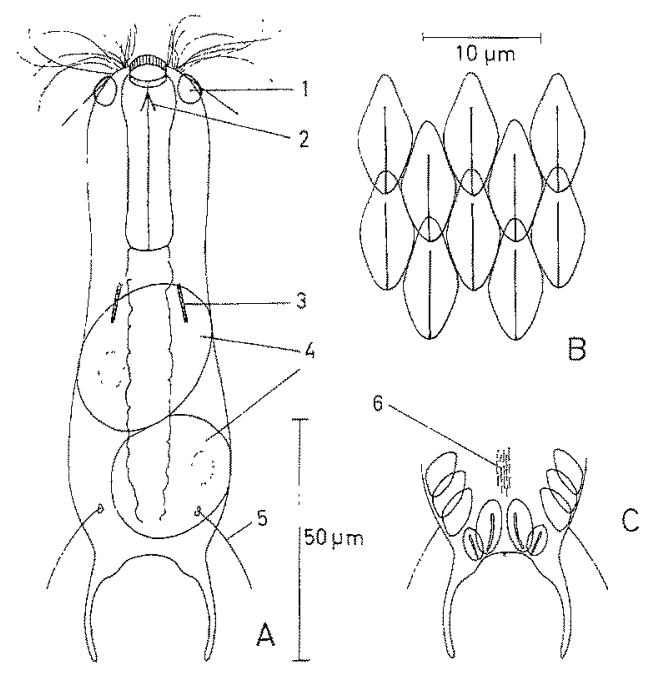

Abb. 22: Heterolepidoderma clipeatum nov. spec. A Habitus, ohne äußere Kutikularelemente, $B$ dorsale Kielschuppen aus der hinteren Rumpfregion, $C$ Hinterende ventral. 1 Pleuren; 2 Mundbewaffnung; 3 Protonephridien; 4 Eier; 5 dorsale Tastborsten; 6 ventrale Kiele

Das Vorderende trägt ein Paar kleiner, jedoch stark kutikularisierter Pleuren, die sich auf lateral und ventrolateral beschränken. Ein Kephalion fehlt.

Die dorsalen Kielschuppen verlaufen über den ganzen Körper in 9 Längsreihen; die dorsomediane Reihe zählt 20 Kielschuppen. Kielschuppen bilden ferner jederseits 2 laterale Reihen und $z u$ viert eine Gruppe auf der Ventralseite des Rumpfendes. Von den Pleuren bis zu den Zehenbasen erstreckt sich auf beiden Körperseiten je eine ventrolaterale Reihe kielloser, annähernd ovaler Schuppen.

Die dorsalen Schuppen sind rhombisch und an ihren Ecken leicht abgerundet. Seitlich stoßen sie mit den Schuppentändern der benachbarten Reihen zusammen, in der Längsrichtung überlappen sie dachziegelartig jeweils ein Viertel der nachfolgenden Schuppe; die freibleibende Schuppenoberfläche trägt einen niedrigen Kiel. Die Schuppen der lateralen Reihen entsprechen in ihrer Form den dorsalen. Die ventralen Schuppen am Rumpfhinterende sind oval und tragen stark kutikularisierte Kiele, die sich auf 
dem mittleren Schuppenpaar ein wenig laterad krümmen. In der Darmregion wird das ventrale $Z$ wischenfeld von 5-7 Reihen kräftiger Kiele bedeckt, die auf schwach kutikularisierten Basisschuppen liegen.

Die Längenmaße einiger dorsomedianer Schuppen aus verschiedenen Körperregionen: die dem rostralen Rand zunächstliegende Schuppe mißt ca. $3 \mu \mathrm{m}$, auf der mittleren Pharynxregion 5,5 $\mu \mathrm{m}$, am Ende der Pharynxregion ca. $4 \mu \mathrm{m}$, auf der breitesten Stelle des Rumpfes beinahe $10 \mu \mathrm{m}$; weiter nach hinten zu werden die Schuppen ein wenig kürzer, mit $11 \mu \mathrm{m}$ ist die dorsomediane Terminalschuppe wiederum länger. Die ventrolateralen Schuppen sind in der vorderen Pharynxregion kreisrund und mit etwas weniger als $3 \mu \mathrm{m}$ Durchmesser sehr klein, werden aber nach hinten zu rasch größer und länglicher, in der 2. Rumpfhälfte mißt ihre Länge ca. $10 \mu \mathrm{m}$. Die Schuppen des mittleren Paares am Rumpfende sind $10 \mu \mathrm{m}$ lang, die ihnen seitlich benachbarten $7 \mu \mathrm{m}$.

Die ventralen Wimperbänder verlaufen über die ganze Körperlänge hin getrennt. Zwischen Pleuren und Mundring inserieren jederseits 8-10 Wimpern; die dem Mundring benachbarten sind mit $10 \mu \mathrm{m}$ etwa halb so lang wie die nahe den Pleuren stehenden. 8-10 $\mu \mathrm{m}$ vor den Zehenbasen inserieren dorsal etwa $20 \mu \mathrm{m}$ lange Tastborsten auf dreieckigen Basisschuppen.

Der Mundring ist $2 \mu \mathrm{m}$ hoch und führt direkt in den $12 \mu \mathrm{m}$ dicken vorderen Pharynxbulbus, der ein Paar feiner, rostrad sich berührender Leisten enthält. Der Durchmesser des Pharynx beträgt hinter dem vorderen Bulbus etwa $9 \mu \mathrm{m}$ und nimmt nach hinten wiederum langsam zu, ohne einen deutlich abgesetzten, hinteren Bulbus zu bilden. Der Darm verläuft gerade; ob der After vor den ventralen Terminalschuppen oder an der hinteren Rumpfkante mündet, entzog sich der Beobachtung.

Ein Paar Protonephridien liegt im 1. Drittel der Darmregion. Ein großes Ei oder 2 kleinere liegen über dem Darm.

D iskussion. Die Schuppenform von $H$. clipeatum ähnelt der von $H$. loricatum, auch die Anzahl der dorsalen Längsreihen und der Schuppen einer Reihe ist bei beiden Arten gleich; in allen übrigen Merkmalen weichen sie jedoch voneinander ab. Im Gegensatz zu $H$. clipeatum besitzt $H$. loricatum ein Kephalion. Die ventrolateralen Strukturen sind sehr verschieden, ebenso die ventroterminalen Elemente. Hintere Tastborsten fehlen bei $H$. loricatum, bei $H$. clipeatum sind sie vorhanden. Mit den anderen Arten der Gattung hat $H$. clipeatum, außer dem vereinenden Merkmal der dorsalen Kielschuppen, wenig gemeinsam. Vor allem die niedrige Schuppenzahl stellt sie abseits von den meisten übrigen Mitgliedern des Genus (siehe Diskussion der Gattung Heterolepidoderma).

Di a g n os e. Heterolepidoderma-Art mit großen rhombischen Kielschuppen. Pleuren vorhanden, Kephalion und Hypostomion fehlen. Kielschuppen über den ganzen Körper hin in 9 Längsreihen, in der dorsomedianen Reihe 20. Am Rumpfhinterrand ein Paar großer und ein Paar kleiner Kielschuppen. Ventrolaterale Schuppen ohne Kiele. Hintere Tastborsten vorhanden. Parthenogenetisch. Gesamtlänge des Körpers $125 \mu \mathrm{m}$, davon Zehenlänge $21 \mu \mathrm{m}$; Körperbreite in der Pharynxregion $26 \mu \mathrm{m}$, in der Rumpfregion $35 \mu \mathrm{m}$; Pharynxlänge $36 \mu \mathrm{m}$. 
Heterolepidoderma contectum nov. spec. (Abb. 23)

Fundort: Rovinj.

Untersuchtes Material: 8 Individuen.

Bei einer Gesamtlänge von $115 \mu \mathrm{m}$, wovon $22 \mu \mathrm{m}$ auf die Länge der Zehen entfallen, bei $28 \mu \mathrm{m}$ Breite in der Pharynxregion und einer Rumpfbreite von $38 \mu \mathrm{m}$ wirkt der Körper dieser Art sehr gedrungen. Die Zehen sind an ihrer Basis stark verdickt und leicht mediad gekrümmt. Die Länge des Pharynx beträgt $36 \mu \mathrm{m}$.

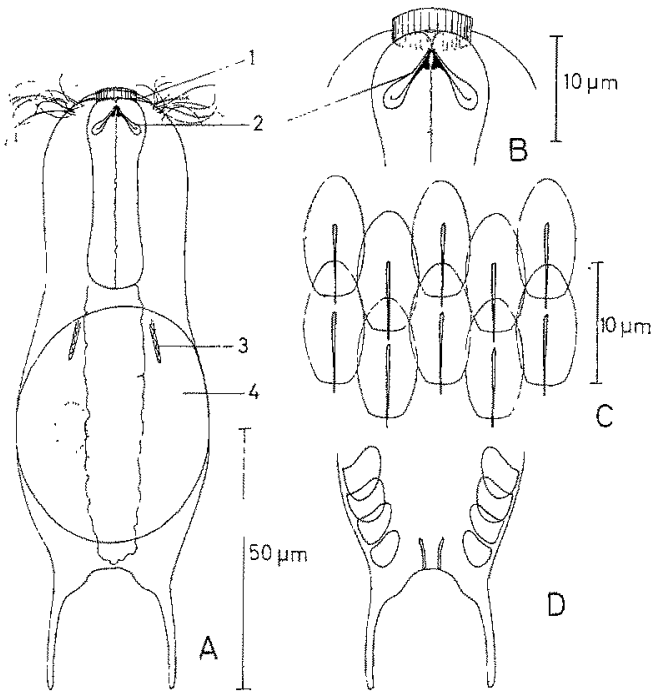

Abb. 23: Heterolepidoderma contectum nov. spec. A Habitus, ohne äußere Kutikularelemente, $B$ vorderer Pharynxabschnitt, $C$ dorsale Kielschuppen aus der mittleren Rumpfregion, $D$ Hinterende ventral. 1 Kephalion; 2 Mundbewaftnung; 3 Protonephridien; 4 Ei. Gemeinsamer Maßstab für $A$ und $D$

Pleuren fehlen. Das sehr schmale und mit dem rostralen Rand parallele Kephalion überragt den etwas vorstehenden Mundring nicht.

Die Verteilung der dorsalen Schuppen ist sehr gleichmäßig. Ober alle Körperregionen hin verlaufen 7 dorsale Kielschuppenreihen, denen sich seitlich eine bereits ein wenig laterad geneigte Reihe anschließt. Die dorsomediane Reihe wird von 15 Schuppen gebildet. Auf dem Rumpf befindet sich jederseits eine ventrolaterale Reihe großer, doch sehr schwach kutikularisierter, kielloser Schuppen. An einem Exemplar begann diese Reihe mit kleinen Schuppen schon in der hinteren Hälfte der Pharynxregion; bedingt durch ihre geringe Dicke und undeutliche Abgrenzung sind diese Schuppen schwer zu sehen, möglicherweise beginnt ihre Reihe noch weiter vorn. Das ventrale

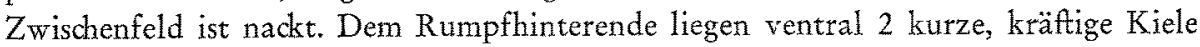
ohne Basisschuppen an.

In allen Körperregionen ist die Form der dorsalen Schuppen gleich: oval, hinten ein wenig quer gestutzt und überall etwa doppelt so lang als breit. Alle dorsalen Schup- 
pen tragen Kiele, die an ihrem distalen Rand etwas verdickt sind und mit dünnen, niedrigen Lamellen auf der hinteren Hälfte ihrer Basisschuppen inserieren; deren Hinterrand überragen sie mit einer feinen Spitze noch ein kleines Stück. Einige Schuppen am Ende der Pharynxregion besitzen diese Spitze nicht. Auf der Pharynx- und Rumpfregion überlappen die vorangehenden Schuppen die nachfolgenden etwa zu einem Viertel ihrer Länge, ein wenig mehr auf dem Übergang von der Pharynx- zur Rumpfregion. Die Seitenränder der Schuppen benachbarter Reihen überdecken sich nur geringfügig. Durch die Gleichzahl der Längsreihen in allen Körperabschnitten bedingt, sind die dorsalen Schuppen in der Pharynxregion mittelgroß, am kleinsten auf der schmalsten Stelle des Körpers und auf der mittleren Rumpfregion am größten; auf dem Rumpfende sind sie wiederum kleiner. Die Länge der Schuppen aus der dorsomedianen Reihe beträgt in der vorderen Pharynxregion fast $4 \mu \mathrm{m}$, in der mittleren Pharynxregion etwas über $5 \mu \mathrm{m}$, am Übergang zum Rumpf $4 \mu \mathrm{m}$, am Ende der 1 . Rumpfhälfte aber über $10 \mu \mathrm{m}$, die letzte Schuppe dieser Reihe mißt $6,5 \mu \mathrm{m}$. Die ventralen Terminalkiele sind $6 \mu \mathrm{m}$ lang. Die ventrolateralen Schuppen sind in der Pharynxregion rund bis oval, auf dem Rumpf entspricht ihre Form vorne eingedellten Ovalen.

Die ventralen Wimperbänder vereinigen sich unter dem Pharynx. Die vorderen Tastwimpern bilden jederseits des Mundringes ein kleines Feld, das sich ein wenig ventralwärts ausdehnt.

Der Mundring hat einen Durchmesser von $8 \mu \mathrm{m}$ und ist $2 \mu \mathrm{m}$ hoch. Der Pharynx besitzt vorne und hinten schwache Bulbusbildungen. Der Durchmesser des Pharynx in seinem mittleren Abschnitt beträgt $9 \mu \mathrm{m}$. Der vordere Bulbus enthält ein Paar außerordentlich kräftiger Spangen, die gegen die Mediane tropfenförmig verdickt sind und nach hinten mit blattartig verbreiterten Enden in die dorsalen Wände der oberen Pharynxlumina ziehen. Von den proximalen Verdickungen erstrecken sich leicht gekrümmte Versteifungsleisten bis auf die distalen Verbreiterungen. Zwischen den ventralen Terminalkielen mündet der After.

An den Seiten des 1. Darmdrittels liegt 1 Paar Protonephridien, deren Geißelkolben etwa $7 \mu \mathrm{m}$ lang werden. Der Raum über dem Darm wird von einem großen Ei fast zur Gänze eingenommen.

D is kus s i n. Selbst in der Gruppe der großschuppigen HeterolepidodermaArten findet sich kein naher Verwandter von $H$. contectum. Die großen, kräftigen und beinahe ovalen Basisschuppen der Dorsalseite mit ihren stark kutikularisierten Kielen, die den Hinterrand der Schuppe mit einer Spitze überragen, sind in der Gattung einzigartig und gemahnen an die Verhältnisse bei Halichaetonotus aculifer. Die Zugehörigkeit zur Gattung Heterolepidoderma wird aber durch die stachellosen ventrolateralen Schuppen erhalten. Innerhalb des Genus besitzt $H$. contectum die stärkste Mundbewaffnung.

Di a g n o e. Heterolepidoderma-Art ohne Pleuren und Hypostomion; Kephalion vorhanden. Schuppen oval, hinten leicht abgestutzt; die Kiele in der Pharynx- und Rumpfregion zu feinen Spitzen ausgezogen. Kielschuppen in 7 dorsalen Längsreihen, in der dorsomedianen Reihe 15. 2 kurze Kiele auf der Ventralseite des Rumpfendes. Tastborsten fehlen. Vorderer Pharynxbulbus mit sehr kräftigen Kutikularspangen. Parthenogenetisch. Gesamtlänge des Körpers $115 \mu \mathrm{m}$, davon Zehenlänge $22 \mu \mathrm{m}$; Kör- 
perbreite in der Pharynxregion $28 \mu \mathrm{m}$, in der Rumpfregion $38 \mu \mathrm{m}$; Pharynxlänge $36 \mu \mathrm{m}$.

Diskussion der Gattung Heterolepidoderma. Bei durchwegs einheitlicher innerer Morphologie stellen gekielte Schuppen gemeinsam mit dem Mangel an stacheltragenden Schuppen ein Merkmals-Paar dar, das für die Gattung Heterolepidoderma definitorischen Inhalt besitzt. Alle anderen kutikularen Bildungen kommen bei den Mitgliedern der Gattung nur verstreut vor und entbehren somit der diagnostischen Signifikanz für das Genus im gesamten. Pleuren und Kephalion sind gemeinsam vertreten bei: $H$. marinum Remane $1926 \mathrm{~b}, H$, armatum Schrom $1966 \mathrm{~b}, H$. istrianum n. sp., H. loricatum n. sp., H. ocellatum Metschnikofp 1865 und H. gracile Remane 1927b; Pleuren fehlen, wohl aber ist das Kephalion vorhanden bei: H. majus Remane 1927b, H. contectum n. sp. und $H$. spec.; das Kephalion fehlt, Pleuren sind vorhanden bei: $H$. clipeatum n. sp. Nicht sicher ist, ob auch $H$. fallax Remane 1936 und $H$. bermaphroditum WILKE 1954 die genannten Elemente besitzen.

REMANE (1936) hat eine hohe Schuppenzahl als charakteristisch für die Gattung Heterolepidoderma angesehen. Jene neueren Funde aber, $H$. armatum und $H$. istrianum, die ihre nahe Verwandtschaft mit $H$. marinum vor allem durch die Anordnung der dorsalen Kiele beweisen, verwischen die Grenzen zwischen schuppenreich und schuppenarm und ermöglichen damit für eine Reihe neuer Arten die, vielleicht nur vorläufige Zuordnung zu diesem Genus.

Während nämlich $H$. marinum, wie auch $H$. majus und $H$. gracile 25 dorsale Längsreihen besitzt, tragen $H$. armatum und $H$. istrianum 17 Reihen und lassen daher denkbar werden, daß der Anschluß der Gattung Heterolepidoderma zu den Gattungen Halichaetonotus und Chaetonotus über die großschuppigen Arten $H$. contectum (mit 7 Längsreiben), $H$. loricatum und $H$. spec. (beide mit 9 Längsreihen) zu suchen ist. Diese letzteren 3 Arten, die in Ermangelung ventrolateraler Stachelreihen nicht zu Halichaetonotus gerechnet werden können, stehen womöglich weniger auf Grund ihrer geringen Schuppenzahl im Kontrast zu den anderen Vertretern des Genus, sondern eher durch die nicht unbeträchtliche, gegenseitige Überlappung ihrer immer kräftig gerandeten Schuppen. Denn bei den anderen Heterolepidoderma-Arten uberdecken sich die Basisschuppen nie; eher neigen sie zudem zur Reduktion, wie sie bei $H$. armatum angebahnt und bei $H$. istrianum vollzogen ist. Die Arten $H$. loricatum, $H$. spec. und $H$. contectum nehmen mithin innerhalb der Gattung eine Sonderstellung ein und werden vermutlich, sobald sich dieser Formenkreis durch neue Funde erweitert hat, die Grundlage zu einem neuen Genus bilden können, das zwischen Halichaetonotus und Heterolepidoderma vermittelt.

Mit welchen Schwierigkeiten eine systematische Einordnung der Arten aus dem Kreis Chaetonotus, Halichaetonotus und Heterolepidoderma verbunden ist, führt eine weitere Art vor Augen: Heterolepidoderma foliatum Renaud-Mornant 1967. Wiewohl die dorsalen Kielschuppen in Form und Verteilung am nächsten mit H. marinum vergleichbar sind, besitzt diese Art nicht nur kleine Stachelschuppen zwischen den Zehenbasen, sondern auch jederseits des ventralen Wimpferfeldes eine Reihe blattartiger Lamellen, die ohne Basisschuppen am Körper inserieren. Ein endgültiges Urteil über die Gattungszugehörigkeit dieser Art wird erst gefällt werden können, wenn größere Sicherheit in der phylogenetischen Entwicklung der Stachelschuppen und ihrer 
Derivate (lamellentragende Schuppen; Kielschuppen; basislose Stacheln, Lamellen, Kiele; unskulpturierte Basisschuppen etc.) gewonnen ist. Hummon (1969) stellt die Art in die Gattung Chaetonotus.

Lepidodermella limogenum nov. spec. (Abb. 24)

Fundort: Alberoni, lagunenseitig.

Untersuchtes Material: 13 Individuen.

Die Gesamtlänge mißt maximal $126 \mu \mathrm{m}$, wovon die Zehen $15 \mu \mathrm{m}$ einnehmen; die verdickten Zehenbasen sind $7 \mu \mathrm{m}$ lang, auf die eigentlichen Haftröhrchen entfallen somit nur $8 \mu \mathrm{m}$. Die Pharynxregion erreicht eine Breite von $26 \mu \mathrm{m}$, der mittlere Rumpfabschnitt $32 \mu \mathrm{m}$. Am Ubergang von der Pharynx-zur Rumpfregion ist der Körper bloß wenig verschmälert und erhält dadurch eine gedrungene Form. Die Länge des Pharynx beträgt 31-33 $\mu \mathrm{m}$.

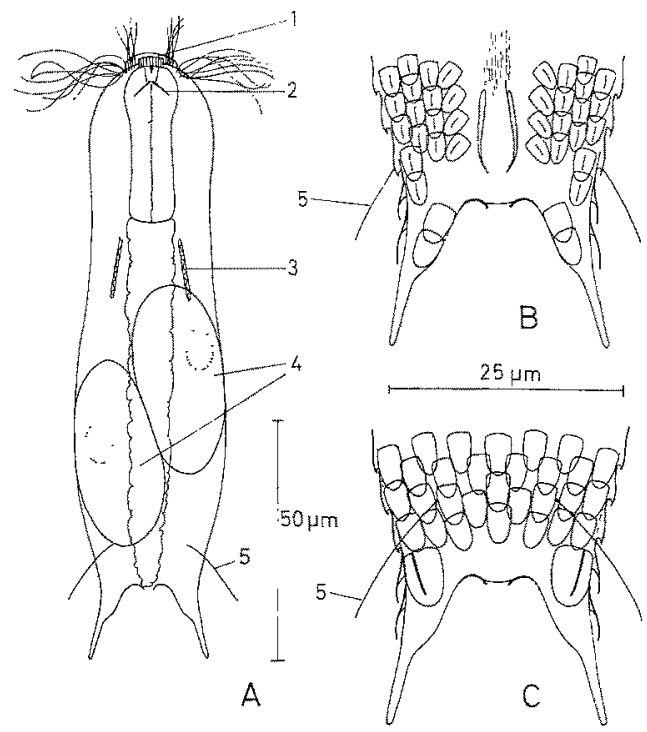

Abb. 24: Lepidodermella limogenum nov. spec. A Habitus, ohne äußere Kutikularelemente, $B$ Hinterende ventral, $C$ Hinterende dorsal. 1 Kephalion; 2 Mundbewaffnung; 3 Protonephridien; 4 Eier; 5 dorsale Tastborsten

Das $11 \mu \mathrm{m}$ breite Kephalion überragt die rostrale Kontur kaum und zeigt keine deutliche hintere Begrenzung. Pleuren sind nicht vorhanden.

Die Verteilung der Schuppen ist mit 13 Längsreihen auf der Dorsalseite des gesamten Körpers sehr gleichmäßig. Die dorsomediane Reihe besteht aus 34 Elementen. Lateral erstreckt sich jeweils eine Reihe vom rostralen Rand bis zu den Zehen; dort sind die letzten beiden Schuppen vergrößert, die hintere liegt jederseits der verdickten Zehenbasis an. Etwa $5 \mu \mathrm{m}$ vor dem Rumpfende lassen die dorsalen Reihen eine nackte 
Fläche frei, die lateral von jeweils einer großen Schuppe begrenzt wird; diese großen Schuppen neigen sich mediad und bedecken mit ihrem hinteren Drittel noch ein Stück die Dorsalseite der Zehenbasen. Ventrolateral verlaufen zu beiden Seiten der ventralen Bewimperung jeweils 4 Reihen kleiner Schuppen von der vorderen Pharynxregion bis knapp vor die Basis der Haftröhrchen. Alle Schuppen der beiden innersten dieser Reihen stehen auswärts gekehrt. 2 größere, hintereinanderliegende Schuppen setzen jederseits die beiden äußeren Reihen noch bis zum Rumpfende fort, das die beiden inneren Reihen nicht erreichen. Die Zehenbasis wird an ihrer inneren Ventralseite von 2 großen Schuppen bedeckt, nach außen $z u$ ist sie nackt. Das ventrale $Z$ wischenfeld ist in der Rumpfregion von 8-10 Kielreihen bestanden, die bis zu 2 langen, eng beieinanderliegenden, terminalen Schienen führen. Zwischen den Zehenbasen ist der Rumpfhinterrand stark kutikularisiert, ohne jedoch ein distinktes Kutikularelement zu bilden.

In allen Körperregionen sind die Schuppen wappenschildförmig, mit geschwungenem, verdicktem Vorderrand. Die dorsalen und lateralen Schuppen tragen keine Kiele, wohl aber die ventrolateralen, und jene beiden, die das dorsale, schuppenlose Feld am Rumpfhinterende seitlich begrenzen. Die ventral den Zehenbasen anliegenden Schuppen sind ungekielt. Durch ihre Quer- und Längswölbung bilden alle Schuppen kleine Kalotten. Wiewohl sie sich in der Längsrichtung dachziegelartig ein wenig überdecken, sind sie - dies läßt sich bei Aufsicht am besten an den lateralen Elementen beobachten - zur Gänze der Epidermis angelagert, die sich also nicht nur buckelartig erhebt, um zum Vorderrand der folgenden Schuppe wieder abzusinken, sondern selbst an der Überlappung teilnimmt. Dadurch liegen die Vorderränder der Schuppen in einem epidermalen Falz. In der hintersten Körperregion überdecken sich die Schuppen auch seitlich etwas. Länge und Breite der Schuppen betragen: in der vorderen Pharynxregion 2,1-2,8 $\mu \mathrm{m}$ und 1,4-1,5 $\mu \mathrm{m}$, in der mittleren Pharynxregion 3,5 $\mu \mathrm{m}$ und 2,2 $\mu \mathrm{m}$, am Ubergang von der Pharynxregion 'zum Rumpf $2,8 \mu \mathrm{m}$ und $1,8 \mu \mathrm{m}$, in der mittleren Rumpfregion 4-4,2 $\mu \mathrm{m}$ und 2,7-2,9 $\mu \mathrm{m}$. Die beiden dorsolateralen Endschuppen sind $6,3 \mu \mathrm{m}$ lang und $4,2 \mu \mathrm{m}$ breit. Die Schuppen der ventrolateralen Reihen sind mit $2,8 \mu \mathrm{m}$ Länge und $2,1 \mu \mathrm{m}$ Breite alle etwa gleich groß. Ein wenig größer sind dagegen die hintersten 2 ventrolateralen; die Ventralschuppen der Zehenbasen messen $4 \mu \mathrm{m}$ in der Länge und $2,8 \mu \mathrm{m}$ in der Breite. Die terminalen Schienen auf der Ventralseite werden $8,4 \mu \mathrm{m}$ lang.

Die ventrale Bewimperung befindet sich zum vorwiegenden Teil in der Pharynxregion, wo sie ein großes Feld bildet, das nur sehr schmale und von wenig Wimpern bestandene Bänder caudad entsendet. Die vorderen Tastwimpern sind deutlich in jederseits 2 Büschel getrennt. Das orale, immer nach vorne weisende, besteht aus 5 etwa $10 \mu \mathrm{m}$ langen, ziemlich steifen Borsten, die unterhalb dem Kephalion inserieren. Das sich laterad und rückwärts neigende Büschel enthält ca. 8 feine Wimpern, die doppelt so lang werden und kräftig schlagen. Auf dem Hinterrücken inseriert ein Paar steifer Tastborsten.

Der stark geriefte Mundring ist 2,5 $\mu \mathrm{m}$ hoch, sein Durchmesser beträgt $5 \mu \mathrm{m}$. Knapp hinter ihm liegt ventromedian vor dem Pharynxeingang ein stark kutikularisierter Höcker. Dahinter, in den dorsalen Lumina des vorderen Pharynxbulbus, sind 2 Paare feiner Spangen zu beobachten: das vordere, kürzere Paar neigt sich nach hinten $\mathrm{zu}$ ein wenig gegen die Mediane und triff mit seinen caudalen Enden auf längere, 
mediad keulenförmig verdickte Elemente, die in der Mitte aneinanderstoßen und distal in die dorsalen Falten einziehen. Die beiden Spangenpaare werden wenig bewegt, sie treten bei der Erweiterung des Pharynxlumens während des Schluckvorganges nur seitlich auseinander und scheinen keinen Einfluß auf den Transport der aufgenommenen Nahrung zu haben. Dies ist um so wahrscheinlicher, da die im Phasenkontrastbild sehr gut unterscheidbaren Wandzellen des vorderen Pharynxbulbus sich wie bei allen Bulbusbildungen der Gastrotrichen radiär um den Mittelpunkt des Bulbus ordnen. Sie vermögen daher bei ihrer Kontraktion den ihnen angelagerten Spangen nur distal gerichtete Bewegungen mitzuteilen. Muskelzüge, die in andere Richtungen wirken könnten, sind nicht vorhanden. Der Durchmesser des vorderen Bulbus beträgt $11 \mu \mathrm{m}$, der des mittleren Pharynxabschnittes $9 \mu \mathrm{m}$. An seinem hinteren Ende ist der Pharynx nur wenig erweitert. Der Darm verläuft gerade, der After mündet am Hinterrand des Rumpfes.

Lateral des vordersten Darmabschnittes liegt ein Paar Protonephridien, deren Geißelkolben $13 \mu \mathrm{m}$ lang sind. Die Zahl der Eier beträgt zumeist 2, selten 1 oder 3.

$D$ iskus sion. Nicht nur der Besitz ventrolateraler Kielschuppen räumt $L$. limogenum eine Sonderstellung in der Gattung ein, auch die eigenartigen Kielschuppen dorsal an den Zehenbasen, die nackten Schuppen ventral vor den Haftröhrchen und die Mundbewaffnung rücken sie ab von den anderen Lepidodermella-Arten. Die Schuppenform ist jener von L. squammatum (DUjardiN 1841) ähnlich.

D i a g n o s e. Lepidodermella-Art mit ventrolateralen Kielschuppen. Kephalion vorhanden; Pleuren und Hypostomion fehlen. 13 dorsale Schuppenlängsreihen in allen Körperregionen; die dorsomediane Reihe besteht aus 34 Schuppen. An den Zehenbasen: ventral jederseits 2 hintereinanderliegende, nackte Schuppen, dorsal je eine große gekielte Schuppe. Ventral 1 Paar terminaler Kiele. Hintere dorsale Tastborsten vorhanden. Parthenogenetisch. Gesamtlänge des Körpers 120-126 $\mu \mathrm{m}$, davon Zehenlänge $15 \mu \mathrm{m}$; Körperbreite in der Pharynxregion $26 \mu \mathrm{m}$, in der Rumpfregion $32 \mu \mathrm{m}$; Pharynxlänge $31 \mu \mathrm{m}$.

\section{Aspidiophorus mediterraneus REMANE $1927 \mathrm{~d}$}

Fundorte: Alberoni seeseitig und lagunenseitig, S. Nicolo, Pta. Sabbioni; Caorle; Rovinj.

Untersuchtes Material: 90 Individuen.

Von den ersten adriatischen Funden dieser Art (SCHRoM 1966b) wurden bereits einige Körpermaße notiert. Zahlreiches neues Material aus dem venezianischen Gebiet und von Rovinj ermöglicht nun, die morphologischen Kenntnisse weiter zu vervollständigen, und die Variabilität einiger Merkmale vorläufig qualitativ zu analysieren.

Die Gesamtlänge adulter Tiere aus dem venezianischen Material beträgt 115 bis $210 \mu \mathrm{m}$, die Länge der Zehen 15-20 $\mu \mathrm{m}$, die Pharynxlänge 35-60 $\mu \mathrm{m}$. Die bei Rovinj gefangenen adulten Exemplare besitzen eine Gesamtlänge von 125-160 $\mu \mathrm{m}$, eine Zehenlänge von 20-28 $\mu \mathrm{m}$ und eine Pharynxlänge von 35-50 $\mu \mathrm{m}$.

Der Körper ist am Ende der Pharynxregion nur wenig verschmälert; je nach dem 
Dottergehalt des einen Eies (oder der maximal 2 Eier) ist der Rumpf schlank bis stark aufgetrieben. Einige Tiere tragen dorsal am Übergang des Rumpfes zu den Zehenbasen ein Paar mediad gerichteter, schwielenförmiger Verdickungen.

Das Kephalion besitzt einen leicht geschwungenen, den Mundring wenig überragenden Vorderrand; der hintere Abschluß des Kephalions ist der schwachen Kutikularisierung wegen nicht erkennbar.

Die Stielschuppen bilden dorsal eine iber den ganzen Körper hin gleiche Anzahl von $L a ̈ n g s r e i h e n$, die allerdings von Individuum $z u$ Individuum sehr verschieden sein kann: je nach dem seitlichen Abstand der Längsreihen tragen große Tiere 13-17, kleine Tiere 11-15 Reihen. Ventrolateral verlaufen in der Pharynxregion jederseits 2-3, in der Rumpfregion 4-6 Längsreihen schwach kutikularisierter Stielschuppen. Mit der unterschiedlichen Längsausdehnung der Stielschuppen-Endplatten varijert auch die Anzahl der Stielschuppen in den Längsreihen - in der dorsomedianen zwischen 30 und 50. Das Längenmaß der Endplatten beträgt bei großen Exemplaren (mit 30-35 dorsomedianen Stielschuppen) zumeist 5-7 $\mu \mathrm{m}$, bei kleineren Exemplaren (mit 35-50 dorsomedianen Stielschuppen) hingegen meist bloß 2-4 $\mu \mathrm{m}$. Die Stielschuppen-Endplatten sind oval, bei großen Tieren jedoch stärker längsgestreckt als bei kleinen Tieren, deren Endplatten oft beinahe kreisrund sind. Uber die Endplatte verläuft ein mehr oder weniger ausgeprägter Kiel. Bei manchen kleinen Tieren sind die Endplatten nur schwach kutikularisiert, namentlich deren Hinterrand kaum erkennbar.

Dorsal vor den Zehenbasen besitzen die meisten kleineren Tiere ein Paar kutikularisierter Bögen, die das Feld der Stielschuppen caudad scharf begrenzen. Die beiden medianen Enden dieser Bögen überragen den Rumpfhinterrand ein kleines Stück. Exemplare, die diese Bildungen tragen, besitzen ventral am Körperende immer ein Paar längsliegender, schmaler Schienen, die ebenfalls in kurze, freie Spitzen ausgezogen sind.

Die ventrale Bewimperung ist in der Pharynxregion dicht und kräftig; sie bildet hier 2 getrennte Bänder, die sich mit schütter stehenden Wimpern in die Rumpfregion fortsetzen, zu deren Beginn jedoch die Trennung der Bänder durch verstreut die Ventalseite bedeckende Wimpern verwischt wird. In der hinteren Hälfte der Rumpfregion sind nur mehr wenige Wimpern vorhanden. Jederseits des Kephalions steht eine Gruppe von 6-8 kurzen Tastwimpern (5-8 $\mu \mathrm{m}$ Länge), der sich weiter laterad eine Gruppe von etwa 5 ungefähr doppelt so langen Wimpern anschließt. Alle untersuchten Exemplare besitzen ein Paar dorsolateraler Sinneshaare, die ca. $10 \mu \mathrm{m}$ vor den Zehenbasen auf kleinen Papillen inserieren. Häufig jedoch tragen kleine Tiere solche Sinneshaare auch am Ende der Pharynxregion.

Der stark geriefte Mundring ist $5 \mu \mathrm{m}$ hoch, sein Durchmesser beträgt etwa $8 \mu \mathrm{m}$. Der Pharynx ist vorne und hinten kaum verdickt. Seinem Vorderende ist ventral ein trapezförmiges Hypostomion angelagert. Der Eingang in das Pharynxlumen ist auf einer Länge von ungefähr $6 \mu \mathrm{m}$ kutikular ausgekleidet. Bei günstigen Beobachtungsverhältnissen scheint diese Bildung die Form eines hohlen Doppelkegels zu haben; an manchen Exemplaren ist mit Sicherheit jedoch nur eine paarige, auf halber Länge mediad geknickte Kontur zu erkennen; zwischen deren hinteren Schenkeln sich aber immer ein medianer, kräftig lkutikularisierter Höcker befindet, der dorsalen Kante des Pharynxlumens ansitzend. In den Zellen des hinteren Pharynxendes ist ein Paar leicht 
geschwungener Stacheln verankert; jeder Stachel ist starr verbunden mit einer S-förmigen Spange, die in die vordersten Darmzellen eindringt. Sowohl die vorderen als auch die hinteren kutikularen Elemente des Pharynx zeigen bei dem Schluckvorgang keinerlei Lageveränderung. Nur die hinteren Spangen scheinen manchmal ein wenig seitwärts auszuweichen, sobald die Kontraktionswelle der Pharynxzellen das Pharynxende erreicht hat. Der die S-förmigen Spangen beherbergende vorderste Darmabschnitt ist völlig frei von Granula und setzt sich damit gegen die darauffolgenden, reich granulierten Darmzellen deutlich ab. Der After mündet terminal.

Ein Paar Protonephridien befindet sich etwa $20 \mu \mathrm{m}$ hinter dem Pharynxende; die Geißelkolben sind ca. $10 \mu \mathrm{m}$ lang und liegen dem Darm dorsolateral eng an. An den meisten kleineren Tieren konnte nur ein mehr oder weniger dotterreiches Ei beobachtet werden, das den ganzen Raum dorsal des Darmes erfüllte. Große Exemplare besitzen hingegen regelmäßig 2 Eier hintereinander angeordnet; das vordere, meist doppelt so groß als das hintere, ragt weit in die Pharynxregion hinein.

\section{ZUSAMMENFASSUNG}

1. 22 neue und 8 bereits bekannte Gastrotrichen-Arten werden beschrieben, die - mittels $\mathrm{MgCl}$-Extraktion gewonnen - eulitoralen und sublitoralen Sandböden der nördlichen Adria entstammen und mit Phasenkontrast-Optik lebend untersucht wurden.

2. Von den neuen Arten sind 7 den Macrodasyoidea und 15 den Chaetonotoidea zuzurechnen.

3. Macrodasys caudatus besitzt 4 verschiedene Bursa-Typen, die regelmäßig mit einer bestimmten Anzahl reifer und unreifer Eier korreliert sind.

4. 2 neue Tetranchyroderma-Arten zeigen eine auf schmale Streifen beschränkte Vierhaker-Bedeckung; an einer weiteren Art dieser Gattung sind die Vierhaker auf kleine laterale Felder in der Pharynxregion reduziert.

5. An Hand 4 neuer Chaetonotus-Arten aus der schultzei-Gruppe wird das die Gruppe gegenüber anderen Arten der Gattung heraushebende Merkmal diskutiert: der dreikantige dorsale Schuppenstachel, dessen mediane, dem Körper abgewandte Kante immer nur in eine Spitze ausgezogen ist.

6. Die Untergattung Halichaetonotus wird aus Chaetonotus herausgehoben und erhält den Rang einer selbständigen Gattung, deren bindendes Merkmal das gemeinsame Auftreten dorsaler Kielschuppen und ventrolateraler Stacheln, Stachel- oder Lamellenschuppen ist.

7. Im Zusammenhang mit 4 neuen Heterolepidoderma-Arten werden die Merkmale dieser Gattung einer Diskussion unterworfen; Arten, die ausschließlich gekielte Schuppen oder auch Kiele ohne deutlich erkennbare Basisschuppen tragen, sind vorläufig auch dann zu Heterolepidoderma zu stellen, wenn diese Elemente nur wenige Längsreihen bilden.

8. Aspidiophorus mediterraneus variiert stark vor allem in Körpergröße, Zahl und Form der Stielschuppen. 
Danksagungen. Für fruchtbare Anregungen. und Hinweise bei dem Entstehen dieser Arbeit habe ich vor allem Herrn Prof. Dr. R. Rredu (Wien) zu danken. Dem frïheren Vorstand des I. Zoologischen Institutes der Universität Wien, Herrn Prof. Dr. Marmeldr, danke ich für die Überlassung eines Arbeitsplatzes. Das stets hilfsbereite Personal des Museo Civico di Storia Naturale in Venedig und dessen Leiter, Herr Prof. Dr. Grordani-SoIkA, ermöglichten die Aufsammlung und Bearbeitung des venezianischen Materials; die Stadt Venedig gewährte mir finanzielle Unterstitzung.

\section{ZITIERTE LITERATUR}

Boaden, P. J. S., 1963. Marine Gastrotricha from the interstitial fauna of some North Wales beaches. Proc. Zool. Soc. London 140, 485-502.

Chandraseihara RaO, G. \& Ganapati, P. N., 1968. Some new interstitial gastrotrichs from the beach sands of Waltair coast. Proc. Ind. Acad. Sci. 67, 35-53.

Clausen, C., 1965. New interstitial species of the family Thaumastodermatidae (Gastrotricha Macrodasyoidea). Sarsia 21, 23-36.

DUJARDIN, F., 1841. Histoire naturelle des Zoophytes infusoires. Roret, Paris.

Ehrenberg, C. J., 1832. Uber die Entwicklung und Lebensdauer der Infusionsthiere, nebst ferneren Beiträgen zu einer Vergleichung ihrer organischen Systeme. Abh. Akad. Wiss. Berlin für 1831 .

Forneris, L., 1961. Beiträge zur Gastrotrichenfauna der Nord- und Ostsee. Kieler Meeresforsch. 17, 206-218.

Ganapati, P. N. \& Chandrasekhara Rao, G., 1967. On some marine gastrotrich from the beach sands of Waltair coast. Proc. Ind. Acad. Sci. 66, 214-225.

Gerlach, S., 1953. Gastrotrichen aus dem Küstengrundwasser des Mittelmeeres. Zool. Anz. 150, 203-211.

- 1961. Uber Gastrotrichen aus dem Meeressand der Malediven (Indischer Ozean). Zool. Anz. $167,471-475$.

GIARD, A., 1904. Sur une faumule charactéristique des sables à Diatomées d'Ambleteuse. I. Les Gastrotriches normaux. II. Les Gastrotriches aberrantes. C. r. Séanc. Soc. Biol. 56, 1161-1165.

D'Hondt, J.-L., 1966. Chaetonotoides marins et d'eau douce de la région d'Arcachon. P.-v. Soc, linn. Bordeaux (A) $103(11), 3-22$.

- 1968. Gastrotriches et Halammohydrides des côtes Flamandes et Picardes. Bull. Mus. Hist. nat., Paris (Sér. 2) 40, 214-227.

Hummon, W. D., 1966. Morphology, life history, and significance of the marine gastrotrich, Chaetonotus testiculophorus n. sp. Trans. Am. microsc. Soc. 85, 450-457.

- 1969. Distributional ecology of marine interstitial Gastrotricha from Woods Hole, Massadusetts, with taxonomic comments on previously described species. Diss., Univ. Massachusetts.

Kaplan, G., 1958. Premières observations sur les Gastrotriches psammophiles des côtes du Calvados. Archs. Zool exp. gén. 96 (Notes et Revue 1), 27-37.

Karling, T. G., 1955. Uber einige Kleintiere des Meeressandes des Nordsee-Ostsee-Gebietes. A.rk. Zool. 7, 241-249.

Konsuloff, S., 1923. Zwei neue Gastrotrichenarten aus Bulgarien. Zool. Anz. 53, 165-168.

Levx, C., 1950. Contribution à l'étude des Gastrotriches de la région de Roscoff. Arch. Zool. exp. gén. 87 (Notes et Revue 1), 31-42.

MetschnikOFF, E., 1865. Uber einige wenig bekannte niedere Thierformen. Z. wiss. Zool. 15, 450-463.

Remane, A., 1924. Neue aberrante Gastrotrichen I: Macrodasys buddenbrocki nov. gen. nov. spec. Zool. Anz. 61, 289-297.

- 1925. Neue aberrante Gastrotrichen II: Turbanella cornuta nov. spec. und T. byalina M. SCHULTZE 1853. Zool. Anz, 64, 309-314. 
- 1926a. Morphologie und Verwandtschaftsbeziehungen der aberranten Gastrotrichen I. Z. Morph. Okol. Tiere 5, 625-754.

- 1926b. Marine Gastrotrichen aus der Ordnung der Chaetonotoidea. Zool. Anz. 66, 243-252.

- 1927a. Xenotrichula velox nov. gen. nov. spec., ein chaetonotoides Gastrotrich mit männlichen Geschlechtsorganen. Zool. Anz. 71, 289-294.

- 1927b. Beiträge zur Systematik der Süßwassergastrotrichen. Zool. Jb. (Abt. Syst. OKol. Tiere) 53, 269-320.

- 1927c. Neue Gastrotricha Macrodasyoidea. Zool. Jb. (Abt. Syst. Okol. Tiere) 54, 203-242.

- 1927d. Gastrotricha. Tierwelt N.- u. Ostsee. 7d, 1-56.

- 1929. Gastrotricha. Handb. Zool. 2, 121-186.

- 1934. Die Gastrotrichen des Küstengrundwassers von Schilksee. Schr. naturw. Ver. Schlesw.Holst. 20, 473-478.

- 1936. Gastrotricha. Bronn's Kl. Ordn. Tierreichs 4, Abt. 2, Buch 1, T. 2, 1-242.

- 1943. Turbanella ambronensis nov. spec., ein neues Gastrotrich aus der Otoplanenzone der Nordsee. Zool. Anz. 141, 237-240.

Renaud-Mornant, J., 1967. Heterolepidoderma foliatum n. sp. (Gastrotricha, Chaetonotoidea) des faciès saumâtres du Bassin d'Arcachon. Bull. Soc. zool. Fr. 92, 161-166.

Schrom, H., 1966a. Verteilung einiger Gastrotrichen im oberen Eulitoral eines nordadriatischen Sandstrandes. Veröff. Inst. Meeresforsch. Bremerh. Sonderband 2, 95-103.

- 1966b. Gastrotrichen aus Feinsanden der Umgebung von Venedig. Boll. Mus. civ. Stor. nat. Venezia 17, 31-45.

SCHUltze, M., 1853. Ober Chaetonotus und Icbthydium EHRs, und eine neue verwandte Gattung Turbanella. Arch. Anat. Physiol. 6, 241-254.

StERRER, W., 1968. Beiträge zur Kenntnis der Gnathostomulida. I. Anatomie und Morphologie des Genus Pterognatbia Sterrer. Ark. Zool. 22, 1-125.

SwEDMark, B., 1956. Etude de la microfaune des sables marins de la région de Marseille. Arch. Zool. exp. gén. 93 (Notes et Revue 2), 70-95.

Trane-Fenchel, A., 1970. Interstitial gastrotrichs in some South Florida Beaches. Ophelia 7, 113-138.

Valkanov, A., 1957. Erster Versuch zur Erforschung der Gastrotrichen des Schwarzen Meeres. Annu. Univ. Sofia (Biol.) 1, 383-399.

WIESER, W., 1957. Gastrotricha Macrodasyoidea from the intertidal of Puget Sound. Trans. Am. microsc. Soc. 76, 372-381.

WILKe, U., 1954. Mediterrane Gastrotrichen. Zool. Jb. (Abt. Syst. Okol. Tiere) 82, 497-550.

Zelrnka, C., 1889. Die Gastrotrichen. Eine monographische Darstellung ihrer Anatomie, Biologie und Systematik. Z. wiss. Zool. 49, 209-384.

Anschrift des Autors: Dr. H. Schrom

Mediterranean Marine Sorting Center

Khereddine

Tunisia 